\section{Pacific Northwest}

National Laboratory

Operated by Battelle for the

U.S. Department of Energy

\title{
EPER Standards Project Report: \\ Technical Review of National Incident \\ Management Standards
}

R.D. Stenner, Project Manager

April 2007

Prepared for

U.S. Department of Homeland Security

Science \& Technology Directorate

Test and Evaluation/Standards Division

Standards Office

Prepared for the U.S. Department of Energy under Contract DE-AC05-76RL01830 


\title{
DISCLAIMER
}

This report was prepared as an account of work sponsored by an agency of the United States Government. Neither the United States Government nor any agency thereof, nor Battelle Memorial Institute, nor any of their employees, makes any warranty, express or implied, or assumes any legal liability or responsibility for the accuracy, completeness, or usefulness of any information, apparatus, product, or process disclosed, or represents that its use would not infringe privately owned rights. Reference herein to any specific commercial product, process, or service by trade name, trademark, manufacturer, or otherwise does not necessarily constitute or imply its endorsement, recommendation, or favoring by the United States Government or any agency thereof, or Battelle Memorial Institute. The views and opinions of authors expressed herein do not necessarily state or reflect those of the United States Government or any agency thereof.

\author{
PACIFIC NORTHWEST NATIONAL LABORATORY \\ operated by \\ BATTELLE \\ for the \\ UNITED STATES DEPARTMENT OF ENERGY \\ under Contract DE-AC05-76RL01830
}

Printed in the United States of America
Available to DOE and DOE contractors from the Office of Scientific and Technical Information,
P.O. Box 62, Oak Ridge, TN 37831-0062;
ph: (865) 576-8401
fax: $(865)$ 576-5728
email: reports@adonis.osti.gov

\begin{abstract}
Available to the public from the National Technical Information Service, U.S. Department of Commerce, 5285 Port Royal Rd., Springfield, VA 22161 ph: (800) 553-6847 fax: $(703) 605-6900$ email: orders@ntis.fedworld.gov online ordering: http://www.ntis.gov/ordering.htm
\end{abstract}

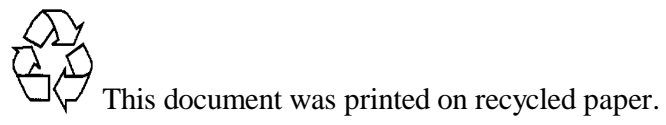


PNNL-16515

\section{EP\&R Standards Project Report: Technical Review of National Incident Management Standards}

April 2007

R.D. Stenner, Project Manager

Prepared for

U.S. Department of Homeland Security

Science \& Technology Directorate

Test and Evaluation/Standards Division

Standards Office

Prepared under

U.S. Department of Energy Contract DE-AC05-76RL01830

Emergency Preparedness and Response (EP\&R) Standards Development Project

Pacific Northwest National Laboratory

Richland, Washington 99352 



\section{Executive Summary}

The importance and necessity for a fully developed and implemented National Incident Management System (NIMS) has been demonstrated in recent years by the impact of national events such as Hurricane Katrina in 2005. Throughout the history of emergency response to major disasters, especially when multiple response organizations are involved, there have been systemic problems in the consistency and uniformity of response operations. Identifying national standards that support the development and implementation of NIMS is key to helping solve these systemic problems. The NIMS seeks to provide uniformity and consistency for incident management by using common terminology and protocols that will enable responders to coordinate their efforts to ensure an efficient response.

Homeland Security Presidential Directive - HSPD-5 required the establishment of the NIMS. Through HSPD-5, the Secretary of Homeland Security was charged with the development and administration of NIMS. As a result, the Federal Emergency Management Agency (FEMA) NIMS Integration Center (NIC) was established, which later became the NIMS Division. One of the responsibilities of the NIMS Division is to identify, evaluate, and facilitate the development and implementation of national standards ${ }^{1}$ that support the NIMS. To assist the NIMS Division, the Pacific Northwest National Laboratory (PNNL) developed a search and review tool to help identify and review existing national standards that can support (in part or as a whole) the NIMS. A technical review team of subject matter experts (SME) reviewed existing standards, as they were located and sorted by the tool, for consistency with specific components of the NIMS. The team organized their findings into four functional categories. All of the various disciplines, which are the cornerstones of emergency preparedness, mitigation, response, and recovery functions involving an all-hazard event or incident of any magnitude, can be fit into one of these four functional categories: Emergency Management, Fire/HAZMAT, Medical Systems, and Law Enforcement. The Emergency Management category was used as a general category for disciplines that did not specifically fit into the other three more specific categories.

The overall technical analysis of the standards on the NIMS Division List produced 14 standards that fit into the three categories of standards that support NIMS management (i.e., systems, operational, and technical). The 14 standards recommended to the NIMS Division for NIMS management support are: National Fire Protection Association (NFPA) 1600, NFPA 1561, NFPA 450, NFPA 472, NFPA 473, NFPA 1500, NFPA 1584, NFPA 1670, NFPA 1710, NFPA 1720, ASTM F1220, ASTM E2413, Joint Commission on Accreditation of Healthcare Organizations (JCAHO)-EM, and the Hospital Emergency Incident Command System (HEICS). Only NFPA 1600 (emergency management system) and NFPA 1561 (incident command system) were considered broadly applicable across all disciplines. The others were associated with only one or more of the four broad functional categories, as discussed in this report.

The review team conducted a technical review of each standard on a list of standards that potentially support incident management and emergency response assembled by FEMA over the past several years, which the NIMS Division subsequently updated once the NIMS was established. Identified as the NIMS Division List, it comprises 141 documents (listed in Appendix A of this report). For this review, the team developed specific NIMS component review criteria from the NIMS document and the National Incident

\footnotetext{
${ }^{1}$ A national-level standard is recognized, accepted, and implemented by all levels of government as well as the private sector and non-governmental organizations.
} 
Management System Capability Assessment Support Tool (NIMCAST). The standards for application to NIMS were reviewed and identified with the full knowledge that Federal, State, local, and tribal authorities are adjusting or changing their procedures and protocols to adapt to a changing response environment. This technical review was designed to identify standards that apply to developing and implementing NIMS within this changing environment.

The standards reviewed were all developed by a respective Standards Development Organization (SDO) for a unique purpose and use, other than NIMS compliance. Thus, considering the expertise represented in the formal SDO standards development process, the review of these standards from a NIMS perspective necessarily had certain limitations. A primary limitation was the interest in identifying incident management system components in standards that may have been developed without considering formal or consistent incident management terminology or management concepts.

To review all the various and complex standards on the NIMS Division List, a tool was designed to consistently locate and sort information based on word-string relationships that were developed from the set of detailed criteria derived from the NIMS document and NIMCAST. The tool was used to locate and sort, based on these criteria, and produce both summary and detailed output results mapped to the specific NIMS components and detailed criteria. This sorted and mapped output was then reviewed by the team to determine its technical applicability to the respective NIMS components and the detailed criteria. The tool selected 61 standards on the NIMS Division List for potential applicability to NIMS compliance. Of the 61 standards, 37 were by NFPA, 19 were by ASTM International, and the remainder were from the American National Standards Institute, JCAHO, the Institute of Electrical and Electronics Engineers, the National Emergency Number Association, the Association of Public-Safety Communications Officials International Project 25, National Institute of Justice, HEICS, and others.

The SME technical review process for the 61 standards consisted of four phases:

Phase 1: The team collectively defined criteria to assess the ability of each standard to meet NIMS objectives, i.e., the extent to which a specific standard, or parts of a standard, contributes to the establishment of a uniform and consistent incident management system across the nation.

Phase 2: Each team member read each standard in its entirety to understand the specific content of each standard.

Phase 3: The team developed a color-coded "dashboard" matrix compatible with the search tool criteria which enabled a visual presentation of an extremely large amount of complex information to show where gaps may exist in standards coverage.

Phase 4: The team collectively discussed all standards, applying the criteria and developing a consensus on the applicability of the whole standard or parts of a standard, reaching a consensus on color-coding, and agreeing on comments to be included in the analysis.

The team reviewed all standards for NIMS application using a 12-step approach that included 1) identifying keywords and concepts found in NIMS component criteria; 2) identifying standards appropriate for review; 3) applying the search tool to identify the presence and frequency of keywords in each standard using the NIMS component criteria derivatives; 4) developing a matrix for each standard to document the presence of keyword "hits" on the horizontal axis; 5) reading each standard thoroughly and 
assessing its applicability and content to NIMS; 6) developing an initial assessment of each standard; 7) the entire team reviewing and discussing each standard using a set of consensus criteria: scope, relevance, operational application, organization level, and completeness (for standards relating to specific emergency response functions, the ability of the standard to contribute to emergency management integration was substituted for the completeness criteria); 8) producing a color-coded matrix for each standard grouped by NIMS component criteria on the vertical axis and the consensus criteria on the horizontal axis, with standards meeting 4 of the 5 criteria rated green, 3 of 5 rated light green, 2 of 5 rated yellow, 1 of 5 rated orange, and 0 of 5 rated red; 9) comparing the finding with the presence of keywords or concepts found by the NIMS component criteria search tool to confirm the presence or absence of specific language; 10) capturing a brief information point describing the team's rationale/conclusion; 11) the entire team reviewing the findings to help ensure consistency within the group process; and 12) placing the findings into a composite matrix of all standards, all criteria, by code, with comments.

Tables showing the color-coding of standards and complete technical analysis data are provided in Appendices A-F of the main report. All results of this analysis were captured in a database included in the tool, which can be used for future retrieval and application.

NOTE: This technical review did not attempt to address the quality of the standards. It focused only on the ability of a standard to address each specific NIMS component criterion. Thus, a red coding does not mean a standard is not a quality standard addressing the purpose for which it was designed. It means only that it did not align very well with the NIMS management criteria. The standards in the Professional Guidelines and Procedures grouping all received a red coding; however, they are very valuable to incident management for the detailed purpose for which they were designed. 



\section{Contents}

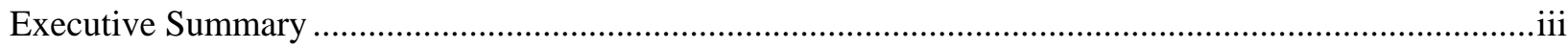

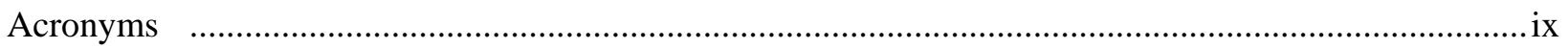

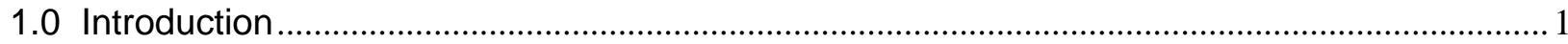

1.1 The National Incident Management System (NIMS) Support Standards ................... 1

1.2 Emergency Management and NIMS Conformity .................................................... 2

Currently, the overarching guidance document issued by FEMA is the State and Local Guide for All-

Hazard Emergency Operations Planning (SLG 101). SLG 101 provides emergency managers and other emergency services personnel information on FEMA's concept for developing risk-based, all-hazard emergency operations plans and serves as the template for the development of comprehensive emergency management programs. SLG 101 is, in essence, the same level of "standard" to the emergency management pillar as National Fire Protection Association (NFPA) 450 is to the Emergency Medical Systems pillar. It could be argued that the SLG 101, from an emergency management perspective, should be given the same priority and status as NFPA 450; however, it is not a Standards Development Organization (SDO)-generated national standard.

Other notable guidance issued for the emergency management community, and that was considered for the review process, includes the National Response Plan (NRP), the Homeland Security Exercise and Evaluation Program (HSEEP), the Emergency Management Performance Grants, Community Hazards Emergency Response-Capability Assurance Process, and the Chemical Stockpile Emergency Preparedness Program. Much of the Emergency Operations Center (EOC) and Emergency Operations Plan (EOP) format and content has been captured in many of these documents. To the best of our knowledge, these documents are currently under review to ensure consistency with NIMS ..................... 3

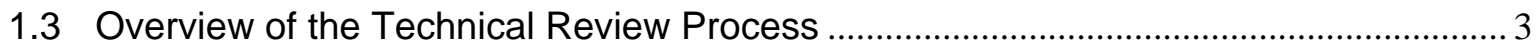

1.4 Limitations of NIMS Standards Review...................................................................... 4

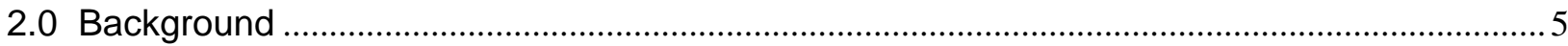

2.1 National Incident Management System, U.S. Department of Homeland Security, and

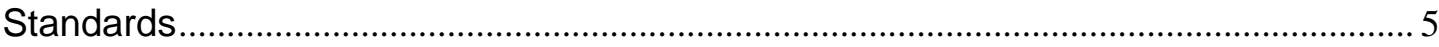

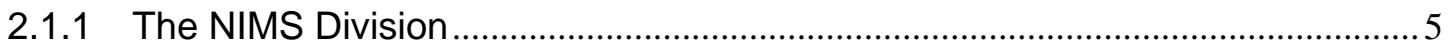

2.1.2 U.S. Department of Homeland Security Office of Standards ............................ 5

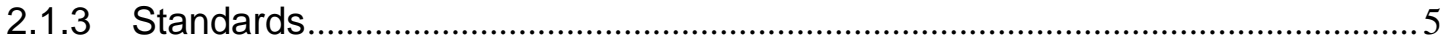

3.0 Design and Development of a Standards Review Tool..................................................... 7

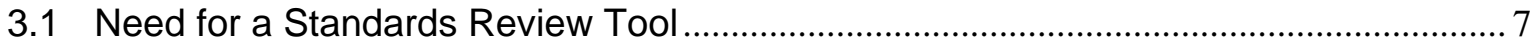

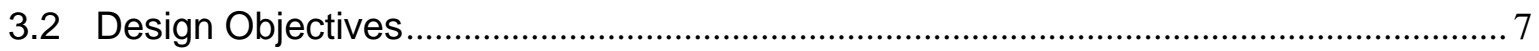

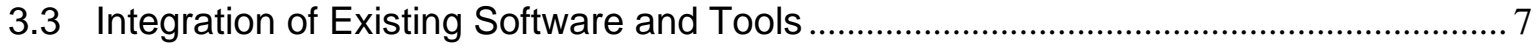

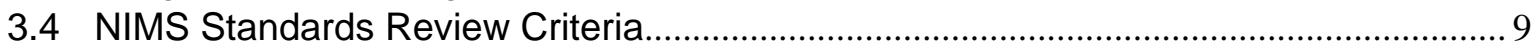

3.5 Output Tables............................................................................................................... 9

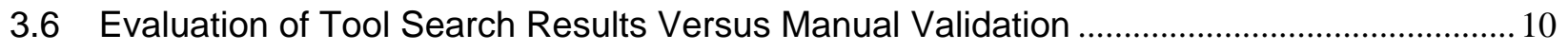

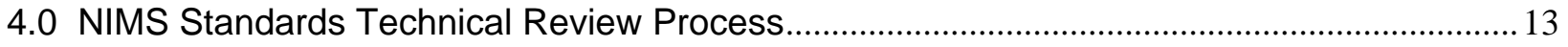

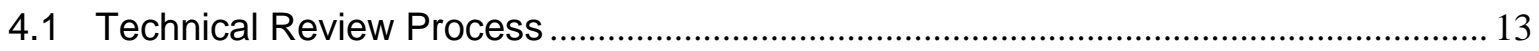

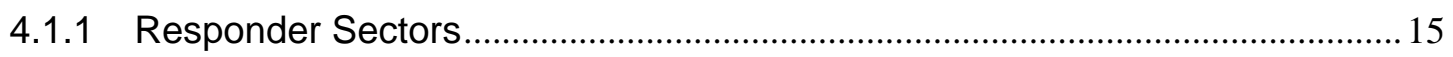




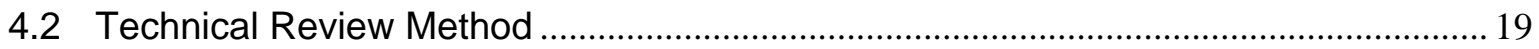

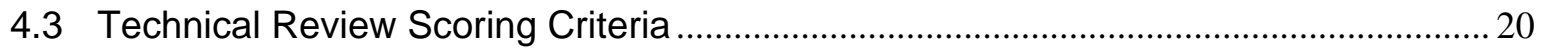

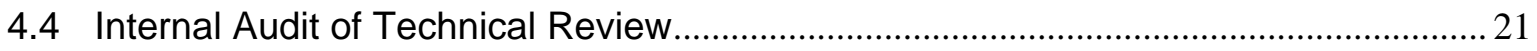



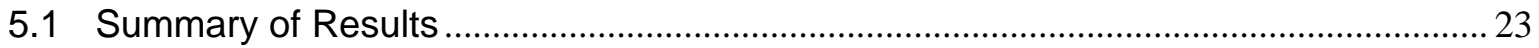

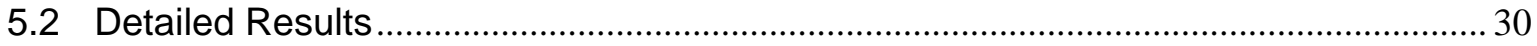

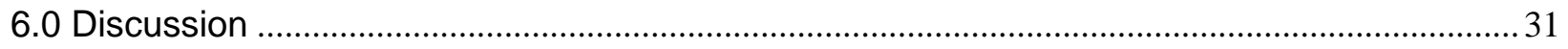

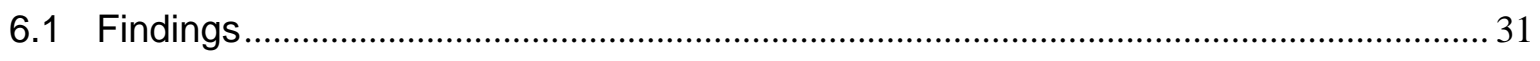

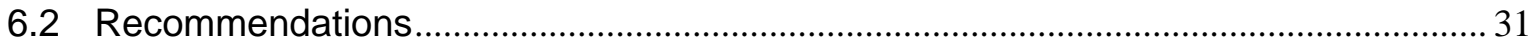

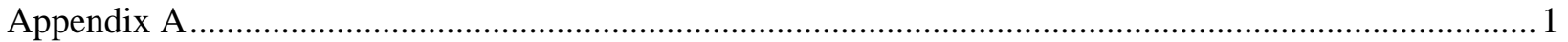

Appendix B1

Appendix C1

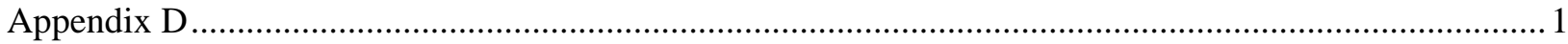

Appendix E19

Appendix F2

Appendix F Complete Technical Analysis Results Tables ............................................................ 1

\section{Figures}

1 Categories of National Standards Potentially Supporting NIMS ................................................ 2

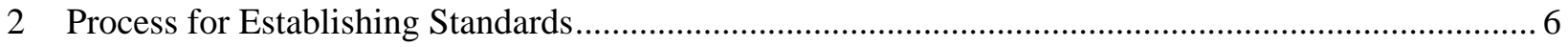

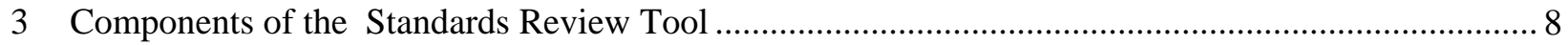

4 Grouping of NIMS Division List Standards into the Four Groups and Types of Standards............... 24

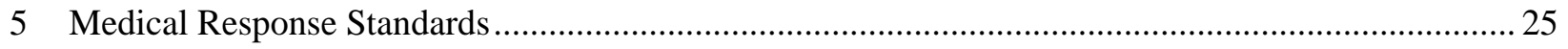

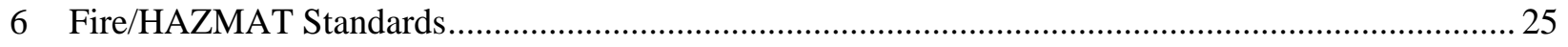

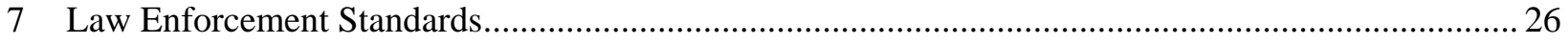

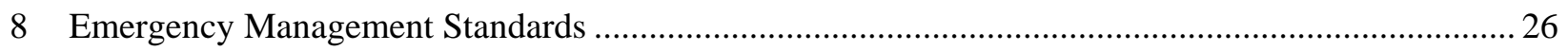

9 Field-Based Versus Setting Based Response Perspective ............................................................... 32

\section{Tables}

1 Example Summary Output Table from Review Tool................................................................ 9

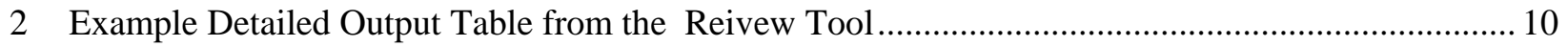

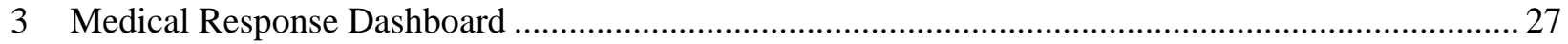

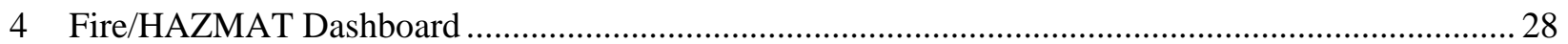




\section{Acronyms}

\begin{tabular}{|c|c|}
\hline ANSI & American National Standards Institute \\
\hline APCO & Association of Public-Safety Communications Officials International \\
\hline ASTM & ASTM International (formerly known as American Society for Testing and Materials) \\
\hline CPGs & Civil Preparedness Guides (CPGs--early FEMA guidance documents) \\
\hline DCPA & Defense Civil Preparedness Agency \\
\hline DHS & U.S. Department of Homeland Security \\
\hline IEEE & Institute of Electrical and Electronics Engineers \\
\hline EMAP & Emergency Management Accreditation Program \\
\hline EMS & Emergency Medical Services \\
\hline EOC & Emergency Operations Center \\
\hline EOP & Emergency Operations Plan \\
\hline ESF & Emergency Support Function \\
\hline ESL & Essential Standards List \\
\hline FEMA & Federal Emergency Management Agency \\
\hline HAZMAT & hazardous materials \\
\hline HEICS & Hospital Emergency Incident Command System \\
\hline HSEEP & Homeland Security Exercise Evaluation Program \\
\hline IAP & Incident Action Plan \\
\hline ICS & Incident Command System \\
\hline JCAHO & Joint Commission on the Accreditation of Healthcare Organizations \\
\hline JIC & Joint Information Center \\
\hline JIS & Joint Information System \\
\hline NEMA & National Emergency Management Association \\
\hline NENA & National Emergency Number Association \\
\hline NFPA & National Fire Protection Association \\
\hline NIJ & National Institute of Justice \\
\hline NIMCAST & National Incident Management System Capability Assessment Support Tool \\
\hline NIMS & National Incident Management System \\
\hline NRP & National Response Plan \\
\hline OSHA & Occupational Safety and Health Administration \\
\hline PNNL & Pacific Northwest National Laboratory \\
\hline
\end{tabular}


SDOs Standards Development Organizations

SME Subject Matter Experts

UC Unified Command 


\subsection{Introduction}

This report presents the design and development aspects of a standards review tool that Pacific Northwest National Laboratory (PNNL) developed for the U.S. Department of Homeland Security (DHS) to help review and identify existing national standards that support DHS functions. The tool was designed and developed to support the need of the DHS Federal Emergency Management Agency (FEMA) National Incident Management System (NIMS) Division to identify key national standards that support (in part or as a whole) the NIMS. Also presented is the technical review process used to confirm or reconcile the sorted output results from the tool, the technical review results, and a discussion of the findings and recommendations.

\subsection{The National Incident Management System (NIMS) Support Standards}

The importance and necessity for a fully developed and fully implemented NIMS was demonstrated by the impact of hurricanes that hit Florida in 2004, and more recently by Hurricane Katrina in 2005. Throughout the history of emergency response to major disasters, especially where multiple response organizations are involved, there have been systemic problems in the consistency and uniformity of response operations. The identification of national standards that support the development and implementation of NIMS is key to helping solve these systemic problems.

The NIMS seeks to provide uniformity and consistency for incident management by using common terminology and protocols that will enable responders to coordinate their efforts to ensure an efficient response. In a recent statement to State Governors, DHS Secretary Chertoff stated: "Hurricane Katrina was a stark reminder of how critical it is for our nation to approach incident management in a coordinated, consistent, and efficient manner." He further pointed out that "our [response] operations must be seamless and based on common incident management doctrine, because the challenges we face as a nation are far greater than capabilities of any one jurisdiction."

A primary objective of the NIMS is to provide an architecture or framework for organizing response on a national scale. It requires use of the Incident Command System (ICS) and represents a core set of doctrine, principles, terminology, and organizational processes that enables effective, efficient, and collaborative incident management at all levels.

The NIMS led to the establishment of the NIMS Division, which has the responsibility for ongoing management and maintenance of the NIMS document. The NIMS Division also has the responsibility for identifying, evaluating, and facilitating the development of national standards ${ }^{2}$ to support NIMS compliance and implementation. The NIMS Division must ensure that the flexibility necessary for effective local response operations is maintained to address specific jurisdictional and geographical needs nationwide. Figure 1 shows the different categories of national standards that potentially support NIMS management. The NIMS Division has the responsibility to identify and integrate pertinent national standards from these categories of standards that support compliance with NIMS.

\footnotetext{
${ }^{2}$ A national-level standard is recognized, accepted, and implemented by all levels of government as well as the private sector and non-governmental organizations.
} 


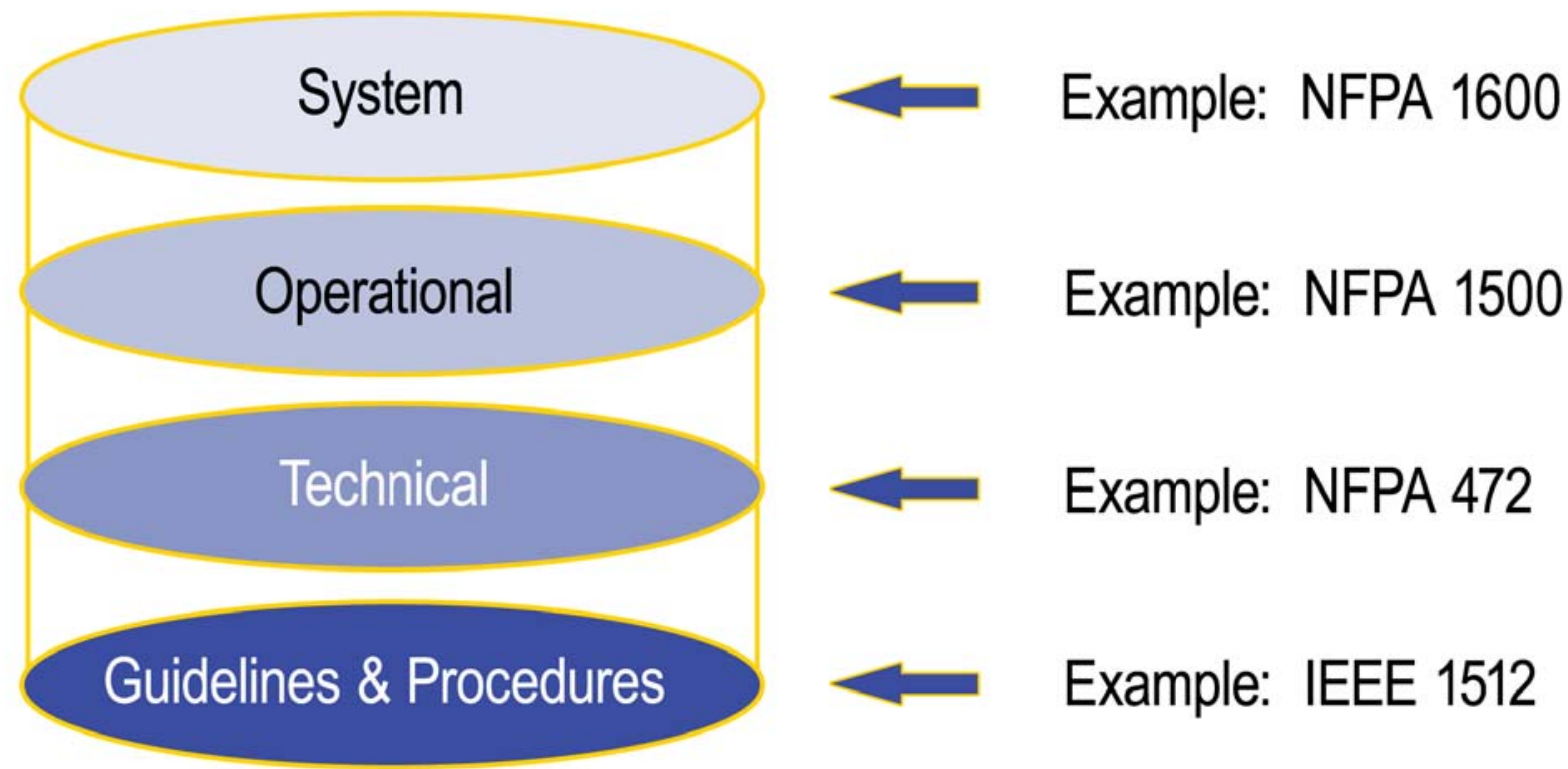

Figure 1. Categories of National Standards Supporting Incident Management

\subsection{Emergency Management and NIMS Conformity}

While reviewing the standards, the team determined that there are four significant functional categories that may be considered as "pillars" of the emergency preparedness, mitigation, response, and recovery functions in an all-hazard event or incident of any magnitude. These functional categories are Emergency Management, Fire/HAZMAT, Medical Systems and Law Enforcement. These four functional categories inevitably are the cornerstones of any response, particularly to those defined in the Target Capabilities List (TCL).

Of the four functional categories, Emergency Management is the one area that historically has not applied "standards." However, the emergency management program guidelines generally focus on performance functions and include the requirements for planning, preparedness, mitigation, response and recovery activities and operations for emergencies resulting from all hazards. Emergency management programs for which FEMA maintains oversight historically have used the terms "guides," "guidelines," or "guidance" to recommend how programs will be implemented at the Tribal, State and local levels of government. These guidelines were developed in the same context in which other NIMS standards were developed. The overall objective was to ensure that programs relating to a particular standard were executed in a comprehensive and consistent manner.

Early FEMA guidance documents were issued as Civil Preparedness Guides (CPGs). Initially, the documents were drawn from materials developed by the Defense Civil Preparedness Agency (DCPA) that focused on planning and preparedness for nuclear attacks on the United States. After DCPA became part of FEMA, the planning guidance quickly evolved into guidelines for other hazards. In addition to the CPGs, FEMA issued guidelines for emergency response to accidents at commercial nuclear power plants following the Three-Mile Island accident in Pennsylvania in 1979. These guidelines, developed in 
concert with the Nuclear Regulatory Commission, became FEMA REP-10, which is still a viable document in use today. As the agency evolved over the next 20 years, guidelines for planning, preparedness, response, and recovery were issued for many other hazards and included guidance on hazard mitigation, floodplain management, hurricane preparedness, hazardous materials and chemical warfare agent stockpiles, to name but a few.

Many of these guidelines essentially were used and are being used as de facto standards ${ }^{3}$, and in some cases, drive the funding criteria for grants to Tribal, State and local governments. Using these guidelines, program reviews conducted by FEMA determine compliance by a respective jurisdiction. In essence, a compilation of these guidelines may be considered as the "principles and practices" of emergency management, or "standard practices."

Currently, the overarching guidance document issued by FEMA is the State and Local Guide for AllHazard Emergency Operations Planning (SLG 101). SLG 101 provides emergency managers and other emergency services personnel information on FEMA's concept for developing risk-based, all-hazard emergency operations plans and serves as the template for the development of comprehensive emergency management programs. SLG 101 is, in essence, the same level of "standard" to the emergency management pillar as National Fire Protection Association (NFPA) 450 is to the Emergency Medical Systems pillar. It could be argued that the SLG 101, from an emergency management perspective, should be given the same priority and status as NFPA 450; however, it is not a Standards Development Organization (SDO)-generated national standard.

Other notable guidance issued for the emergency management community, and that was considered for the review process, includes the National Response Plan (NRP), the Homeland Security Exercise and Evaluation Program (HSEEP), the Emergency Management Performance Grants, Community Hazards Emergency Response-Capability Assurance Process, and the Chemical Stockpile Emergency Preparedness Program. Much of the Emergency Operations Center (EOC) and Emergency Operations Plan (EOP) format and content has been captured in many of these documents. To the best of our knowledge, these documents are currently under review to ensure consistency with NIMS.

\subsection{Overview of the Technical Review Process}

Over the past several years, FEMA has been compiling a list of standards documents that potentially support incident management and emergency response. Once NIMS was established, the NIMS Division updated this list and provided it to the review team. Hereafter in this document, this list will be referred to as the NIMS Division List. The NIMS Division List contains 141 documents. Appendix A provides the complete NIMS Division List of potential NIMS support standards.

The technical review of the standards on the NIMS Division List was done in a dynamic and fluid environment. Emergency managers, incident managers/commanders, and first responders continue to develop strategies and procedures that enhance coordination and communication while policy makers are modifying incident management terminologies, implementation strategies, and educational processes that support preparedness, response, and mitigation.

\footnotetext{
${ }^{3}$ A de facto standard generally refers to a process, procedure, or specification that is well-known and has such broad acceptance as to be regarded as a standard. However, it was not developed as a result of a formal development process.
} 
The NIMS Division list was reviewed with the knowledge that Federal, State, local and tribal authorities are adjusting or changing their procedures and protocols to adapt to a changing response environment. For example, the set of Emergency Support Functions (ESFs) that are identified in the NRP are not universal; that is, they are not necessarily consistent between and among the various levels of government. Also at the time of this review, the NRP was being revised, and the private sector has no current requirements for meeting governmental expectations for emergency preparedness and disaster response.

This technical review was designed to identify standards that apply to developing and implementing NIMS within this changing environment. For the most part, the standards identified as the result of this review will assist with preparedness and response activities regardless of anticipated changes in ESFs, the NRP, or incident management processes.

The technical review process enabled as few or as many standards to be selected as necessary to ensure a basic consistency among the various emergency management authorities without pre-determining or forcing any specific viewpoint or procedure. As a result of this approach, NIMS policy makers will be able to select from an identified universe of adopted standards that will not impede ongoing improvements or changes in other emergency management documents and strategies.

\subsection{Limitations of NIMS Standards Review}

The review of the NIMS Division list has certain limitations. The primary limitation is that these standards were developed for a purpose other than supporting a national-level incident management system, i.e. NIMS. There is no expectation that the processes, principles, and terminology in these standards are consistent. This limitation is not a deficiency in either the standard or the adoption process but instead represents an evolving and maturing of emergency management principles and the incremental establishment of a consistent nationwide incident management system. For example, the review found many instances where a standard could be updated to include incident management terminology in the definitions section and in the body of the standard itself. In other instances, standards intended for use by specific response functions (e.g., fire, emergency medical services [EMS], law enforcement, etc.) did not address the responsibility of the function to coordinate within a chain of command or incident management structure. These examples illustrate that a standard may be perfectly suited to the situation for which it was developed but does not include state-of-the-art references to incident management systems, processes or structures.

Our technical review process was not designed to identify specific remedial actions for SDOs to take in relation to NIMS. This review was technically focused and did not attempt to address usability at the jurisdictional level. These standards should first be examined for their ability to technically link and support the various components and criteria of NIMS and then should be reviewed for their ability to be implemented and integrated into emergency management programs and organizations nationwide. 


\subsection{Background}

\subsection{National Incident Management System, U.S. Department of Homeland Security, and Standards}

\subsubsection{The NIMS Division}

The NIMS Division has the responsibility to facilitate the establishment of standards in various areas pertaining to incident management; however, it does not have statutory authority to develop Federal standards or the responsibility or resources to establish a process or infrastructure to adopt private sector standards.

The NIMS Division strategy for the development and promulgation of NIMS-related standards involves working with other components of DHS, other Federal agencies and departments, and State and local governments. The NIMS Division wants to establish a list of standards that it could use to develop compliance metrics and would help NIMS users with respect to implementation.

\subsubsection{U.S. Department of Homeland Security Office of Standards}

The DHS Office of Standards has a mission to develop and coordinate the adoption of national standards and appropriate evaluation methods to meet the needs of homeland security. DHS has three management directives that establish policy and procedures regarding the adoption and development of standards. They establish a DHS National Standards Program designed to assist in identifying, creating, and cataloging all standards necessary for the proper execution of DHS activities, which includes the NIMS.

\subsubsection{Standards}

The Office of Standards has developed an integrated standards adoption process and infrastructure that includes a series of standards working groups. The Incident Management Standards Subject Area Working Group (IM-SSAWG) was established specifically to address incident management (NIMS) related standards. It will gather, analyze, and maintain information on standards that support NIMS, especially as they enhance a Tribal, State, or local jurisdiction's ability to use DHS's resources when managing an incident of national significance. Figure 2 shows the basic relationship between NIMSsupport standards, DHS adoption, and NIMS compliance and implementation. 


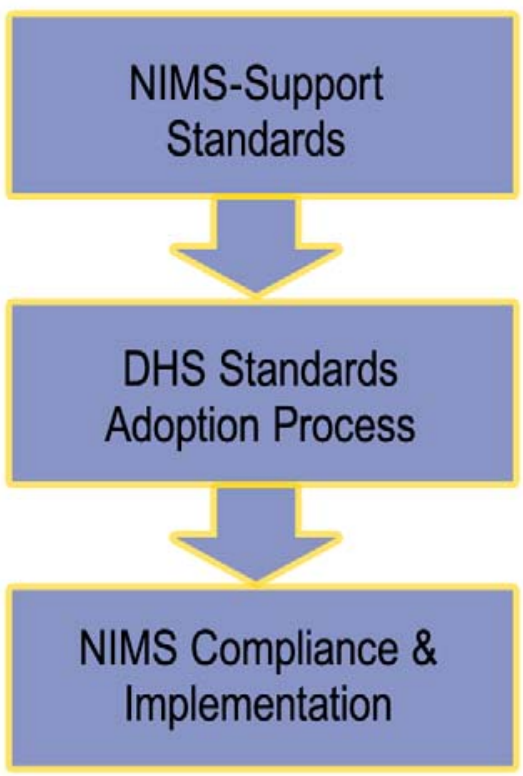

Figure 2. Process for Establishing Standards 


\subsection{Design and Development of a Standards Review Tool}

\subsection{Need for a Standards Review Tool}

Given the amount of complex and detailed information that needed to be reviewed for consistency among the standards, as well as consistency with the concepts and principles articulated in the NIMS document, it was clear that a content analysis tool was needed.

\subsection{Design Objectives}

In designing the tool, it was also clear that it could not replace the knowledge and experience of qualified experts in incident and emergency management. Thus, the tool was designed to consistently locate, sort and classify (summarize) information based on word-string relationships. The relationships were developed from a set of detailed criteria derived from the NIMS document and the National Incident Management System Capability Assessment Support Tool (NIMCAST).

\subsection{Integration of Existing Software and Tools}

The tool was initially designed around the Pacific Northwest National Laboratory's IN-SPIRE ${ }^{\mathrm{TM}}$ software system using its ability to search large volumes of text and identify informational relationships. This word relationship search capability was linked with a text extraction process to extract text from the published format of the different standards (i.e., PDF, DOC, HTML formats). A text editor (such as $\mathrm{TextPad}^{\mathrm{TM}}$ ) was used to clean up and prepare the text for conversion into a DocBook XML schema. AsciiDoc $^{4}$ was used for that conversion. After the document content was converted into a valid XML format, it was imported into a native-XML database ( $\mathrm{eXist}^{5}$ ) for analysis and post-processing. Also stored in this database were specific queries derived from the detailed NIMS criteria. Results were uploaded to a web service that delivers summary results in a detailed report, scoring information to a PHP code and a MySQL database for storing the scoring results. The scoring process is discussed in Section 4, NIMS Standards Technical Review Process. A general diagram of the tool components is shown in Figure 3.

\footnotetext{
${ }^{4}$ AsciiDoc is a markup language. It requires installation of a special AsciiDoc converter program that can convert AsciiDoc document in html, pdf, and other formats. The converter program is written in Python. AsciiDoc is released under the GNU General Public License.

${ }^{5}$ eXist is an open source database management system entirely built on XML technology. eXist uses XML and XML queries to manage data rather than using SQL or the standard SQL 92. eXist tends to be bigger than most database formats, which does impact performance.
} 


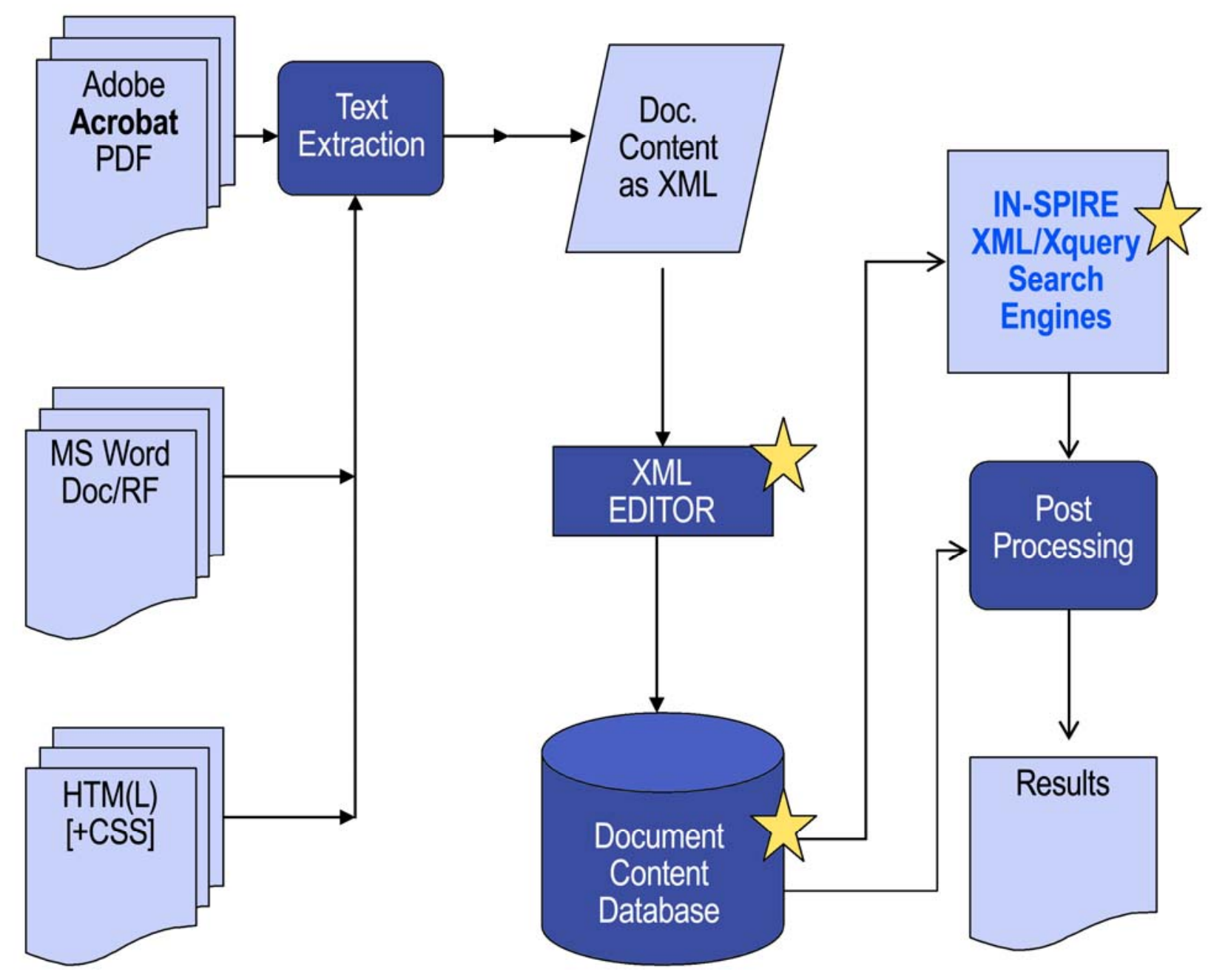

Figure 3. Components of the Standards Review Tool

The following word relationship routines are incorporated into the tool:

Match - searches for text that exactly matches the search criteria, including order-of-word string and form of words

Fuzzy - searches for text that exactly matches the search criteria, including order-of-word string, but searches considering various forms of the words in the word string (e.g., monitor, monitoring, monitored)

Near - searches for text containing all the words in the word string criteria in the specific order with less than one word between them, it is case-sensitive

$\boldsymbol{\&}=-$ searches for text containing all the words in the word string criteria in any order without regard to distance between them. 
Selecting the best word relationship search routine to use depends on the intent of the search. For example, if one is looking for an exact title or word combination, the Match routine is best. The flexibility of a search progresses through the list of search routines; the $\&=$ search is the most flexible. The trade-off that must be balanced throughout the list is the tool's selection of duplicate findings. After some trial and error, we used the $\&=$ routine for our review of the standards on the NIMS Division List because it was easy to spot and remove duplicates. The $\&=$ routine provided the most assurance of finding text relating to the NIMS criteria.

\subsection{NIMS Standards Review Criteria}

To conduct a consistent in-depth technical review of each standard, it was necessary to develop detailed and specific criteria that reflected all of the requirements necessary for consistency with NIMS. The NIMS document and NIMCAST were used as the baseline documents input to derive these criteria. NIMCAST provides a very detailed set of checklists for compliance with NIMS, which were very helpful in deriving specific criteria. The initial criteria derived from these two documents were further refined using a recent draft of the NIMS upgrade document. The detailed NIMS search-term criteria are listed in Appendix B.

\subsection{Output Tables}

The review tool produces both summary and detailed output tables designed for the team to use in conducting the technical review. Table 1 is an example summary output table.

Table 1. Example Summary Output Table from the Review Tool

\begin{tabular}{|l|l|l|l|}
\hline \multicolumn{1}{|c|}{ Component } & \multicolumn{2}{c|}{ Document } \\
\cline { 3 - 4 } & NFPA1561 & NEPA 1600 \\
\hline I & Preparedness & & \\
\hline I-A & Preparedness Organizations and Programs & 3 near $4 \&=$ & 5 near $6 \&=$ \\
\hline I-B & Implement Emergency Preparedness Cycle & 4 near $4 \&=$ & 3 near $4 \&=$ \\
\hline II & Communications and Information Management & 23 near & 6 near $7 \&=$ \\
\hline II-A & Communications and Incident Management & $24 \&=$ & 4 near $4 \&=$ \\
\hline II-B & Effective Communications, Information Management and Information Sharing & 1 near $1 \&=$ \\
\hline II-C & $\begin{array}{l}\text { Establishing and Maintaining a Common Operating Picture and Ensuring } \\
\text { Accessibility and Interoperability }\end{array}$ & & $1 \&=$ \\
\hline II-D & Managing Interoperable Communications and Data & & \\
\hline
\end{tabular}

The Near and $\&=$ search routines were applied to a portion of the NIMS criteria to produce the example output summary shown in Table 1 . The difference in resulting search routine findings is shown in this example. An example detailed output table is shown in Table 2. The detailed output example is that of the specific NIMS component/criteria grouping shown in red. 
Table 2. Example Detailed Output Table from the Review Tool

\begin{tabular}{|c|c|}
\hline $\begin{array}{l}\text { Co } \\
\mathrm{mp}\end{array}$ & II-B. Effective Communications, Information Management and Information Sharing \\
\hline $\mathrm{Qu}$ & $. \&=$ 'Incident communications' and $. \&=$ 'Incident Command common communications operating system' \\
\hline $\mathrm{Qu}$ & $. \&=$ 'Incident communications' and $. \&=$ 'Incident Command interoperable communications' \\
\hline $\mathrm{Qu}$ & $. \&=$ 'Emergency' and $. \&=$ 'Communications' \\
\hline & $\begin{array}{l}\text { NFPA1561 } \\
\text { •6.1 Communication Systems } \\
\text { •6.1.1 The communications system shall meet the requirements of the emergency response agency for } \\
\text { routine and large-scale emergencies. } \\
\text { •6.1.4* An ESO shall provide additional radio channels for the volume of communications relating to } \\
\text { incidents with multiple tactical channels and for the complexity of multiple emergency incidents. } \\
\text { •6.3 Emergency Traffic } \\
\text { •6.3.1* The communications system shall provide a standard method to give priority to the transmission of } \\
\text { emergency messages and notification of imminent hazards over that of routine communications to all } \\
\text { levels of the incident command structure. } \\
\text { •6.4 Telecommunicator Support } \\
\text { •6.4.3* The incident commander shall be provided with reports of elapsed time-on-scene at emergency } \\
\text { incidents in 10-minute intervals from the ESO Communications Center, until reports are terminated by the } \\
\text { incident commander. } \\
\text { •7.1 Incident Commander } \\
\text { • } 7.1 .9 \text { The incident commander shall be responsible for controlling communications on the tactical, } \\
\text { command, and designated emergency traffic channels for that incident. }\end{array}$ \\
\hline $\mathrm{Qu}$ & $. \&=$ 'Emergency' and $. \&=$ 'Warnings' \\
\hline $\mathrm{Qu}$ & $\&=$ 'Public communications' \\
\hline $\mathrm{Qu}$ & $. \&=$ 'Communication warnings' \\
\hline
\end{tabular}

\subsection{Evaluation of Tool Search Results Versus Manual Validation}

From exploring the capabilities of the various search routines (i.e., Match, Fuzzy, Near, and \&=), we found that the Near and $\&=$ routines produced the best results when comparing the tool's ability to find the same materials found by manually searching the NFPA 1561 and NFPA 1600 standards. These two standards were chosen for the manual versus tool search comparison because previous work indicated they were the two standards that would most likely provide the best fit to the NIMS criteria.

\subsubsection{Component I - Preparedness}

The $\&=$ routine found all of the topics on preparedness that were found manually and found two additional topics on business continuity and training. The Near routine missed five topics that the $\&=$ routine found. The $\&=$ routine produced two duplicate finds under the same criteria element for preparedness. These were fairly obvious so would not be difficult to spot and eliminate in the team technical review of the output from this search. 


\subsubsection{Component II - Communications and Information Management}

The $\&=$ routine found all of the topics on communications and information management that were found manually and found five additional topics on hazard mitigation and avoidance, incident management/ communications, mutual aid planning/communications, emergency traffic, and warning systems. The Near routine missed two topics that the $\&=$ routine found. The $\&=$ routine produced three duplicate finds under the same criteria element for communications and information management. These were fairly obvious so would not be difficult to spot and eliminate in the team technical review of the output from this search.

\subsubsection{Component III - Resource Management}

The $\&=$ routine found all of the topics on resource management that were found manually and found two additional topics on resource loss and financial resources. The Near routine missed six topics that the $\&=$ routine found. The $\&=$ routine produced one duplicate find under the same criteria element for resource management. It was fairly obvious so would not be difficult to spot and eliminate in the team technical review of the output from this search.

\subsubsection{Component IV - Command and Management}

The $\&$ = routine found all of the topics on command and management that were found manually and found seven additional topics on emergency medical care, emergency traffic, telecommunication support, logistics \& facilities, resource accountability, mutual aid request, and business impact analysis. The Near routine missed 22 topics that the $\&=$ routine found. The $\&=$ routine produced two duplicate finds under the same criteria element for command and management. These were fairly obvious so would not be difficult to spot and eliminate in the team technical review of the output from this search.

The results of this manual quality of search review indicated that the best search routine to use was the $\&=$. While there is a slight down side in that it can identify duplicate finds, because of the different order of word relationships in the same topic, it appears these duplicates would not be difficult to manage during the team technical review of the search output. The ability to find additional topics seems to outweigh any difficulty associated with duplicates. 



\subsection{NIMS Standards Technical Review Process}

\subsection{Technical Review Process}

This section describes the process the team used to review the 61 standards on the NIMS Division List selected by the tool for potential applicability to NIMS compliance. The standards review process consisted of four phases:

Phase 1: The team collectively defined criteria to assess the ability of each standard to meet NIMS objectives, i.e., the extent to which a specific standard, or parts of a standard, contributes to the establishment of a uniform and consistent incident management system across the nation.

Phase 2: Each team member read each standard in its entirety to understand the specific content of each standard.

Phase 3: The team collectively developed a color-coded "dashboard" matrix compatible with the search tool criteria, which enabled a visual presentation of an extremely large amount of complex information to show where gaps may exist in standards coverage.

Phase 4: The team collectively discussed each standard, applying the criteria and developing a consensus on the applicability of the whole standard or parts of each standard, reaching a consensus on color-coding, and agreeing on comments to be included in the analysis.

The team first reviewed NFPA 1600, Standard on Disaster/Emergency Management and Business Continuity Programs and NFPA 1561, Standard on Emergency Services Incident Management System. These two standards were determined to possess overarching or "system" content that supports incident preparedness and management regardless of functional incident response activities (fire, EMS, law enforcement, etc.). By beginning with "system" standards, the team was able to develop a set of criteria that could be consistently applied across all standards.

The NIMS component criteria categories used for the key word search were also used to focus the group discussion, analysis, and color-coding for all standards. NIMS component criteria categories were used in the keyword search and by the team to ensure that all standards were assessed against NIMS component criteria for applicability to NIMS. Those categories are:

- Preparedness Organizations and Programs

- Implement Emergency Preparedness Cycle

- Communications and Information management

- Effective Communications, Information Management, and Information Sharing

- Establishing and Maintaining a Common Operating Picture and Ensuring Accessibility and Interoperability

- Managing Interoperable Communications and Data

- Resource Management

- Categorizing Resources

- Effective Management of Resources

- Inventorying Process 
- Resource Acquisition

- Mobilizing Resources

- Recovering Resources

- Reimbursement

- Command and Management

- Field Command and Management Functions

- Modular, Scalable Incident Command System

- Interactive Management Components

- Measurable objectives

- Management Characteristics

- Modular Organization

- Management by Objectives

- Incident Action Plan

- Manageable Span of Control

- Pre-designated Incident Locations and Facilities

- Comprehensive Resource Management

- Integrated Communications

- Establishment and Transfer of Command

- Unified Command

- Incident Management Accountability

- Information and Intelligence Management

- ICS Organization and Operations

- ICS Single Command (IC)

- ICS Unified Command (UC)

- ICS Incident Action Plan (IAP)

- ICS Resources

- ICS Area Command

- Emergency Operations Center

- Joint Information System (JIS) and Center (JIC)

- Incident Management Hazard Identification, Risk Management, and Impact Analysis

- Supporting Technologies.

The review team identified five consensus criteria (i.e., scope, relevance, operational application, organization level, and completeness) for use in distilling and managing the review process, which led to the development of the color-coding process.

By bifurcating the review (i.e., reviewing NFPA 1600 and NFPA 1561 system standards first, followed by function-specific standards), the team was able to conceptualize a framework encompassing all standards. This approach allowed the team to expand the review framework from a simplistic colorcoding of all standards to one that recognizes inherent differences in the purpose of standards. System standards have applicability across the full range of first responder functions (emergency management, fire, EMS, law enforcement, medical, etc.); however, function-specific standards may have limited applicability to the overall incident management system and, instead, relate to only one (or more) of the individual responder disciplines.

After completing reviews of NFPA 1600 and 1561, the team identified the need for one of the five criteria (scope, relevance, operational application, organization level, and completeness) used to assess the system 
standards to be modified to better assess those standards relating to specific emergency response functions.

The team changed the criteria "completeness of incident management processes" to "integrates the incident management process" for response function standards to better accommodate differences among standards that are oriented toward executing incident management functions versus those that are oriented toward describing the expectations of first responders who perform operations within an incident management process. This modification maintains the integrity of the review process and the color-coding system, but more accurately reflects the actual scope and purpose of individual standards.

The team developed a diagram that facilitated its discussion and reviews, and enables a visual representation of a hierarchy of system applicability, function-specific applicability, and interrelationships among standards for coverage or gap analysis. The language the team used evolved to include system standards, operational standards, technical standards, and professional guidance/procedural standards. An example of this hierarchy is:

1. A standard that requires a set of NIMS terms to be used by all responders and incident managers

2. A standard that requires a common set of procedures to be used by all responders regardless of incident cause

3. A standard that applies to specific incidents by causation

4. A standard that identifies types of duty uniforms for a specific first responder function.

Finally, each standard was placed into one of four broad functional categories: Emergency Management, Fire/HAZMAT, Medical Response, and Law Enforcement. These categories allow for cross-comparison of standards and more clear identification of gaps in coverage. Standards relating to other response functions (e.g., Public Works, Environment, Public Health, etc.) were not on the NIMS Division List and thus were not reviewed during this cycle. However, they could easily be fit into one of these four broad categories. These four broad functional categories were chosen for simplicity and ease of grouping standards because many standards will cross several of the more detailed functional categories. A brief discussion of a couple of the more detailed functional discipline categories is provided below.

\subsubsection{Responder Sectors}

The 2002-2003 HSEEP training strategy listed ten "response disciplines" as the target audience for training courses funded through the FY 2003 State Homeland Security Grant Program. Those groups of responders are identified below by an asterisk $(*)$. The term "response discipline" was dropped in a subsequent iteration of the HSEEP because of a shift in emphasis. For that reason, the term "responder sectors" is used here to reflect the updated terminology. The HSEEP training priority list did not include an additional seven responder sectors, identified below by a number symbol (\#). The following is a listing of these response disciplines:

- $\quad$ Fire Service Personnel (FS)*

- Emergency Medical Services Personnel (EMS)*

- Health Care Personnel (HC)*

- HAZMAT Responders (HZ)*

- Law Enforcement Personnel (LE)*

- Public Safety Communications Personnel (PSC)* 
- Emergency Management Agency Personnel (EMA)*

- Public Works Personnel (PW)*

- Public Health Personnel (PH)*

- Government Administration Personnel (GA)*

- Environmental \#

- Urban Search and Rescue \#

- Victim Support (e.g., social services, Red Cross, volunteer organizations, and religious organizations) \#

- Private Security Guards \#

- Mental Health \#

- Coroner/Medical Examiner \#

- Animal Control/Veterinary \#

\subsubsection{Definitions of Responder Sectors}

The following are definitions for each of these response sector disciplines.

Fire Services: Initial response, fire suppression, explosive ordnance disposal, standby unit, decontamination, rescue, technical rescue, and recovery.

Emergency Medical Service/Emergency Medicine: Triage, treatment, transportation, medical communications, air operations, sustainment, and protocols.

Health and Hospitals: Treatment, hospitals, decontamination, surge capacity, and hospital security.

HAZMAT: Entry, site access control, safe refuge area, decontamination, personal protection equipment selection, and reconnaissance.

Law Enforcement: Initial response, scene security, force protection, investigation, law enforcement task force, explosive ordnance disposal, traffic control, and evacuation.

Public Safety Communications: Initial identification and linking responders and emergency management.

Emergency Management: Command and operations: organization of initial response, reinforced response organization, multi-division/group organization, information, liaison, damage assessment, economic impact, operational planning, intergovernmental communications, and assessment.

- Planning: situation, resources, documentation, and demobilization.

- Logistics: communications, medical, supply, food, facilities, and transportation.

- Finance/Administration: time, procurement, compensation/claims, and cost. 
Public Works: Heavy equipment, public utilities, debris management, drainage, and water/runoff treatment.

Public health: Quarantine, medical advice, epidemiology, public outreach and education, and enforcement.

Government administration: Public information, evacuation, requests for resources, and coordination.

Environmental: Environmental health, assessment (air, water, soil, flora, fauna), analysis, contamination, cleanup, and enforcement.

\section{Others:}

- Urban Search and Rescue

- Victim Support (e.g., social services, Red Cross, volunteer organizations, and religious organizations)

- Mental Health

- Coroner/Medical Examiner

\subsubsection{Federal Emergency Support Functions (ESF)}

The Federal ESFs are presented with their ESF Coordinators, as identified by the NRP.

ESF \#1 - Transportation

- Federal and civil transportation support

- Transportation safety

- Restoration/recovery of transportation infrastructure

- Movement restrictions

- Damage and impact assessment

ESF Coordinator: U.S. Department of Transportation

\section{ESF \#2 - Communications}

- Coordination with telecommunications industry

- Restoration/repair and temporary provisioning of communications infrastructure

- Protection, restoration, and sustainment of national cyber and information technology resources ESF Coordinator: DHS/National Communications System

\section{ESF \#3 - Public Works and Engineering}

- Infrastructure protection and emergency repair

- Infrastructure restoration

- Engineering services, construction management

- Critical infrastructure liaison

ESF Coordinator: U.S. Department of Defense/U.S. Army Corps of Engineers 
ESF \#4 - Firefighting

- Firefighting activities on Federal lands

- Resource support to rural and urban firefighting operations

ESF Coordinator: U.S. Department of Agriculture

\section{ESF \#5 - Emergency Management}

- Coordination of incident management efforts

- Issuance of mission assignments

- Resource and human capital

- Incident action planning

- Financial management

ESF Coordinator: DHS/FEMA

\section{ESF \#6 - Mass Care, Housing, and Human Services}

- Mass care

- Disaster housing

- Human services

ESF Coordinator: DHS/FEMA

\section{ESF \#7 - Resource Support}

- Resource support (facility space, office equipment and supplies, contracting services, etc.) ESF Coordinator: U.S. General Services Administration

\section{ESF \#8 - Public Health and Medical Services}

- Public health

- Medical

- Mental health services

- Mortuary services

ESF Coordinator: U.S. Department of Health and Human Services

\section{ESF \#9 - Urban Search and Rescue}

- Life-saving assistance

- Urban search and rescue

ESF Coordinator: DHS/FEMA

\section{ESF \#10 - Oil and Hazardous Materials Response}

- Oil and hazardous materials (chemical, biological, radiological, etc.) response

- Environmental safety and short- and long-term cleanup ESF Coordinator: U.S. Environmental Protection Agency and DHS U.S. Coast Guard

\section{ESF \#11 - Agriculture and Natural Resources}

- Nutrition assistance

- Animal and plant disease/pest response

- Food safety and security 
- Natural and cultural resources and historic properties protection and restoration

ESF Coordinator: U.S. Department of Agriculture

ESF \#12 - Energy

- Energy infrastructure assessment, repair, and restoration

- Energy industry utilities coordination

- Energy forecast

ESF Coordinator: U.S. Department of Energy

ESF \#13 - Public Safety and Security

- Facility and resource security

- Security planning and technical and resource assistance

- Public safety/security support

- Support to access, traffic, and crowd control

ESF Coordinator: U.S. Department of Justice

\section{ESF \#14 - Long-Term Community Recovery}

- Social and economic community impact assessment

- Long-term community recovery assistance to States, local governments, and the private sector

- Mitigation analysis and program implementation

ESF Coordinator: DHS/FEMA

\section{ESF \#15 - External Affairs}

- Emergency public information and protective action guidance

- Media and community relations

- Congressional and international affairs

- Tribal and insular affairs

ESF Coordinator: DHS

\subsection{Technical Review Method}

This section describes the methodology (steps) the team used to review the 61 standards on the NIMS Division List selected by the tool for potential applicability to NIMS. The overall approach used to review all standards for NIMS application, which incorporates the four phase SME technical review, consisted of 12 steps:

1. Identification of keywords and concepts found within NIMS component criteria;

2. Identification of standards appropriate for review;

3. Application of the search tool to identify the presence and frequency of keywords in each standard using the NIMS component criteria derivatives;

4. Development of a matrix for each standard to record the presence of keyword/phrase relationship "hits" found in the respective standard;

5. Intensive reading of each standard by each member of the team to assess the applicability of the standard and its content to NIMS;

6. Development of an initial assessment of each standard by each SME; 
7. Review and discussion of each standard by the entire team, using a set of consensus criteria: scope, relevance, operational application, organization level, and completeness (as described in paragraph 4.1). For standards relating to specific emergency response functions, the ability of the standard to contribute to emergency management integration was substituted for the completeness criteria.

8. Production of a color-coded matrix for each standard grouped by NIMS component criteria on the vertical axis and the consensus criteria on the horizontal axis; the color-coding was assigned using the criteria of Step 7 and color assignments made based on the following rules: 4 of the 5 criteria found rated green, 3 of 5 rated light green, 2 of 5 rated yellow, 1 of 5 rated orange, and 0 of 5 rated red;

9. Comparison of the SME finding with the presence of keywords or concepts found by the NIMS component criteria search tool to confirm the presence or absence of specific language;

10. Capturing a brief information point describing the rationale/conclusion of the team;

11. Review of the findings by the full team to help ensure consistency within the group process; and

12. Placement of the SME findings into a composite matrix of all standards, all criteria, by code, with comments.

The results of this analysis were captured in a database integral to the tool for future retrieval and application.

\subsection{Technical Review Scoring Criteria}

The technical review used the following criteria for color-code scoring of each standard. Integration and completeness were evaluated together in the color-coding process.

SCOPE: the degree to which a standard (or part of a standard) covers the incident management process, generally including "who" and "what." Many standards are not intended to cover the full range of incident management processes, but rather are limited in scope as stated in the introduction to the standard. Examples of such limitations include applicability to "emergency service organizations" but not "emergency operations centers," "deployment of resources" but not "acquisition, allocation or recovery of resources," or requirements for "planning" but not a "plan."

RELEVANCE: the degree to which a standard (or part of a standard) establishes its rationale in incident management processes, generally including the "why" of the standard. Many standards are specifically oriented toward a specific group of personnel or a specific function but cannot be generalized to other groups, functions, or organizational levels. Examples of such limitation include applicability to emergency management and incident management system processes versus applicability to a specific first responder group (fire, EMS, etc.).

OPERATIONS/HOW: the degree to which a standard (or part of a standard) states the activities to be performed in the context of incident management processes. Many standards do not identify the actions to be taken by response personnel, deferring these descriptions to standard operating procedures, and do not address the integration of response actions with incident management processes.

ORGANIZATION LEVEL: the degree to which a standard (or part of a standard) identifies the placement of the entity in a command, or authority, decision-making structure. Many standards to not 
address the responsibility of the entity responsible for implementing the standard within a chain of command.

INTEGRATION: the degree to which a standard (or part of a standard) recognizes and states the requirement to participate as a component in an overall emergency management strategy or operation, with associated communication, cooperation, and coordination up and down a chain of command or incident management process.

COMPLETENESS: the degree to which the standard "fills out" the incident management system and processes, enabling a smooth coordination of preparedness activities and emergency management processes. Many standards do not specifically address a systems approach to executing the targeted responsibilities or do not use terminology consistent with NIMS.

\subsection{Internal Audit of Technical Review}

In reviewing the standards, the team used NIMS component criteria that had been previously subdivided into five categories including planning, communications, resources, field command, and technology. The purpose of the review was to determine the extent to which a particular standard addressed each of these components and their subdivisions. As previously described, the team associated colors with each standard to reflect how completely the standard addressed the NIMS component criteria with respect to scope, relevance, implementation, organization, and systems completeness/integration. The results of this effort are compiled in a matrix that indicates the appropriate color designations (Appendix D). The matrix also references the specific chapter of the respective standards in which the NIMS component criteria can be located. Review of the 61 standards was an iterative process and frequently required the team to return to a previously reviewed standard to ascertain relationships with the particular standard being discussed at the time. Upon re-reviewing a standard previously examined for this purpose, the team found it necessary to change only five previous color designations in an array of more than 680. This subsequent review process provided a means of auditing previously determined color designations and reinforced the validation of the process. 



\subsection{Standards Review Results}

\subsection{Summary of Results}

This section presents a summary of the results from the team technical review of 61 of the 141 standards on the NIMS Division List for applicability and relevance to NIMS. The remaining 80 standards were screened out by the review tool because no connection to the specific NIMS component criteria was found for any of the components in these standards (NFPA 471 was dismissed because the NFPA is in the process of eliminating it). Of the 61 standards, 37 were by the NFPA, 19 were by ASTM International, and the remainder were from the American National Standards Institute (ANSI), the Joint Commission on Accreditation of Healthcare Organizations (JCAHO), the Institute of Electrical and Electronics Engineers (IEEE), the National Emergency Number Association (NENA), the Association of Public-Safety Communications Officials International (APCO) Project 25, National Institute of Justice (NIJ), and others. This technical review process focused only on a standard's ability to align with the specific NIMS component criteria. It does not reflect on the value of a standard and the purpose for which it was developed (i.e., this technical review does not address the quality of a standard or applicability to the response community outside its ability to support NIMS).

As discussed in Section 1.1, the review discovered four different categories of standards: systems type standards, operational level standards, technical standards, and professional guidelines and procedures (see Figure 1). While they are certainly important to an integrated incidence response for the specific function of their respective design, we believe the professional guidelines and procedures standards are of such focused detail that they are beyond the management scope of NIMS. As would be expected, the majority of the standards that were reviewed fit into the professional guidelines and procedures category. Thus, our results focus on the other three types of standards (i.e., systems, operational, and technical). We identified all the professional guidelines and procedure standards on the NIMS Division List as to where they fit within the four categories but did not analyze them in detail. This does not mean that NIMS management should not use the professional guidelines and procedures standards for resources, credential requirements, etc. It will be important to ensure that the standards used for NIMS management are consistent with these professional guidelines and procedures standards.

The overall technical analysis of the standards on the NIMS Division List produced 14 standards that fit into the three NIMS management categories (i.e., systems, operational, and technical). Identifying these 14 standards accomplished one of the primary goals for the analysis of the standards on the NIMS Division List, which was to thoroughly and consistently analyze all of the listed standards and identify those that the NIMS Division could focus on for NIMS implementation and compliance. It also satisfied another goal, which was to identify and record the specific sections of these standards that apply to each of the specific NIMS components/criteria. These detailed results are presented in Appendix F.

Figure 4 shows how all the standards reviewed from the NIMS Division List fit into the four categories (i.e., Medical Response, Fire/HAZMAT, Law Enforcement, and Emergency Management) and into the four types of standards (i.e., Systems. Operational, Technical, and Professional Guidelines and Procedural). 


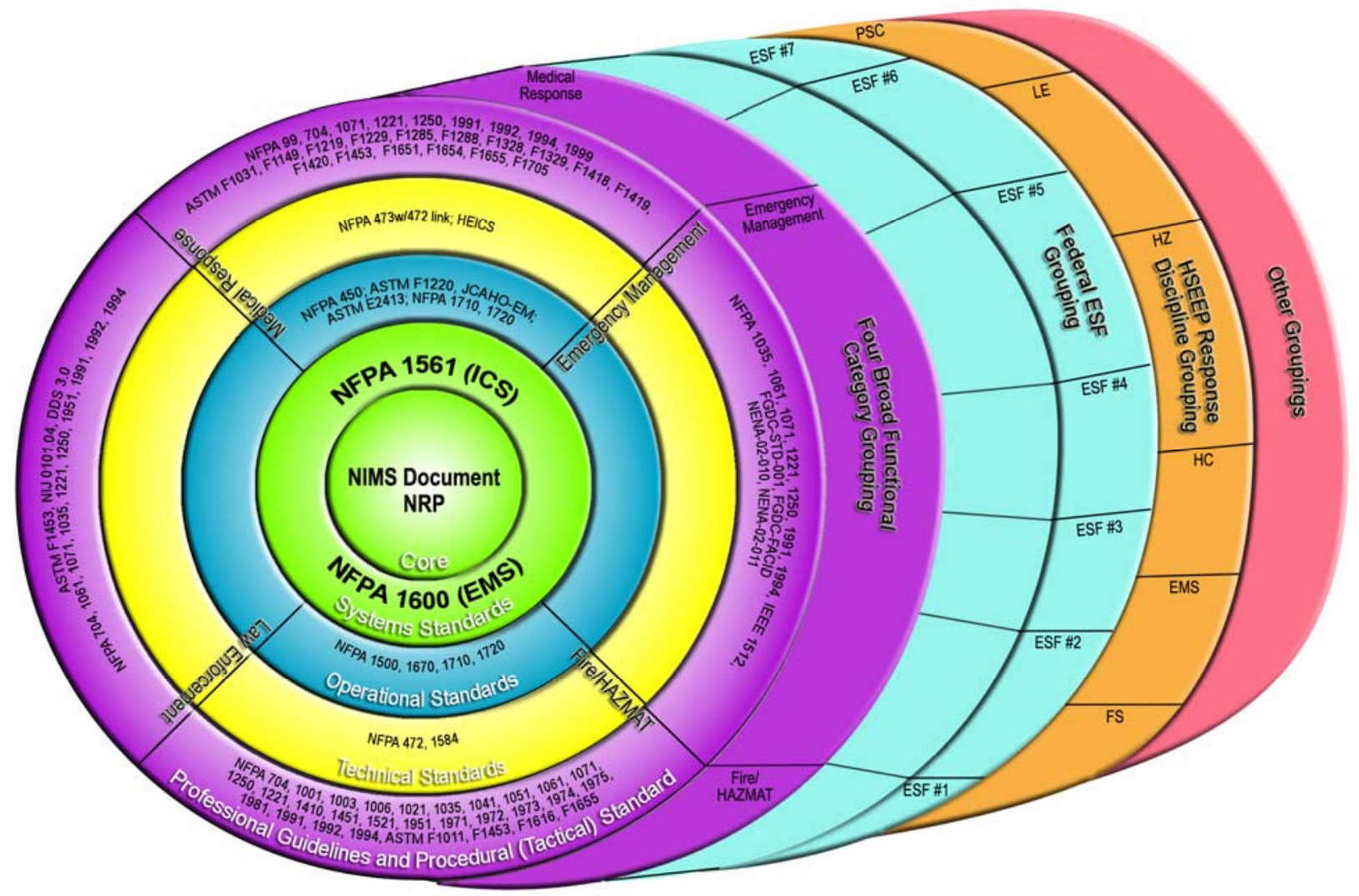

Figure 4. Grouping of NIMS Division List Standards into the Four Groups and Four Types of Standards

The four functional categories of standards are very broad and encompass several ESFs; Figures 5-8 provide a simplified breakout of each of the four functional categories shown in Figure 4. As shown in Figures 7 and 8, the breakout of the Law Enforcement and Emergency Management categories is not complete. The NIMS Division List did not include the compliment of standards that would fit into these two categories. Future work is being planned to obtain the Law Enforcement standards. Standards development work is ongoing for standards that would help complete the Emergency Management grouping. 


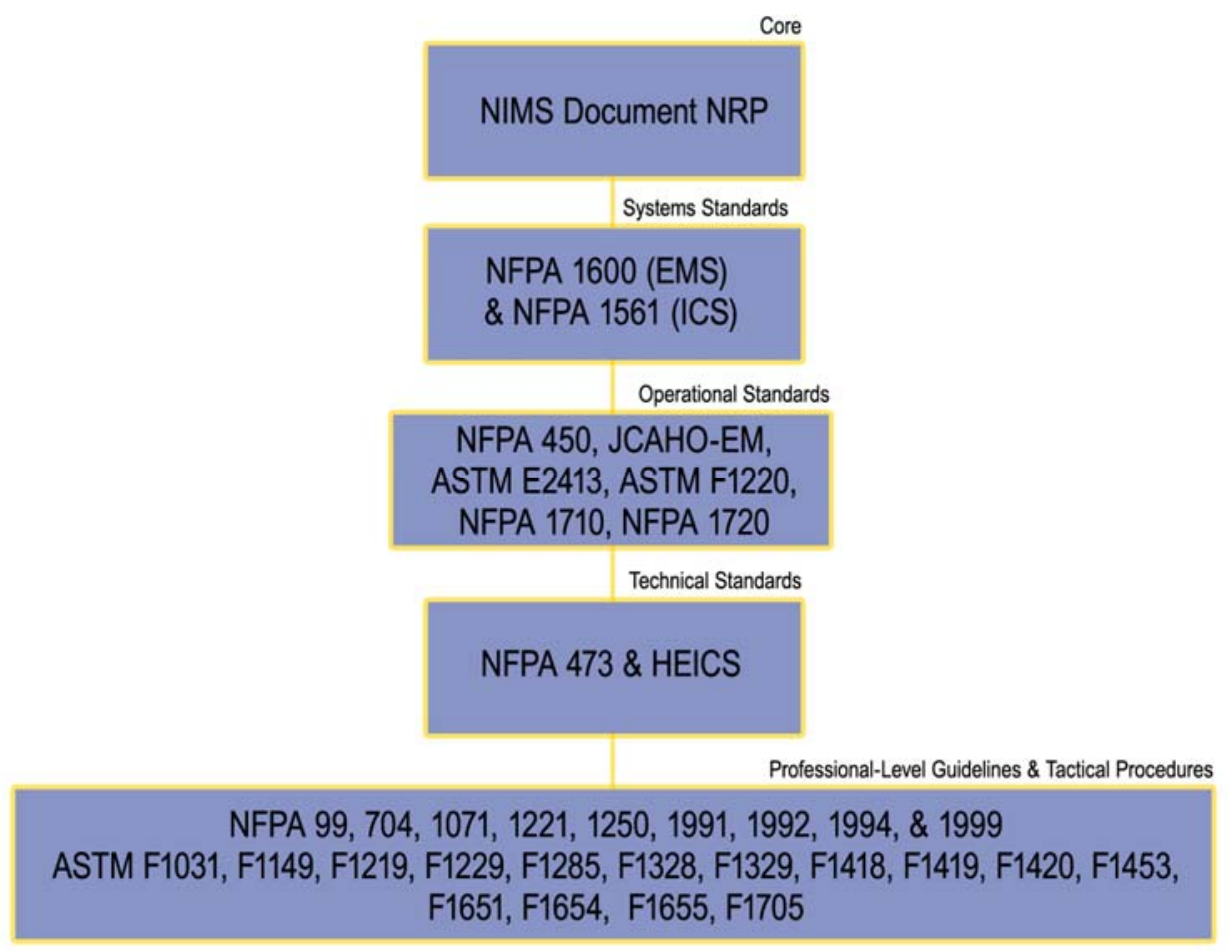

Figure 5. Medical Response Standards

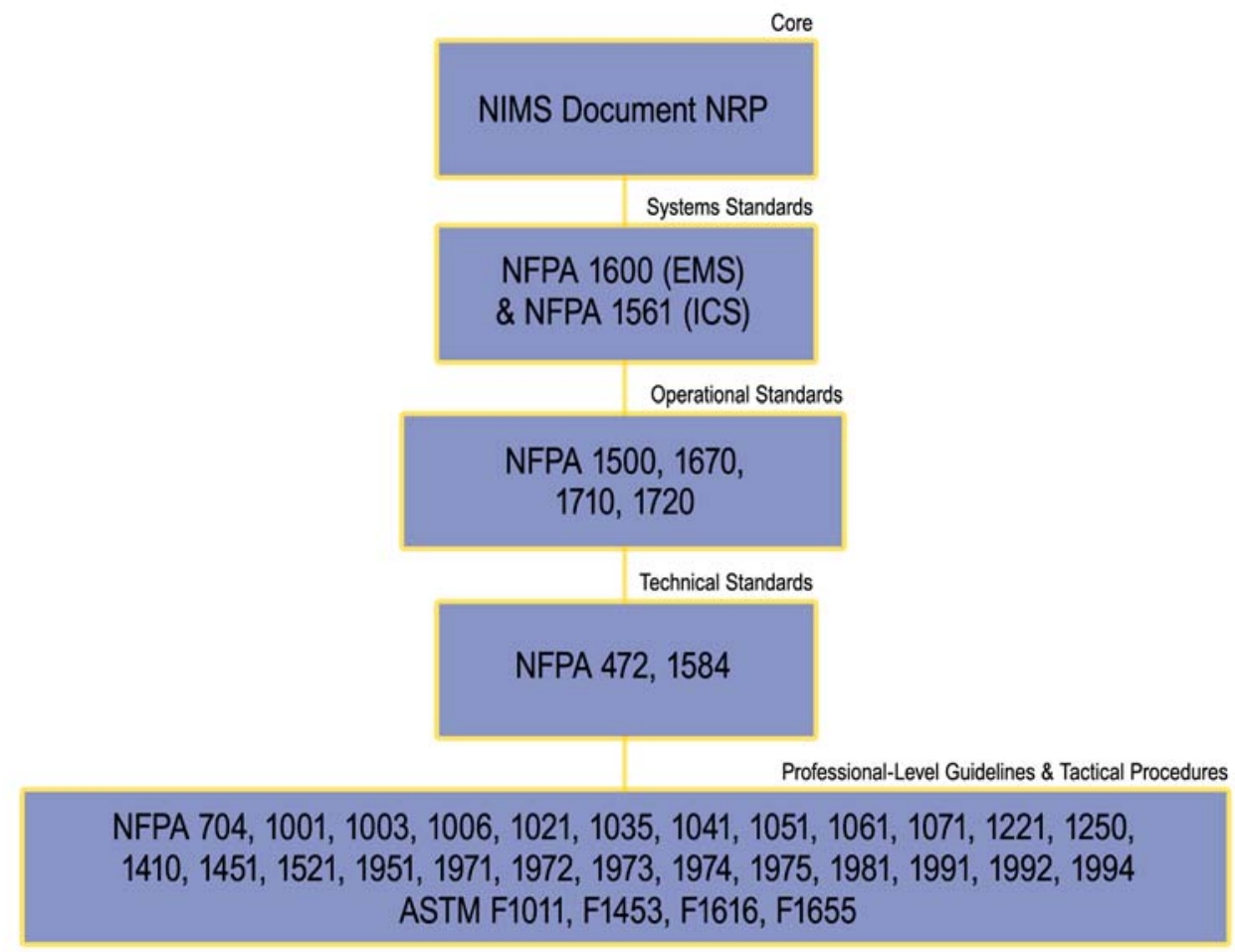

Figure 6. Fire/HAZMAT Standards 


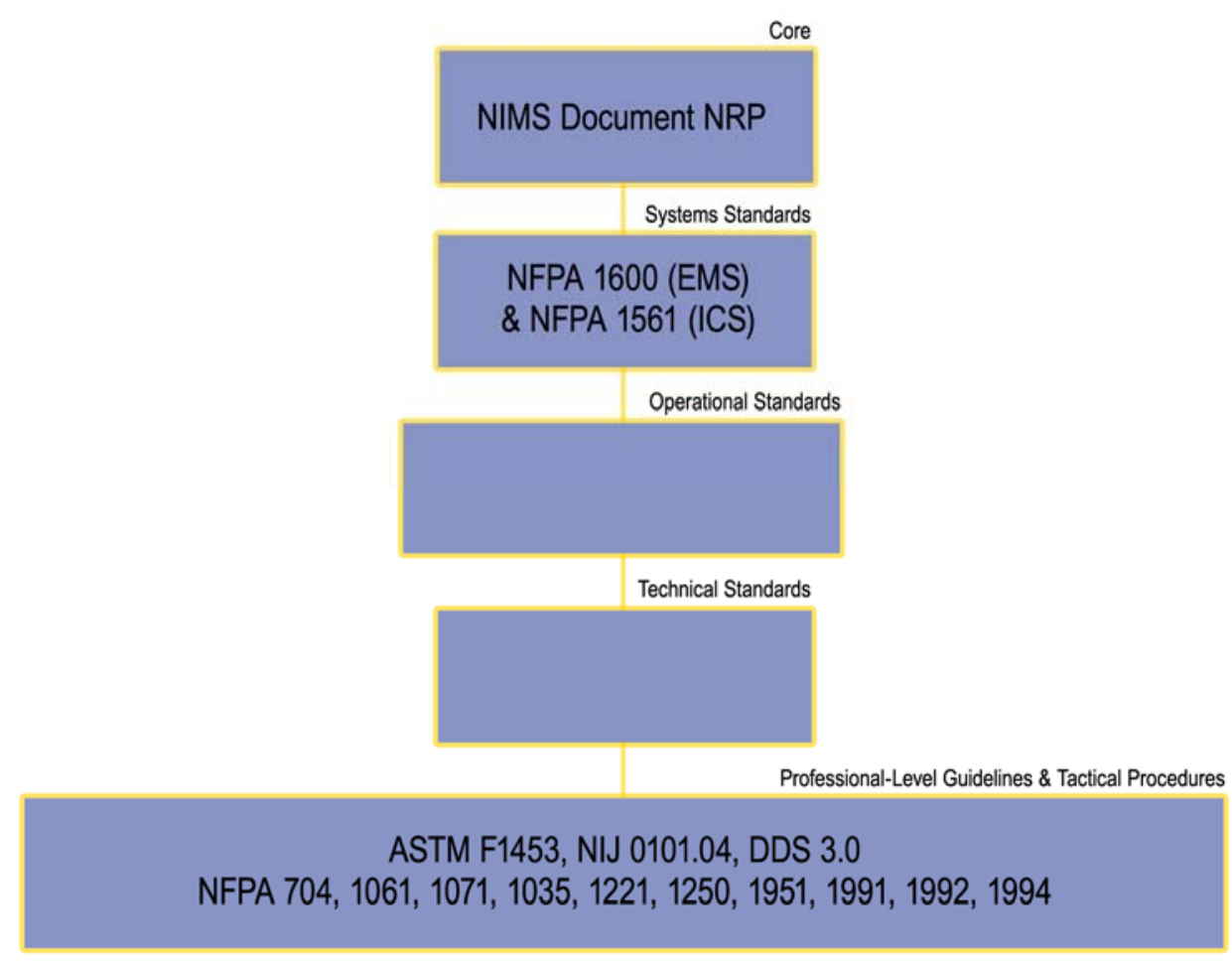

Figure 7. Law Enforcement Standards

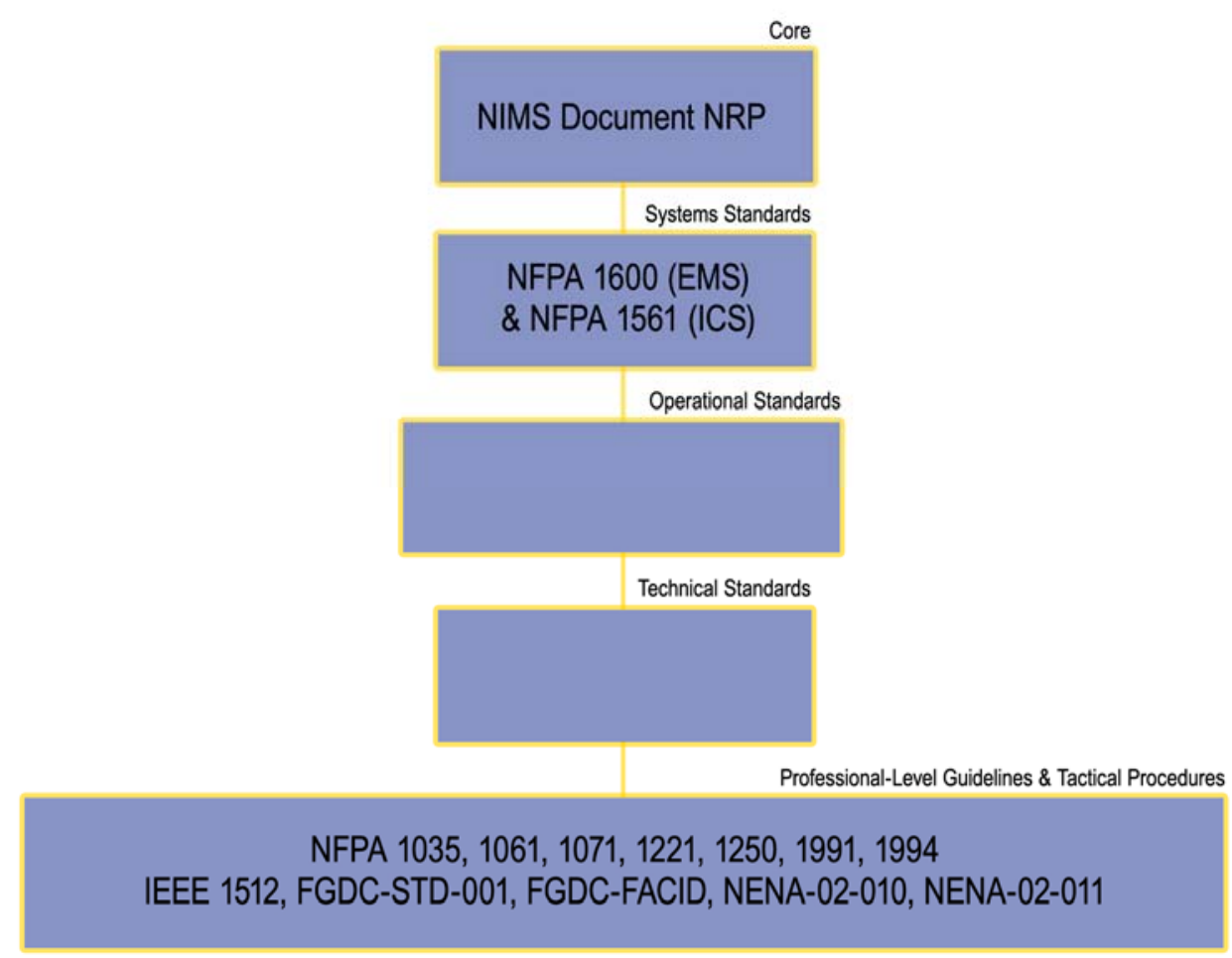

Figure 8. Emergency Management Standards 
Using the technical review process and color-coding discussed in Section 4.0, color-coded dashboard tables were prepared for the Medical Response and Fire/HAZMAT categories. Additional standards will need to be located or developed to complete dashboard tables for the Law Enforcement and Emergency Management categories.

The purpose of these dashboard tables is to provide, at a quick glance, which standards tend to align the best with each of the respective NIMS components and criteria. Green means it aligns well with the respective NIMS component and criteria. Light green means it aligns fairly well, but is missing a couple of criteria. Yellow means it is missing three of the criteria. Orange means it is missing four of the criteria. Red means it doesn't address any of the five criteria very well. However, a red coding does not mean a standard is not a quality standard addressing the purpose for which it was designed. It means only that it did not align with the NIMS management criteria very well. The standards in the Professional Guidelines and Procedures grouping all received a red coding; however, they are very valuable to incident management for the detailed purpose for which they were designed. The detailed results presented in Appendices $\mathrm{C}$ through $\mathrm{F}$ include tables showing the color-coding for each standard, the specific sections of the standard that apply to the respective NIMS components/criteria, and a list of the criteria missing for each standard that is color-coded other than green or red.

The Medical Response Dashboard is shown in Table 3. The Fire/HAZMAT Dashboard is shown in Table 4.

Table 3. Medical Response Dashboard

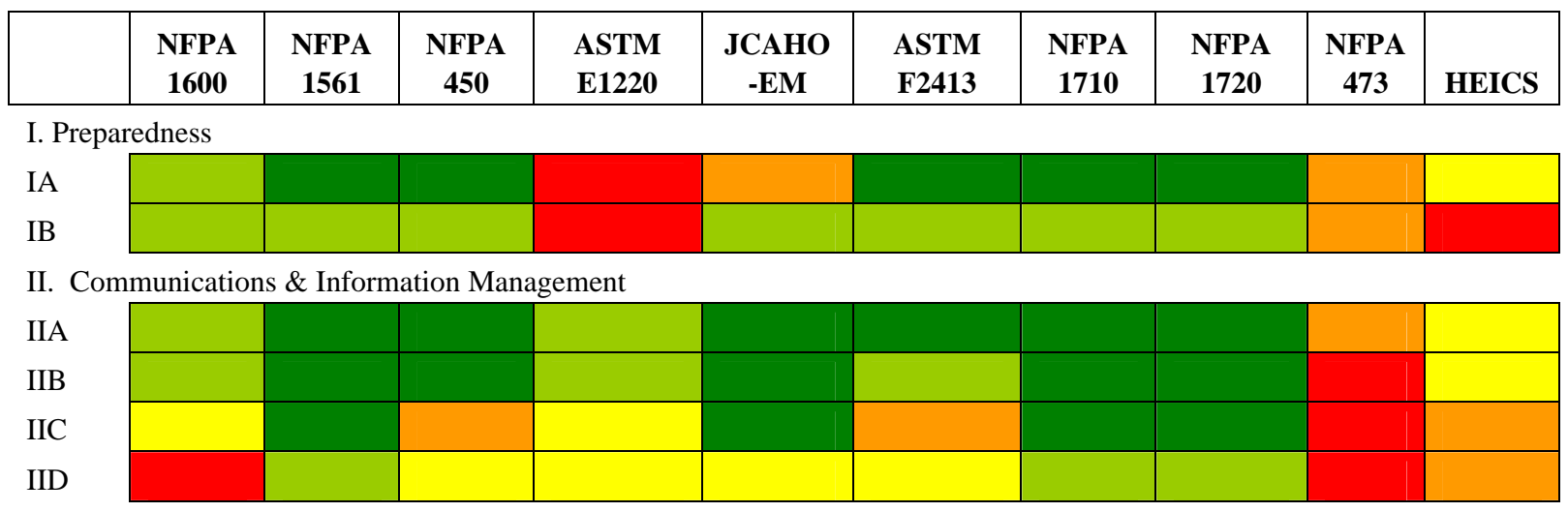

III. Resource Management

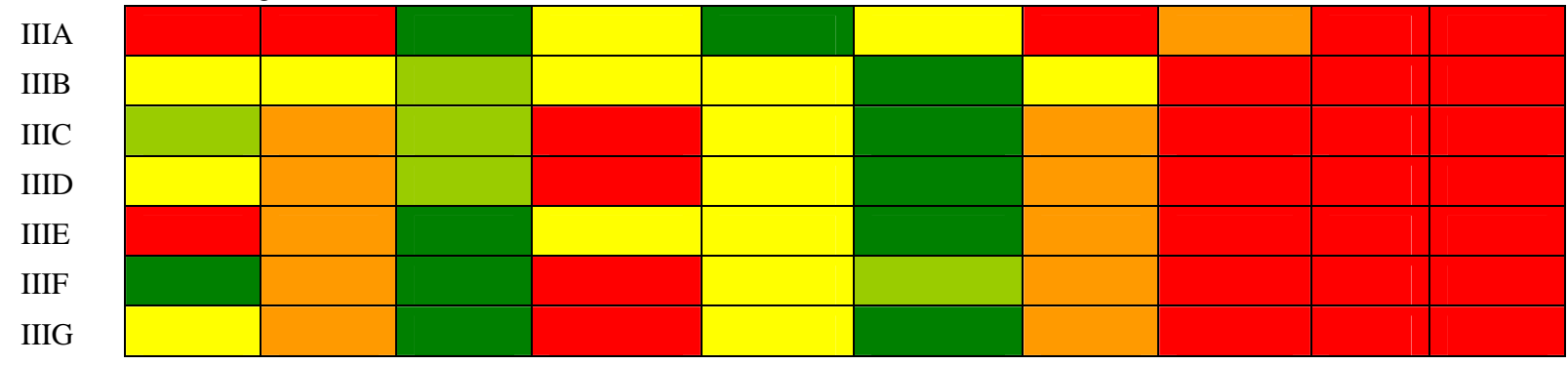




\begin{tabular}{|c|c|c|c|c|c|c|c|c|c|c|}
\hline & NFPA & NFPA & NFPA & ASTM & JCAHO & ASTM & NFPA & NFPA & NFPA & \\
& 1600 & 1561 & 450 & E1220 & -EM & F2413 & 1710 & 1720 & 473 & HEICS \\
\hline
\end{tabular}

IV. Command and Management

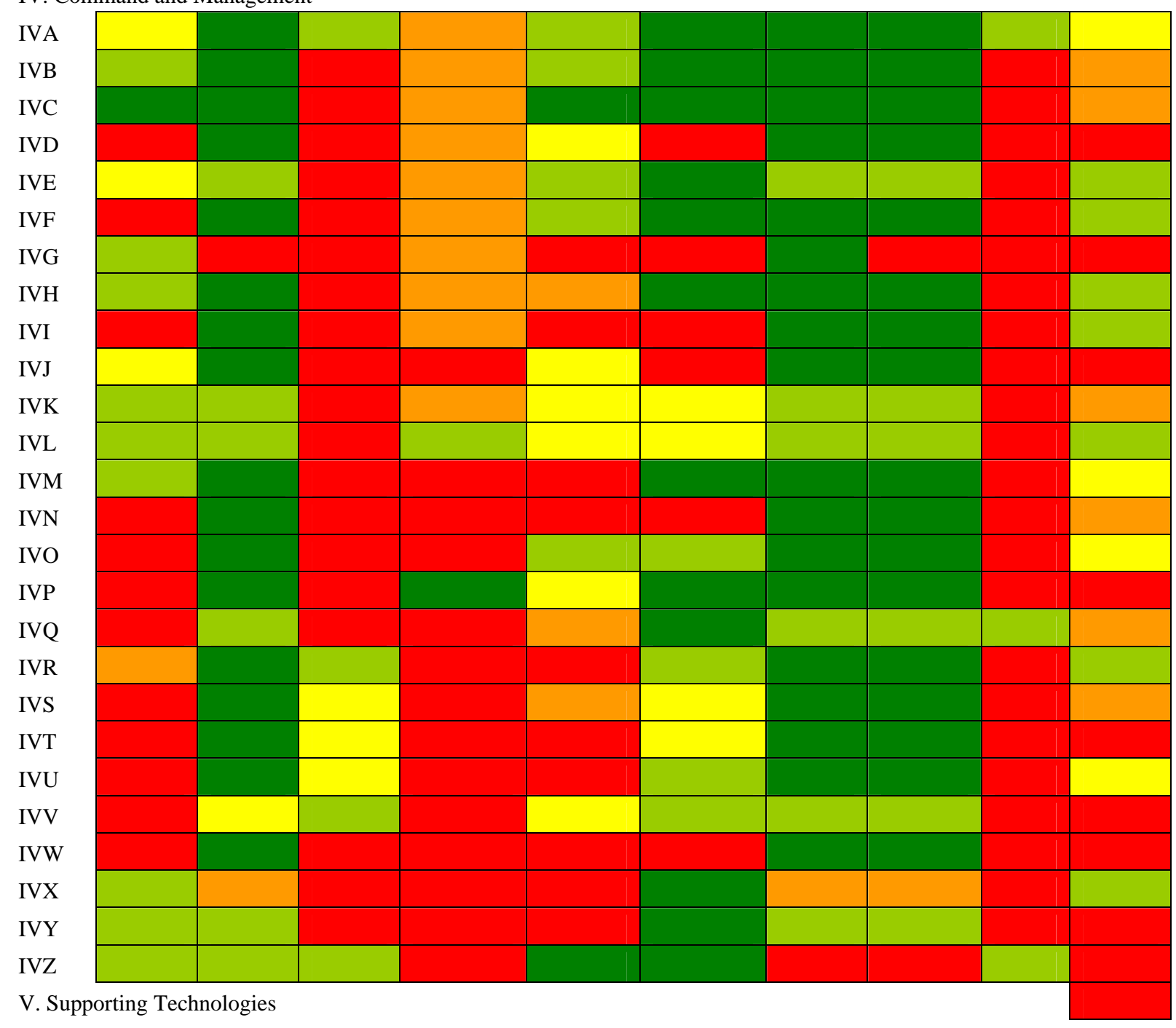

Table 4. Fire/HAZMAT Dashboard

\begin{tabular}{|c|c|c|c|c|c|c|c|c|}
\hline & NFPA & NFPA & NFPA & NFPA & NFPA & NFPA & NFPA & \\
& 1600 & 1561 & 1500 & 1670 & 1710 & 1720 & 472 & NFPA 1584 \\
\hline
\end{tabular}

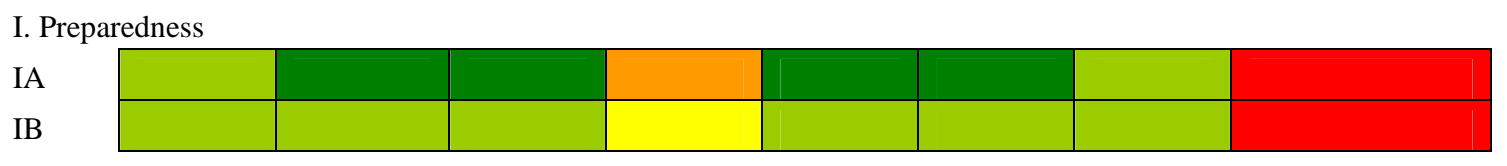

II. Communications \& Information Management

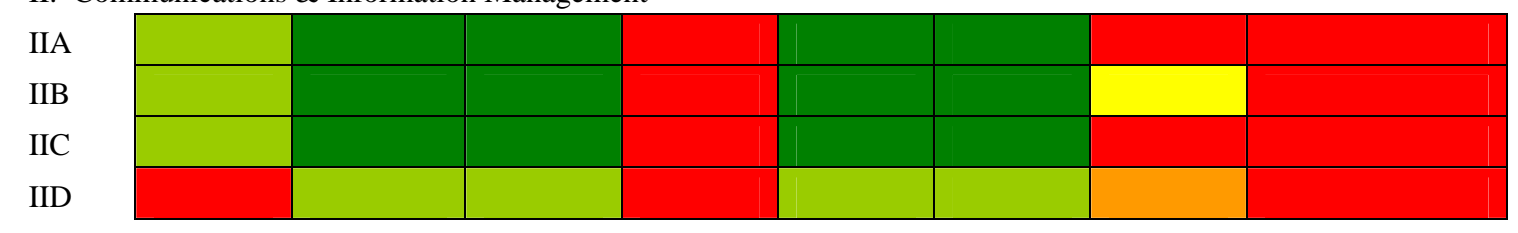




\begin{tabular}{|c|c|c|c|c|c|c|c|c|}
\hline & NFPA & NFPA & NFPA & NFPA & NFPA & NFPA & NFPA & \\
& 1600 & 1561 & 1500 & 1670 & 1710 & 1720 & 472 & NFPA 1584 \\
\hline
\end{tabular}

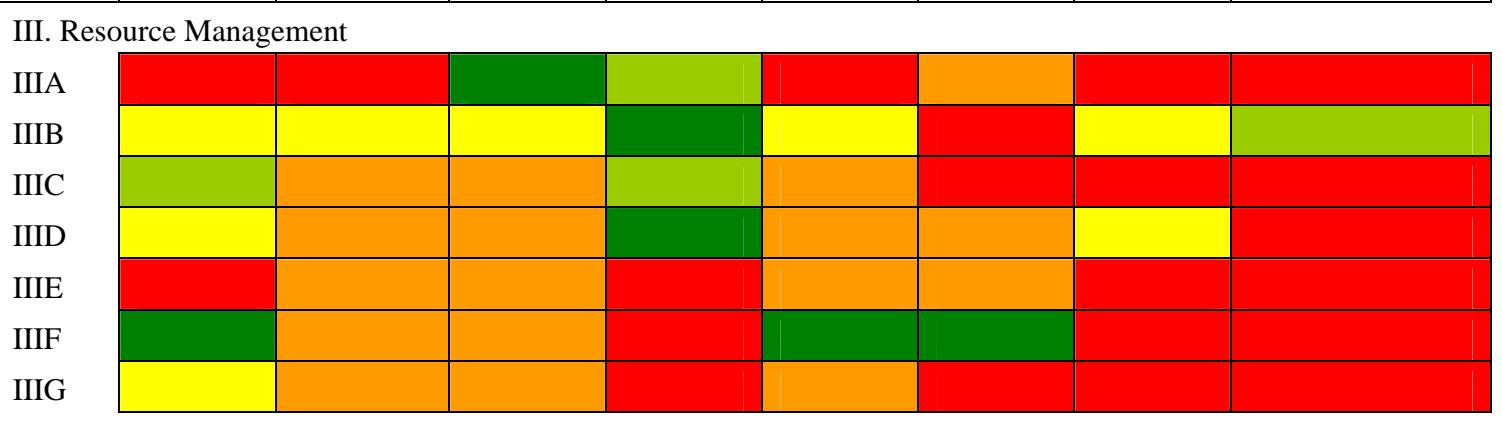

IV. Command and Management

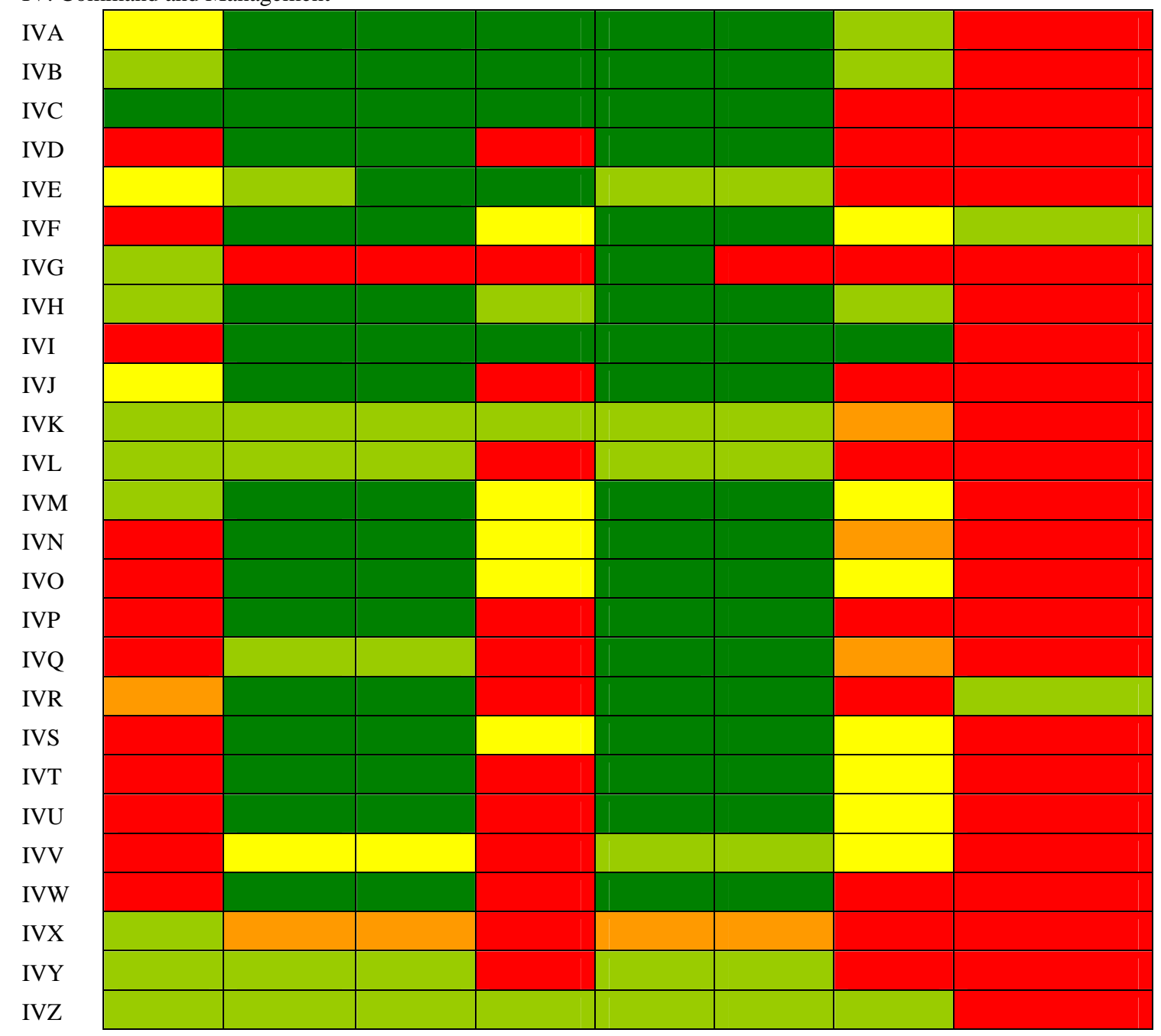

V. Supporting Technologies 


\subsection{Detailed Results}

This section presents the detailed results from the team technical review of 61 of the 141 standards on the NIMS Division List for applicability to NIMS.

Tables showing the color-coding, identification of the specific chapters addressing the respective NIMS component/criteria, and a listing of the missing criteria for color codes other than green or red for the two System Standard (i.e., NFPA 1561 and NFPA 1600) that cross all four standards grouping are provided in Appendix C.

Tables showing the color-coding, identification of the specific chapters addressing the respective NIMS component/criteria, and a listing of the missing criteria for color codes other than green or red for the Medical Response Standards are provided in Appendix D.

Tables showing the color-coding, identification of the specific chapters addressing the respective NIMS component/criteria, and a listing of the missing criteria for color codes other than green or red for the Fire/HAZMAT Standards are provided in Appendix E.

Tables showing the complete technical analysis results are provided in Appendix F. 


\subsection{Discussion}

\subsection{Findings}

The overall technical analysis of the standards on the NIMS Division List produced 14 standards that fit into the three categories of standards that support NIMS management (i.e., systems, operational, and technical). The fourth standard category is "professional guidelines and procedural (tactical) type standards." The team believes that, while the standards in this fourth category are very important and valuable for the tactical capability of the specific response discipline of focus, the development and management of these types of standards should be left up to their respective professional response organization.

The 14 standards recommended to the NIMS Division for NIMS support are: NFPA 1600, NFPA 1561, NFPA 450, NFPA 472, NFPA 473, NFPA 1500, NFPA 1584, NFPA 1670, NFPA 1710, NFPA 1720, ASTM F1220, ASTM E2413, JCAHO-EM, and HEICS. Only the NFPA 1600 (incident management system) and NFPA 1561 (incident command system) were considered broadly applicable across all disciplines. The JCAHO-EM, HEICS, ASTM 2413, ASTM F1220, NFPA 450, NFPA 473, NFPA 1710, NFPA 1720 are all associated with the medical response broad discipline grouping. The NFPA 472, NFPA 1500, NFPA 1584, NFPA 1670, NFPA 1710, and NFPA 1720 are all associated with the fire/HAZMAT broad discipline grouping. The NIMS Division List did not include any systems, operational, or technical category standards that supported either the law enforcement or the emergency management broad discipline functional categories.

There are two perspectives that need to be in balance for a response that is truly consistent with the concepts and principles of NIMS. One is the on-scene, incident response-based perspective, and the other the incident support-based perspective. Figure 9 shows this relationship. Standards help to relate these two perspectives.

\subsection{Recommendations}

The NFPA 1600 ( emergency management system) and the NFPA 1564 (incident command system) standards are recommended to the NIMS Division for national incident management support (i.e., NIMS support) across all response disciplines. These standards are high-level system standards that help define the "what to address" with respect to incident management systems and incident command systems.

These two standards can be considered as "umbrella"-type standards. The coupling of these two umbrella standards with the operational and technical standards identified for each respective broad discipline grouping is recommended as a means of integrating the incident management process. For example, the operational and technical standards tend to address the "who, when, where, and how" needed for interoperability. The specific tactical detail should be left to the respective response organizations carrying out the incident response.

Since law enforcement standards were not included in the NIMS Division List, it is recommended that a concerted effort be made to locate and obtain the existing standards that potentially support NIMS for law enforcement. Once obtained, it is recommended that these law enforcement standards be reviewed using this same technical review process. 
Incident Response-Based Sectors

Operations usually/mostly performed

at primary incident sites(s)

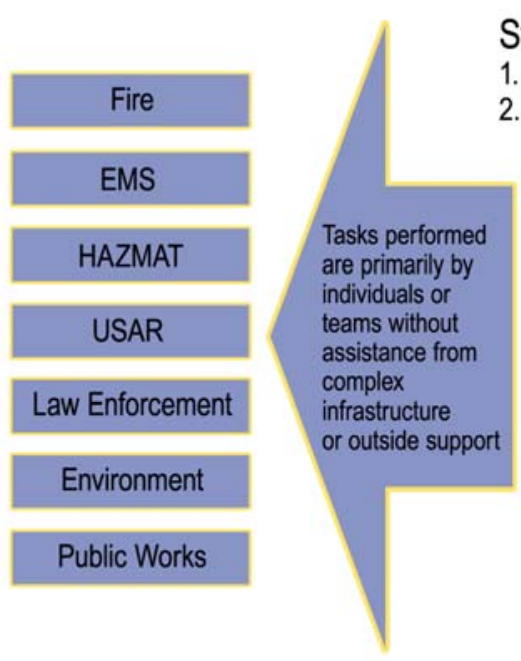

Incident Support-Based Sectors

Operations usually/mostly performed at home facility or adjacent to primary incident site(s)

\begin{tabular}{|c|}
\hline Emergency Management \\
\hline Government Administrators \\
\hline Health/Hospitals \\
\hline Public Safety Communications \\
\hline Public Health
\end{tabular}

Figure 9. Incident Response-Based Versus Incident Support-Based Perspective 


\section{Appendix A}

\section{The NIMS Division List of Potential NIMS Support Standards}





\section{Appendix A}

\section{The NIMS Division List of Potential NIMS Support Standards}

\begin{tabular}{|c|c|}
\hline 1 & NFPA 1600, Standard on Disaster/Emergency Management and Business Continuity Programs \\
\hline 2 & NFPA 1561, Standard on Fire Department Incident Management Systems \\
\hline 3 & NFPA 1670, Standard on Operations and Training for Technical Rescue Incidents \\
\hline 4 & NFPA 1500, Fire Department Occupational Safety and Health Program \\
\hline 5 & NFPA 1250, Recommended Practice in Emergency Service Organization Risk Management \\
\hline 6 & NFPA 1410, Standard on Training for Initial Emergency Scene Operations Covers \\
\hline 7 & NFPA 1451, Standard for a Fire Service Vehicle Operations Training Program \\
\hline 8 & NFPA 1584, Standard on Station/Work Uniforms for Fire and Emergency Services \\
\hline 9 & National Fire Service Accreditation Program \\
\hline 10 & NFPA 472, Standard for Professional Competence of Responders to Hazardous Materials Incidents \\
\hline 11 & NFPA 1071, Standard fro Emergency Vehicle Technician Professional Qualifications \\
\hline 12 & NFPA 1971, Protective Clothing for Structural Firefighting \\
\hline 13 & NFPA 1981, Standard on Open-Circuit Self-Contained Breathing Apparatus for Firefighters. \\
\hline 14 & NFPA 1991, Vapor-Protective Suits for Hazardous Chemical Emergencies \\
\hline 15 & NFPA 1992, Liquid Splash Protective Suits for Hazardous Chemical Emergencies \\
\hline 16 & NFPA 1994, Standard for Protective Ensembles for Chemical/Biological Terrorism Incidents \\
\hline 17 & NFPA 1999, Emergency medical protective clothing \\
\hline 18 & NFPA 1951, Standard on Protective Ensemble for USAR Operations \\
\hline 19 & NFPA 1221, Standard for the installation, Maintenance, and Use of Emergency Services Communication Systems \\
\hline 20 & Emergency Management Accreditation Program (EMAP) \\
\hline 21 & Certified Emergency Manager Program \\
\hline 22 & EMSF01, Emergency Management Standards for Health Care Organizations and Their Communities \\
\hline 23 & JCAHO-EM Environment of Care 1.4, Emergency Management Standard \\
\hline 24 & Comprehensive Hospital Accreditation \\
\hline 25 & JCAHO-EM Environment of Care 2.9.1 Emergency Management Standard \\
\hline 26 & JCAHO-EM Environment of Care 5.14.4.1, Emergency Management Standard \\
\hline 27 & ASTM F1127, Standard Guide for Containment by Emergency Response Personnel of Hazardous Material Spills \\
\hline 28 & OSHA 1910.120 (PSTAA) \\
\hline 29 & NFPA 704, Standard System for the Identification of the Hazards of Materials for Emergency Response \\
\hline 30 & Superfund Emergency Response Program (PSTAA) \\
\hline 31 & NFPA 471, Standard for Competencies for EMS Personnel Responding to Hazardous Materials Incidents \\
\hline 32 & NFPA 473, Standard for Competencies for EMS Personnel Responding to Hazardous Materials Incidents \\
\hline 33 & ANSI N42.32, Performance Criteria for Alarming Personal Radiation Detectors for Homeland Security \\
\hline 34 & ANSI N42.33, Radiation Detection Instrumentation for Homeland Security \\
\hline 35 & ANSI N42.34, Performance Criteria for Hand-Held Instruments for the Detection and Identification of Radionuclides \\
\hline 36 & ANSI N42.35, Evaluation and Performance of Radiation Detection Portal Monitors for Use in Homeland Security \\
\hline 37 & CBRN Standard for Open-Circuit Self-Contained Breathing Apparatus \\
\hline 38 & $\begin{array}{l}\text { Standard Guide for Chemical, Biological, Radiological, and Nuclear (CBRN) Full Facepiece Air Purifying } \\
\text { Respirator (APR). }\end{array}$ \\
\hline 39 & $\begin{array}{l}\text { ASTM F1655, Standard Guide for Training First Responders Who Practice in Wilderness, Delayed, or Prolonged } \\
\text { Transport Settings (PSTAA). }\end{array}$ \\
\hline
\end{tabular}




\begin{tabular}{|c|c|}
\hline 40 & NFPA 450, Guide for Emergency Medical Services and Systems \\
\hline 41 & Emergency Vehicle Operators Course (Ambulance), National Standard Curriculum \\
\hline 42 & 1995 Emergency Vehicle Operators Course (Ambulance), National Standard Curriculum \\
\hline 43 & ASTM 1705, Standard Guide for Training Emergency Medical Services Ambulance Operators \\
\hline 44 & NHTSA, First Responder National Standard Curriculum \\
\hline 45 & EMT-Basic, National Standard Curriculum (PSTAA) \\
\hline 46 & ASTM F1031, Standard Practice for Training the Emergency Medical Technician (Basic) \\
\hline 47 & EMT-Intermediate, National Standard Curriculum (PSTAA) \\
\hline 48 & EMT-Paramedic, National Standard Curriculum (PSTAA) \\
\hline 49 & ASTM F1651, Standard Guide for Training the Emergency Medical Technician (Paramedic) \\
\hline 50 & P EMT-P and EMT-I Continuing Education National Guidelines \\
\hline 51 & ASTM F1616, Standard Guide for Scope of Performance of First Responders \\
\hline 52 & Public Safety Training Academy Accreditation \\
\hline 53 & NIJ Standard 0101.04, Ballistic Resistance of Personal Body Armor \\
\hline 54 & Public Safety Communications Accreditation Program \\
\hline 55 & $\begin{array}{l}\text { IEEE Std 1512-2000, IEEE Standard for Common Incident Management Message Sets for Use by Emergency } \\
\text { Management Centers }\end{array}$ \\
\hline 56 & NENA 02-010, Standard Formats \& Protocols for ALI Data Exchange, ALI Response \& GIS Mapping \\
\hline 57 & AAPCO Project 25 Conventional Control Messages (TIA/EIA TSB 102.AABG) \\
\hline 58 & NENA 02-011, Data Standards for Local Exchange Carriers, ALI Service Providers \& 9-1-1 Jurisdictions \\
\hline 59 & APWA Accreditation and Self-Assessment \\
\hline 60 & AMBER Alert Message Schema [Based on the operational version 3.0 of the Global Justice XML Data Model] \\
\hline 61 & NENA-01-002, NENA (National Emergency Number Association) Master Glossary of 9-1-1 Terminology \\
\hline 62 & Inter-RF System Interface Overview [TSB 102.BACC] \\
\hline 63 & Inter-RF System Interface Messages Definition [TIA TSB 102.BACA] \\
\hline 64 & Bluetooth Specification \\
\hline 65 & $\begin{array}{l}\text { Regional Information Sharing Systems (RISS) Database Node Type } 1 \text { Documentation - RISS Data Exchange } \\
\text { Specification } 1.0\end{array}$ \\
\hline 66 & $\begin{array}{l}\text { Regional Information Sharing Systems (RISS) Program Data Exchange Specification 1.0, RISS Type } 1 \text { Node } \\
\text { Documentation }\end{array}$ \\
\hline 67 & Justice and Public Safety XML Data Dictionary Schema (DDS 2.1) \\
\hline 68 & Justice and Public Safety XML Data Dictionary Schema (DDS 3.0) \\
\hline 69 & $\begin{array}{l}\text { ANSI/NIST-ITL 1-2000, Data Format for the Interchange of Fingerprint, Facial, Scar Mark and Tattoo (SMT) } \\
\text { information }\end{array}$ \\
\hline 70 & APCO Project 25 Common Air Interface Operational Description for Conventional Channels [TSB 102.BAAD] \\
\hline 71 & APCO Project 25 System and Standards Definition TSB102-A (Revision of TSB102) \\
\hline 72 & APCO Project 25 Security Services Overview [TIA TSB 102.AAAB] \\
\hline 73 & APCO Project 25 Trunking Control Channel Formats [ANSI/TIA/EIA- 102.AABB] \\
\hline 74 & APCO Project 25 Circuit Data Specification [ANSI/TIA/EIA-102.BAEC-2000] \\
\hline 75 & APCO Project 25 Link Control Word Formats and Messages [TIA/EIA TSB-102.AABF] \\
\hline 76 & Digital C4FM/CQPSK Transceiver Performance Recommendations [TIA/EIA/IS-102.CAAB] \\
\hline 77 & Digital C4FM/CQPSK Transceiver Measurement Methods [ANSI/TIA/EIA-102.CAAA] \\
\hline 78 & APCO Project 25 Common Air Interface Reserved Values [TIA/EIA-102.BAAC] \\
\hline 79 & APCO Project 25 Over the Air Re-keying (OTAR) Protocol [TIA TSB 102.AACA] \\
\hline 80 & APCO Project 25 Data Overview [ANSI/TIA/EIA-102.BAEA-2000] \\
\hline 81 & APCO Project 25 Packet Data Specification [ANSI/TIA/EIA-102.BAEB-2000] \\
\hline 82 & A Standard for Encoding, Exchanging, and Storing Public Safety Data \\
\hline 83 & APCO Project 25 Common Air Interface Conformance Test TIA/EIA TSB 102.BAAB-A \\
\hline 84 & $\begin{array}{l}\text { APCO Project } 25 \text { Frequency Division Multiple Access (FDMA) Common Air Interface, New Technology Standards } \\
\text { Project, Digital Radio Technical Standards }\end{array}$ \\
\hline
\end{tabular}




\begin{tabular}{|c|c|}
\hline 85 & APCO Project 25 Trunking Procedures [TIA TSB 102.AABD] \\
\hline 86 & APCO Project 25 Trunking Control Channel Messages [ANSI/TIA/EIA- 102.AABC-2000] \\
\hline 87 & Vocoder Mean Opinion Score Conformance Test [ANSI/TIA/EIA-102.BABB] \\
\hline 88 & APCO Project 25 Vocoder Reference Test [ANSI/TIA/EIA-102.BABC] \\
\hline 89 & APCO Project 25 Vocoder Description [ANSI/TIA/EIA-102.BABA] \\
\hline 90 & APCO Project 25 Radio Control Protocol (RCP) [ANSI/TIA/EIA- 102.BAEE-2000] \\
\hline 91 & APCO Project 25 Network Management Interface Overview [TIA TSB 102.BAFA-A] \\
\hline 92 & Conformance Tests for the APCO Project 25 Over the Air Re-keying (OTAR) Protocol [TIA/EIA TSB 102.AACC] \\
\hline 93 & Over The Air Re-keying (OTAR) Operational Description [TSB 102.AACB] \\
\hline 94 & Conformance Test for the APCO Project 25 DES Encryption Protocol [TIA/EIA/IS-102.AAAC] \\
\hline 95 & APCO Project 25 DES Encryption Protocol [TIA/EIA/IS-102.AAAA-A] \\
\hline 96 & Telephone Interconnect Requirements and Definitions (Voice Service) [ANSI/TIA/EIA-102.BADA-2000] \\
\hline 97 & APCO Project 25 Conventional Control Messages [TIA/EIA TSB 102.AABG] \\
\hline 98 & $\begin{array}{l}\text { Determination of Laboratory Respirator Protection Level (LRPL) Quantitative, Medium Flow, Deep Probe, Corn Oil, } \\
\text { Fit Factor Performance Test for Chemical, Biological, Radiological, and Nuclear (CBRN) Full Facepiece Respiratory } \\
\text { Protective Devices (RPD) Standard Testing Procedure (STP) }\end{array}$ \\
\hline 99 & ANSI Z87,1 Certified Safety Eye Protection \\
\hline 100 & NFPA 99, Health Care Facilities \\
\hline 101 & NFPA 1006 Standard for Rescue Technician (2000) \\
\hline 102 & NFPA 1021 Standard for Fire Officer Professional Qualifications (1997) \\
\hline 103 & NFPA 1035 Standard for Fire Service and Life Safety Educator Professional Qualifications (1996 edition) \\
\hline 104 & NFPA 1051 Standard for Wildland Fire Fighter Professional Qualifications (1995) \\
\hline 105 & NFPA 1521 Fire Department Safety Officer (1997) \\
\hline 106 & HEICS I, II, III Hospital Emergency Incident Command System (1992) \\
\hline 107 & ASTM 2413, Standard Guide for Hospital Preparedness and Response \\
\hline 108 & NFPA 1061 Standard for Professional Qualifications for Public Safety Telecommunicator, 1996 Edition \\
\hline 109 & NFPA 1041 Standard for Fire Service Instructor Professional Qualifications, 1996 Edition \\
\hline 110 & NFPA 1003 Standard for Airport Fire Fighter Professional Qualifications, 2000 Edition \\
\hline 111 & NFPA 1001 Standard for Fire Fighter Professional Qualifications, 1997 Edition \\
\hline 112 & NFPA 1975 Standard on Station/Work Uniforms for Fire and Emergency Services \\
\hline 113 & Standard for a United States National Grid, FGDC-STD-011-2001 \\
\hline 114 & FGDC-STD-001, Content Standard for Digital Geospatial Metadata (CSDGM) \\
\hline 115 & FGDC-FACID, Content Standard for Facility ID \\
\hline 116 & $\begin{array}{l}\text { ASTM F1011 Standard Guide for Developing a Hazardous Materials Training Curriculum for Initial Response } \\
\text { Personnel }\end{array}$ \\
\hline 117 & $\begin{array}{l}\text { ASTM F1149 Standard Practice for Qualifications, Responsibilities, and Authorities of Individuals and Institutions } \\
\text { Providing Medical Direction of Emergency Medical Services }\end{array}$ \\
\hline 118 & ASTM F1418 Standard Guide for Training the Emergency Medical Technician (Basic) in Roles and Responsibilities \\
\hline 119 & $\begin{array}{l}\text { ASTM F1453 Standard Guide for Training and Evaluation of First Responders Who Provide Emergency Medical } \\
\text { Care }\end{array}$ \\
\hline 120 & $\begin{array}{l}\text { ASTM F1654 Standard Guide for Training and Evaluation of Individuals Who are Responsible for or Perform Triage } \\
\text { in a Pre-hospital Environment }\end{array}$ \\
\hline 121 & EMAC-01, Emergency Management Assistance Compact \\
\hline 122 & FEMA Resource Typing Definitions - 1 \\
\hline 123 & SLG-101, Guide for All-Hazard Emergency Operations Planning \\
\hline 124 & $\begin{array}{l}\text { IEEE Std 1512-2000, IEEE Standard for Common Incident Management Message Sets for Use by Emergency } \\
\text { Management Centers }\end{array}$ \\
\hline 125 & OASIS Standard 200402 Common Alerting Protocol v1.0 \\
\hline
\end{tabular}




\begin{tabular}{|c|c|}
\hline 126 & The FEMA Comprehensive Exercise Program \\
\hline 127 & NFPA 1000 Standard for Fire Service Professional Qualifications, Accreditation, and Certification Systems \\
\hline 128 & NFPA 1404 Standard for Fire Service Respiratory Protection Training \\
\hline 129 & $\begin{array}{l}\text { NFPA } 1710 \text { Standard for the Organization and Deployment of Fire Suppression Operations, Emergency Medical } \\
\text { Operations, and Special Operations to the Public by Career Fire Departments }\end{array}$ \\
\hline 130 & $\begin{array}{l}\text { NFPA } 1720 \text { Standard for the Organization and Deployment of Fire Suppression Operations, Emergency Medical } \\
\text { Operations, and Special Operations to the Public by Volunteer Fire Departments }\end{array}$ \\
\hline 131 & NIMS-NSC-TDG, NIMS National Standard Curriculum Training Development Guidance \\
\hline 132 & $\begin{array}{l}\text { ASTM F1219, Standard Guide for Training the Emergency Medical Technician (Basic) to Perform Patient Initial and } \\
\text { Detailed Assessment }\end{array}$ \\
\hline 133 & ASTM F1229, Standard Guide for the Qualification and Training of EMS Air Medical Patient Care Providers \\
\hline 134 & $\begin{array}{l}\text { ASTM F1285, Standard Guide for Training the Emergency Medical Technician (Basic) to Perform Patient } \\
\text { Examination Techniques }\end{array}$ \\
\hline 135 & $\begin{array}{l}\text { ASTM F1328, Standard Guide for Training Emergency Medical Technician (Basic) to Prepare Patients for Medical } \\
\text { Transport }\end{array}$ \\
\hline 136 & $\begin{array}{l}\text { ASTM F1329, Standard Guide for Training the Emergency Medical Technician (Basic) in Basic Anatomy and } \\
\text { Physiology }\end{array}$ \\
\hline 137 & ASTM F1419, Standard Guide for Training the Emergency Medical Technician (Basic) to Manage Shock \\
\hline 138 & $\begin{array}{l}\text { ASTM F1420, Standard Guide for Training the Emergency Medical Technician (Basic) to Perform Patient } \\
\text { Management Techniques }\end{array}$ \\
\hline 139 & ASTM 1220, Standard Guide for Emergency Medical Services System (EMSS) Telecommunications \\
\hline 140 & FGDC-ADCS, Data Content Standard Public Review - Draft \\
\hline 141 & HSEEP Volume I, II, II, IV, \& V, USDHS Homeland Security Exercise and Evaluation Program \\
\hline
\end{tabular}




\section{Appendix B}

\section{Detailed NIMS Component Criteria Search Terms}





\section{Appendix B}

\section{Detailed NIMS Component Criteria Search Terms}

\section{NIMS Focused Standards Review Key Search Terms and Phrases}

\section{NIMS Component I - Preparedness}

- Emergency $^{\dagger}$ Operations $^{\dagger}$ Center $^{(0 r)}$ EOC

- Emergency $^{+}$response $^{+}$nongovernmental ${ }^{+}$organization $^{(\infty r)} \mathrm{NGO}$

0 private ${ }^{t}$ outreach

- Emergency ${ }^{+}$management

o public $^{\dagger}$ awareness

0 information $^{+}$systems

- Emergency ${ }^{+}$response

0 information ${ }^{+}$operations ${ }^{\natural}$ security

0 resource management

\section{I-A. Preparedness Organizations and Programs}

- Emergency ${ }^{\dagger}$ Preparedness
$0{ }^{+}$cycle
$0+$ planning
$0 \quad{ }^{+}$training
0 +equipping
0 texercising
$0 \quad{ }^{+}$evaluating
$0{ }^{+}$corrective actions
$0{ }^{+}$mitigation actions

- Disaster $^{(\oplus r)}$ Emergency $^{\dagger}$ Management
o Authority $^{+}$Having $^{+}$Jurisdiction $^{(\infty i)}$ AHJ
o Business $^{t}$ Continuity ${ }^{\natural t}$ Program
o Program

- Training

- Exercises $^{+}$Evaluations $^{+}$Corrective $^{+}$Actions

- Public $^{+}$Communications ${ }^{+t}$ Planning

- Public ${ }^{+}$awareness

- $\quad$ Financial ${ }^{+}$Planning

- Resource $^{t}$ Management

0 "Planning

o ${ }^{+}$Objectives

- Mutual $^{+}$aid

o ${ }^{+}$Planning

$0 \quad{ }^{t}$ Exercise

- Emergency ${ }^{\dagger}$ Operations 

$0 \quad{ }^{+}$Planning
O Control

- Financial Planning

\section{I-B. Implement Emergency Preparedness Cycle}

- Emergency ${ }^{\dagger}$ Operations ${ }^{\dagger}$ Plan $^{(0)}$ EOP
$0{ }^{+}$organization $^{+}$structures
$0{ }^{+}{ }^{+}$oles ${ }^{+}$responsibilities
0 policies
$0{ }^{+}$protocols
$0{ }^{+}$concept $^{+}$of $^{+}$operations
$0 \quad{ }^{+}$hazard ${ }^{+}$specific ${ }^{+}$planning
$0{ }^{+}$response ${ }^{+}$procedures
$0{ }^{+}$action $^{+}$oriented $^{+}$checklists
o $\quad{ }^{+}$Standard ${ }^{+}$Operating ${ }^{+}$Procedures
$0{ }^{+} \mathrm{SOP}$
O $\quad{ }^{+}$Field $^{+}$Operations ${ }^{+}$Guide
$0{ }^{+}$FOG
$0{ }^{+}{ }^{\text {risk }}{ }^{+}$based ${ }^{+}$hazard
o ${ }^{+}$personnel ${ }^{+}$equipment
$0{ }^{+}$training ${ }^{+}$exercising
$0{ }^{+}$corrective $^{+}$action $^{(0 r)}$ mitigation ${ }^{+}$plans
- ${ }^{+}$lessons ${ }^{+}$learned
- ${ }^{+}$reduce ${ }^{+}$risks
$0{ }^{+}{ }^{\text {recovery }}{ }^{+}$plans
- ${ }^{+}$long-term
- ${ }^{+}$restoration

- Emergency $^{+}$response $^{+}$training $^{+}$exercises

$0{ }^{+}$incident $^{+}$command

$0{ }^{+}{ }_{\text {incident }}^{+}$management

$0{ }^{+}$all ${ }^{+}$hazards

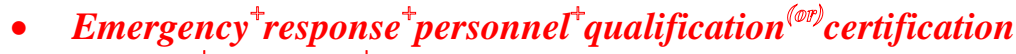

$0{ }^{+}$personnel $^{+}$qualification

o ${ }^{+}$personnel ${ }^{+}$credentialling

O ${ }^{+}$personnel ${ }^{+}$certification

- Emergency $^{+}$response $e^{+}$equipment ${ }^{+}$certification
$0{ }^{+}$equipment ${ }^{+}$acquisition
0 performance
$0 \quad{ }^{+}$interoperability

- Emergency $^{+}$response $^{+}$mutual ${ }^{+}$aid $^{+}$agreements
$0{ }^{+}$key ${ }^{+}$terms
$0{ }^{+}{ }^{+}$oles ${ }^{+}$responsibilities
$0{ }^{+}$procedures
$0{ }^{+}$requesting ${ }^{+}$assistance
o ${ }^{+}$providing ${ }^{+}$assistance
$0 \quad{ }^{+}$reimbursement
o ${ }^{+}$notification
$0{ }^{+}{ }^{+}$interoperable ${ }^{+}$communications ${ }^{+}$protocols
$0{ }^{+}$relationships
$0{ }^{*}$ other ${ }^{+}$agreements 


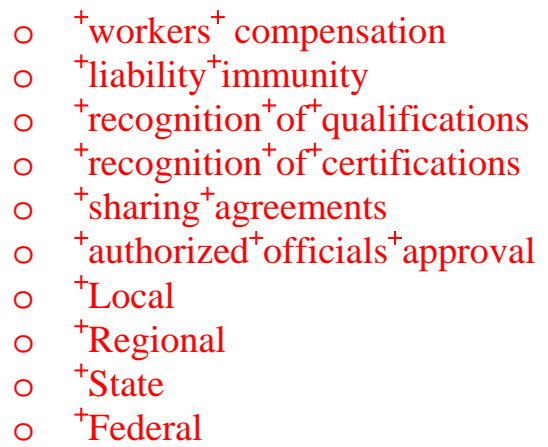

- Business $^{+}$Continuity $^{+}$Programs

$0{ }^{+}$Recovery

$0{ }^{+}$Analysis

- $\quad$ Preparedness ${ }^{+}$hazard $^{+}$assessment

- Preparedness $^{+}$risk $^{+}$assessment

- Hazard $^{+}$mitigation ${ }^{+}$strategy

- Risk $^{+}$Management

- Hazard $^{+}$Assessment

- Hazard $^{+}$Mitigation

\section{NIMS Component II - Communications and Information management}

\section{II-A. Communications and Incident Management}

- Incident ${ }^{+}$communications ${ }^{+}$plan

- ICP

- Incident-based ${ }^{\dagger}$ communications ${ }^{\downarrow}$ center

- Incident $^{+}$Command $^{+}$System $^{(\varpi r)}$ ICS

o common terminology

o communications ${ }^{\dagger}$ management

0 Intelligence ${ }^{t}$ sharing

- Communication procedures

- Communication Systems

- Incident Management System

- Mutual Aid Agreement

- Direction Control Coordination

- Crisis Communication

- Crisis Public Information

- Public awareness

\section{II-B. Effective Communications, Information Management} and Information Sharing

- Incident communications

O Incident ${ }^{+}$Command $^{+}$common $^{+}$communications $^{+t}$ operating $^{+}$system

O Incident ${ }^{+}$Command $^{+}$interoperabile ${ }^{+}$communications

- Emergency

o Communications

o Warnings

- Public Communications 
- Communication Warnings

\section{II-C. Establishing and Maintaining a Common Operating Picture and Ensuring Accessibility and Interoperability}

- Common $^{+}$incident ${ }^{+}$management ${ }^{+}$operating $^{+}$picture

$\begin{array}{ll}{ }_{0}^{+} \text {accessibility } \\ 0 & { }^{+} \text {interoperability }\end{array}$

II-D. Managing Interoperable Communications and Data

- Managing ${ }^{+}$incident $^{+}$communication

- Managing $^{\dagger}$ incident ${ }^{\dagger}$ data

- Incident information $^{+}$management ${ }^{+}$policies

- Emergency $^{+}$Operations ${ }^{+}$Center $^{(0)}$ EOC

o networks

- Incident $^{\dagger}$ Action ${ }^{+}$Plan $^{(\oplus)}$ IAP

$0{ }^{+}$indications ${ }^{+}$warnings

$0{ }^{+}$incident ${ }^{+}$notifications

$0{ }^{+}$public ${ }^{+}$communications

o ${ }^{+}$technology ${ }^{+}$use

$0{ }^{+}{ }^{+}$formation ${ }^{+}$management

$0 \quad{ }^{+}$integrate ${ }^{+}$command $^{+}$tactical $^{+}$support ${ }^{+}$units

$0{ }^{+}$incident $^{+}$situation $^{+}$report

- Incident Communications Plan ${ }^{(\oplus)}$ ICP

\section{NIMS Component III - Resource Management}

\section{III-A. Categorizing Resources}

- Emergency response ${ }^{+}$credentialing

- Emergency ${ }^{\dagger}$ response $e^{+}$resource ${ }^{+}$typing
$0{ }^{+}$Size
$0{ }^{+}$Capacity
$0{ }^{+}$Skill

III-B. Effective Management of Resources

- Emergency ${ }^{\dagger}$ response ${ }^{+}$resource ${ }^{+}$acquisition

- Emergency response $e^{+}$resource $e^{+}$allocation

- Emergency ${ }^{+}$response $e^{+}$resource $e^{+}$tracking

- Iinventorying emergency response ${ }^{+}$resources
o Supplies
o Equipment
o Facilities
o Personnel
o Response personnel
o Response teams

- Resource Management

- Resource planning

- Resource objectives

- Mutual aid planning 
- Mutual aid agreements

\section{III-C. Inventorying Process}

- Local $^{+t}$ EOC $^{+}$resource ${ }^{+}$inventorying

- Local $^{+}$Emergency $^{+}$Operations ${ }^{+}$Center $^{+}$resource ${ }^{+}$inventorying

- Multiagency pre-incidednt resource ${ }^{+t}$ inventorying

- Multiagency incident $t^{+}$response $e^{+}$resource $e^{t}$ inventorying

- Validated $^{+}$incident $^{+}$resources ${ }^{+}$inventorying

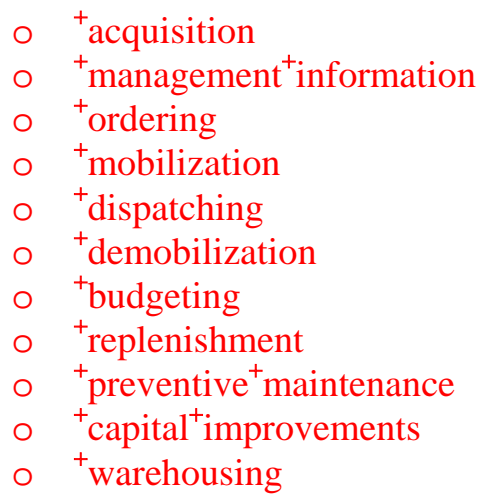

\section{III-D. Resource Acquisition}

- Identifying ${ }^{\dagger}$ emergency response $e^{\dagger}$ resource ${ }^{+}$requirements

- Ordering $^{\dagger}$ emergency ${ }^{\dagger}$ response ${ }^{\dagger}$ resources

- Acquiring ${ }^{+}$emergency ${ }^{+}$response ${ }^{+}$resources

- Mutual Aid Agreement

- Mutual Aid Planning

\section{IIIE. Mobilizing Resources}

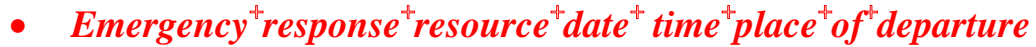

- Emergency $^{+}$response $e^{+}$resource ${ }^{+}$mode ${ }^{+}$of ${ }^{+}$transportation

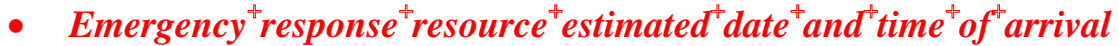

- Emergency $y^{+}$response ${ }^{+t}$ resource $e^{+}$reporting ${ }^{+}$location

- Emergency $^{+}$response ${ }^{+}$resource ${ }^{+}$anticipated $^{+}$assignment

- Emergency $^{+}$response $e^{+}$resource $e^{+}$order ${ }^{+}$number

- Emergency ${ }^{+}$response $e^{+t}$ resource $e^{+}$incident $t^{+}$number

- Emergency $^{+}$response $e^{+}$resource ${ }^{+}$cost $^{+}$funding $^{+}$codes

\section{III-F. Recovering Resources}

- Emergency $^{+}$response ${ }^{+}$resource ${ }^{+}$demobilization

0 tpersonnel

- ${ }^{+}$occupational ${ }^{+}$health

- ${ }^{+}$mental ${ }^{+}$health

- ${ }^{+}$monitoring

$0 \quad{ }^{+}$nonexpendable ${ }^{+}$resources

- ${ }^{+}$restore

- ${ }^{+}$replace

$0 \quad{ }^{+}$expendable ${ }^{+}$resources

- +accounting 
- ${ }^{+}$restocking

\section{III-G. Reimbursement}

- Emergency response ${ }^{+1}$ resource $e^{\dagger}$ reimbursement $t^{\dagger}$ process

$0{ }^{+}$life $^{+}$cycle ${ }^{+}$costing

$0{ }^{+}$incident ${ }^{+}$life ${ }^{+}$cycle

o ${ }^{+}$life ${ }^{+}$cycle

o tbilling

o collecting

- Finance

- Financial Administration

\section{NIMS Component IV - Command and Management}

IV-A. Field Command and Management Functions

- Incident ${ }^{\dagger}$ Command $^{+}$System ${ }^{(0 r)}$ ICS $^{+}$organization

$0{ }^{*}$ doctrine

0 procedures

o Flexible $^{\dagger}$ ICS $^{\dagger}$ organization ${ }^{\dagger}$ structure

o Incident ${ }^{\dagger}$ Commander ${ }^{+t}$ authority

0 thazard-based flexibility

- Emergency Operations

- Emergency Control Planning

- Program Management

- Advisory Committee

- Tactical Operations

- Emergency Operations Center ${ }^{(0 r)}$ EOC

IV-B. Modular, Scalable Incident Command System

- Incident $^{+}$Command $^{+}$System ${ }^{(\bullet r)}$ ICS

O ${ }^{+}$single ${ }^{+}$jurisdiction ${ }^{(\infty)}$ agency

$0 \quad{ }^{+}$multiple ${ }^{+}$jurisdictions ${ }^{(\oplus r)}$ agencies

$0{ }^{\dagger}$ applicable ${ }^{+}$throughout ${ }^{\ddagger}$ country

o "adaptable new technology

0 tadaptable incidents

$0{ }^{+}$scalable $^{+}$organization ${ }^{\star}$ structure

IV-C. Interactive Management Components

- Incident ${ }^{+}$Command $^{+}$System ${ }^{(๗)}$ ICS

o implemented $^{+}$processes $^{+}$procedures $^{+}$plans

\section{IV-D. Measurable objectives}

- Incident management ${ }^{\dagger}$ goals

- Incident management objectives

\section{IV-E. Management Characteristics}

- Incident ${ }^{+}$management ${ }^{+}$terminology

$0 \quad{ }^{\dagger}$ organizational ${ }^{\dagger}$ function 


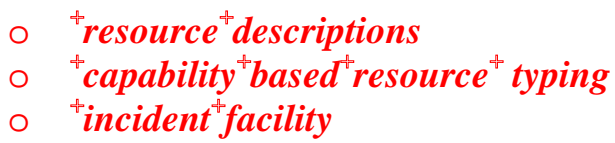

\section{IV-F. Modular Organization}

- Top $^{+}$down $^{+}$incident $^{+}$management ${ }^{+}$organization $^{+}$structure

- Incident management $t^{+}$command $^{+}$structure $^{+t}$ based $^{+}$on $^{+}$incident ${ }^{\dagger}$ complexity

- Incident $t^{+t}$ Commander determines ${ }^{+} \mathrm{ICS}^{+t}$ expansion

- Number $^{+}$of $^{+}$Incident $^{+}$Command $^{+}$positions $^{+}$expands $^{+}$with $^{+}$incident $^{\dagger}$ expansion

- Incident Command $^{+}$System $^{(\bullet r)}$ ICS $^{\dagger}$ hazard $^{+}$specific $^{+}$expansion

- Logistics

- Facilities

\section{IV-G. Management by Objectives}

- Overarching incident management ${ }^{\dagger}$ objectives

- Specific measurable incident management ${ }^{+t}$ objectives

0 functions

0 activities

- Documentating ${ }^{+}$incident $^{+}$management ${ }^{+}$activities

- Incident $^{+}$management ${ }^{+}$corrective $^{+}$action $^{+}$plan

\section{IV-H. Incident Action Plan}

- Incident ${ }^{+}$action $^{+}$plan

- IAP

- Accountability

- Emergency management Control

- Span of control

- Command general staffing

- Incident command functions

- Multi-agency coordination

\section{IV-I. Manageable Span of Control}

- Incident ${ }^{t}$ Command ${ }^{\dagger}$ System ${ }^{(\bullet)}$ ICS

$0{ }^{+t}$ supervisory ${ }^{(0 r)}$ span $^{+t}$ of control

$0{ }^{+}$supervisor $^{\dagger}$ span $^{+}$three ${ }^{+}$to $^{+}$seven $^{+}$subordinates

- ISO Responsibilities

- Incident safety officer

\section{IV-J. Predesignated Incident Locations and Facilities}

- Incident ${ }^{\dagger}$ Command $^{\dagger}$ determines ${ }^{\dagger}$ operational $^{\dagger}$ locations

- Incident management $t^{+}$facilities ${ }^{+}$situationally located

- Incident $^{+}$command $^{+}$posts $^{(\oplus r)}$ bases $^{(\infty r)}$ camps $^{(\oplus r)}$ staging $^{+}$areas $^{(\oplus r)}$ triage

IV-K. Comprehensive Resource Management

- Incident ${ }^{+}$management ${ }^{+}$resource $^{+}$utilization

- Incident management $t^{\dagger}$ resource ${ }^{\dagger}$ categorizing

- Incident management $t^{\dagger}$ resource ${ }^{\dagger}$ ordering 
- Incident management $t^{+}$resource ${ }^{+}$dispatching

- Incident ${ }^{+}$management ${ }^{+}$resource ${ }^{+}$tracking

- Incident management resource recovering

- Incident management reimbursement

- Domestic ${ }^{+}$incident ${ }^{+}$management

o ${ }^{+}$personnel

0 teams

$0 \quad+$ equipment

$0 \quad+$ supplies

$0{ }^{+}$facilities

- Incident resource management

- Mutual Aid

\section{IV-L. Integrated Communications}

- Incident management ${ }^{\dagger}$ common $^{+}$communications $^{+}$plan

- Incident ${ }^{+}$management ${ }^{+}$interoperable ${ }^{+}$communications

$0{ }^{+}$processes

- Incident $^{+}$management ${ }^{\dagger}$ interoperable ${ }^{\dagger}$ communications $^{\dagger}$ architecture

$0{ }^{+}{ }^{\text {common }}{ }^{+}$communications

- + equipment

- + systems

- ${ }^{+}$protocols

$0 \quad{ }^{+}$integrated $^{+}$voice $^{+}$data $^{+}$communications ${ }^{+}$systems

IV-M. Establishment and Transfer of Command

- Incident command establishment

- Incident $^{+}$command $^{+}$primary $^{+}$authority $^{+}$establishment

- Incident command transfer

- Incident command transfer briefing

IV-N. Unified Command

- Institutionalized ${ }^{+}$incident $t^{t}$ unified $^{+t}$ command $^{+t}$ process

- Unified $^{+}$command $^{+}$single $^{+}$jurisdiction $^{+}$with $^{+}$multiagency $^{+}$involvement

- Unified ${ }^{+}$command ${ }^{+}$agency ${ }^{\dagger}$ authority

- Unified ${ }^{+}$command ${ }^{+}$agency ${ }^{\dagger}$ responsibility

- Unified ${ }^{+}$command ${ }^{+}$agency ${ }^{+}$accountability

- Interagency coordination

\section{IV-O. Incident Management Accountability}

- Incident check-in procedures

$0{ }^{+}$responders ${ }^{+}$assigned ${ }^{+}$one $^{+}$supervisor

$0{ }^{+}$responders ${ }^{+}$report-in ${ }^{+}$procedures

O ${ }^{+}{ }^{+}$response ${ }^{+}$operations ${ }^{+}$direction $^{+}$and $^{+}$control

$0{ }^{+}{ }^{+}$resource ${ }^{+}$status $^{+}{ }$changes ${ }^{+}$recording ${ }^{+}$reporting

- Incident Action $^{+}$Plan

- IAP

- Incident $^{+}$Unity $^{+}$of ${ }^{\dagger}$ Command

- Incident $^{\dagger}$ Command $^{\dagger}$ Span $^{\dagger}$ of Control 
- Incident $t^{\ddagger}$ esource $e^{\ddagger}$ Tracking

IV-P. Incident Management Deployment

- Emergency ${ }^{+}$response $e^{+}$personnel ${ }^{+}$on $^{+}$request $^{+}$dispatch

- Emergency $^{+}$response $e^{t}$ equipment $t^{+}{ }^{+t}$ request $t^{+t}$ dispatch

- Emergency ${ }^{\dagger}$ responder ${ }^{+}$self-dispatch

\section{IV-Q. Information and Intelligence Management}

- Emergency ${ }^{+}$management jurisdiction
$0{ }^{+}$information ${ }^{+}$gathering
$0{ }^{+}$information ${ }^{+}$sharing
$0 \quad{ }^{+}$intelligence ${ }^{+}$sharing

\section{IV-R. ICS Organization and Operations}

- Incident ${ }^{+}$Command ${ }^{\dagger}$ System ${ }^{(\bullet r)}$ ICS

$0{ }^{+}$organization ${ }^{\dagger}$ operations

$0 \quad{ }^{+}$command $^{+}$general ${ }^{+}$staff

$0{ }^{+}{ }^{+}$command $^{+}$staff $^{+}$responsibilities

o ${ }^{\dagger}$ Public ${ }^{\dagger}$ Information ${ }^{\dagger}$ Officer

$0 \quad{ }^{+} \mathrm{PIO}$

o ${ }^{\star}$ Safety ${ }^{\ddagger}$ Officer

$0{ }^{+} \mathrm{SO}$

O ${ }^{+}$Liaison $^{+}$Officer

O ${ }^{+}$LNO

o ${ }^{\ddagger}$ Operations ${ }^{\dagger}$ Section ${ }^{\star}$ Chief

o ${ }^{\dagger}$ Planning ${ }^{\dagger}$ Section ${ }^{\dagger}$ Chief

O ${ }^{+}$Logistics ${ }^{+}$Planning ${ }^{\dagger}$ Chief

$0{ }^{+}$Finance/Administration ${ }^{\dagger}$ Chief

$0{ }^{+}$Advisory ${ }^{+}$Committee $^{+}$interagency ${ }^{+}$coordination

o + Business ${ }^{+}$continuity

- Public Information Officer PIO

- Safety Officer SO

- Liason Officer LNO

- Operations Section chief

- Logistics Planning chief

- Finance chief

- Finance/Administration $^{\dagger}$ Chief

- Advisory committee

- Business Continuity

\section{IV-S. ICS Single Command IC}

- Single Incident+Command ${ }^{(0 r)} I^{\dagger} C^{\dagger}$ single $^{\dagger}$ jurisdiction ${ }^{\dagger}$ incident

- Single ${ }^{+}$Incident ${ }^{+}$Command $^{(\varpi r)}$ IC $^{+}$multiple ${ }^{+}$jurisdiction ${ }^{+}$incident

- Incident ${ }^{+}$Command $^{(0 r)}$ IC $^{+}$Incident ${ }^{+}$Action ${ }^{+}$Plan

- Incident I $^{\dagger}$ ommand ${ }^{(\oplus r)}$ IC $^{+\dagger}$ incident objectives

IV-T. ICS Unified Command UC

- Unified Command ${ }^{(0 r)} U C^{\dagger}$ structure 
- Unified ${ }^{+}$Command $^{(\varpi)}$ UC $^{+\hbar}$ incident $^{\dagger}$ strategies

- Unified $^{+}$Command ${ }^{(\infty x)} U^{+} C^{+}$objectives

- Unified ${ }^{+}$Command $^{(\varpi r)} U^{-C^{+}}$joint $^{+}$tactical $^{+}$operations

- Establishment of command

- Transfer of command

- Termination of command

IV-U. ICS Incident Action Plan (IAP)

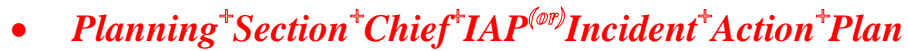

- Incident $^{+}$Action+Plan ${ }^{(\infty r)}$ IAP $^{+}$Unified $^{+}$Command $^{(0 r)}$ UC $^{+}$approval

- Operations $^{\dagger}$ Section $^{\dagger}$ Chief $^{\dagger}$ Incident $^{\dagger}$ Action $^{\dagger}$ Plan $^{(\oplus r)}$ IAP $^{\dagger}$ implementation

IV-V. ICS Resources

- Incident ${ }^{+t}$ Command $^{+}$System ${ }^{(\varpi r)}$ ICS

$0{ }^{\dagger}$ Single ${ }^{\dagger}$ Resources

0 ${ }^{+}$Task $^{+}$Forces

$0 \quad{ }^{+}$Strike ${ }^{+}$Teams

IV-W. ICS Area Command

- Area $^{+}$Command $^{+}$Multiple $^{+}$incidents

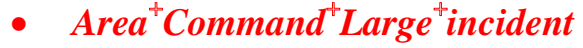

- Unified $^{+}$Area $^{\dagger}$ Command

IV-X. Emergency Operations Center

- Emergency ${ }^{+}$Operations ${ }^{+}$Center

- EOC

- Emergency $^{+}$Operations ${ }^{+}$Center $^{(\varpi r)}$ EOC

$0{ }^{+}$resource ${ }^{t}$ dispatch ${ }^{+t}$ tracking

$0{ }^{\dagger}$ multiagency ${ }^{\dagger}$ coordination ${ }^{\dagger}$ entities

IV-Y. Joint Information System (JIS) and Center (JIC)

- JIS

- Joint $^{+}$Information $^{+}$System

- JIC

- Joint $^{+}$Information ${ }^{+}$Center

IV-Z. Incident Management Hazard Identification, Risk Management, and Impact Analysis

- Incident Management

o Hazard Identification

o Risk Assessment

o Impact analysis

o Hazard Mitigation

- Program evaluation

- Business continuity

NIMS Component V - Supporting Technologies 
- Incident $^{\dagger}$ Command $^{+}$System ${ }^{(\oplus \pi)}$ ICS

$0 \quad{ }^{+}$Technology

$0{ }^{+}$voice ${ }^{t+}$ data $^{\dagger}$ communications ${ }^{+t}$ systems

$0{ }^{+}$voice $^{\dagger}$ data $^{\dagger}$ display ${ }^{\dagger}$ systems

$0 \quad{ }^{+}$Emergency ${ }^{+}$Operations ${ }^{+}$Center ${ }^{+}$Technology

\section{Legend}

${ }^{+}=>\quad$ means "and" for a linked word string that needs to be found in relationship together before tool will return a find.

$(0)=>$ means these terms are exchangeable and need to be search with the ${ }^{+}$terms using both terms is separate word relationship strings (e.g., Emergency ${ }^{+}$Operations ${ }^{+} \mathrm{Center}^{(0)} \mathrm{EOC}^{+}$resource ${ }^{+}$dispatch ${ }^{+}$tracking should be searched as

Emergency ${ }^{+}$Operations ${ }^{+} \mathrm{Center}^{+}{ }^{+}$esource ${ }^{+}$dispatch ${ }^{+}$tracking and as $\mathrm{EOC}^{+}$resource $^{+}$dispatch ${ }^{+}$tracking). 



\section{Appendix C}

\section{Color Coding, Applicable Chapters, and Missing Criteria Tables for Systems Standards (NFPA 1561 [ICS] and NFPA 1600 [EMS])}





\section{Appendix C - Color Coding, Applicable Chapters, and Missing Criteria Tables for Systems Standards}

\begin{tabular}{|l|l|l|l|l|l|c|}
\hline NFPA 1600 & Chapter 1 & Chapter 2 & Chapter 3 & Chapter 4 & Chapter 5 & $\begin{array}{c}\text { NFPA } \\
1600\end{array}$ \\
\hline
\end{tabular}

I. Preparedness

IA. Organization

IB. Cycle

II. Communications \& Information Management

\begin{tabular}{|l|l|l|l|l|l|}
\hline & & & & $5.3 .1-5.14$ & \\
\hline & & & & & \\
\hline & & & & & \\
\hline
\end{tabular}

Operational Communications

IIA

IIB

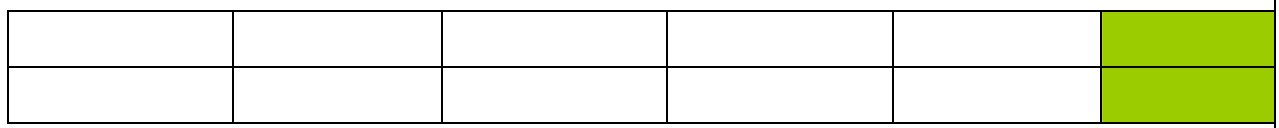

Interoperability

IIC

IID

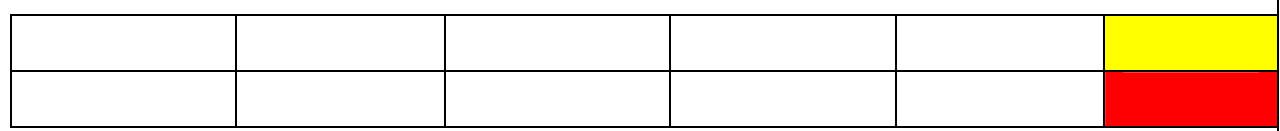

III. Resource Management

Categorizing; Mgmt; Inventory; Acquisition

IIIA

IIIB

IIIC

IIID

IVV

Recovery

IIIB

IIIF

IIIG

IVK

\begin{tabular}{|l|l|l|l|}
\hline & & & \\
\hline & & & \\
\hline & & & \\
\hline & & & \\
\hline & & & \\
\hline
\end{tabular}

$5.5 .1-5.11 .2$

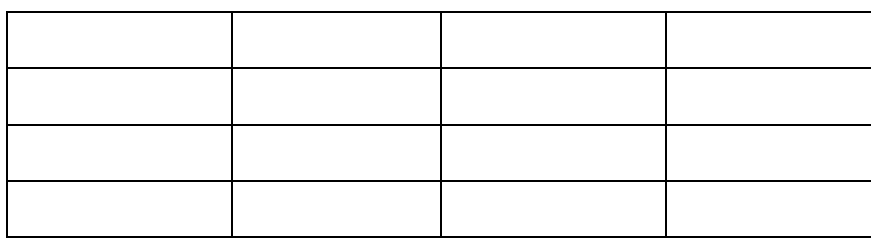

IV. Command and Management

$5.8 ; 5.10$

5.14

Incident Management Structure

IVF

IVI

IVR

IVS

IVT

IVW

Incident Management Planning

\begin{tabular}{|l|l|l|l|l|l|}
\hline & & & & & \\
\hline & & & & & \\
\hline & & & & & \\
\hline & & & & & \\
\hline & & & & & \\
\hline & & & & & \\
\hline
\end{tabular}

IVC

IVD



C.1 
IVE

IVG

Establishment of Command

IVB

IVN

\section{Command Operations}

IVA

IVH

IVO

IVQ

IVU

IVZ

\begin{tabular}{|l|l|l|l|l|l|}
\hline & & & & & \\
\hline & & & & & \\
\hline
\end{tabular}

\begin{tabular}{|l|l|l|l|l|l|}
\hline & & & & & \\
\hline & & & & & \\
\hline & & & & & \\
\hline
\end{tabular}

Resource Mobilization \& Deployment

IIIE

IVK

IVM

IVP

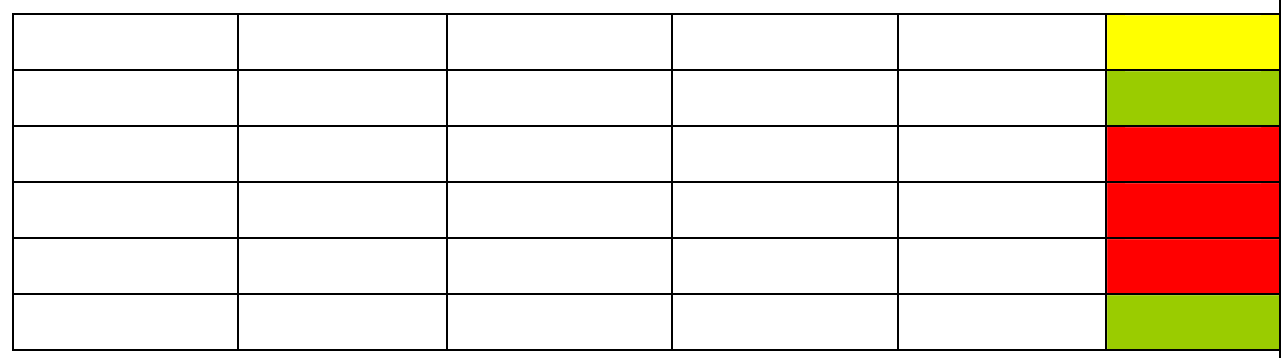

\begin{tabular}{|l|l|l|l|l|}
\hline & & & & \\
\hline & & & & \\
\hline & & & & \\
\hline & & & & \\
\hline
\end{tabular}

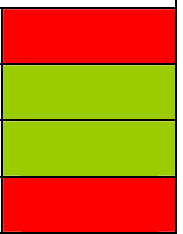

Incident Management Support

IVJ

IVL

IVX

IVY

\section{Supporting Technologies}

\begin{tabular}{|l|l|l|l|l|l|}
\hline & & & & & \\
\hline & & & & & \\
\hline & & & & & \\
\hline & & & & & \\
\hline
\end{tabular}




\begin{tabular}{|c|c|c|c|c|c|c|c|}
\hline NFPA 1561 & Chapter 4 & Chapter 5 & $\begin{array}{c}\text { Chapter } \\
6\end{array}$ & $\begin{array}{c}\text { Chapter } \\
7\end{array}$ & $\begin{array}{c}\text { Chapter } \\
8 \\
\end{array}$ & Chapter 9 & NFPA 1561 \\
\hline
\end{tabular}

\section{Preparedness}

IA. Organization

IB. Cycle

II. Communications \& Information Management

Operational

Communications

IIA

IIB

\begin{tabular}{|c|c|c|c|c|c|c|}
\hline $\mathrm{X}$ & $\mathrm{X}$ & & $\mathrm{X}$ & & $\mathrm{X}$ & \\
\hline & & & & & & \\
\hline & & & & & & \\
\hline & & $\mathrm{X}$ & $\mathrm{X}$ & & & \\
& & & $\mathrm{X}$ & & & \\
\hline
\end{tabular}

Interoperability

IIC

IID
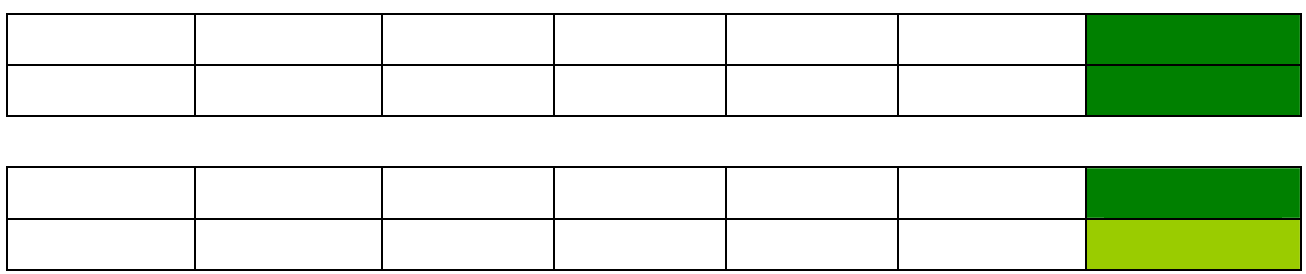

III. Resource Management

Categorizing; Mgmt; Inventory; Acquisition

IIIA

IIIB

IIIC

IIID

IVV

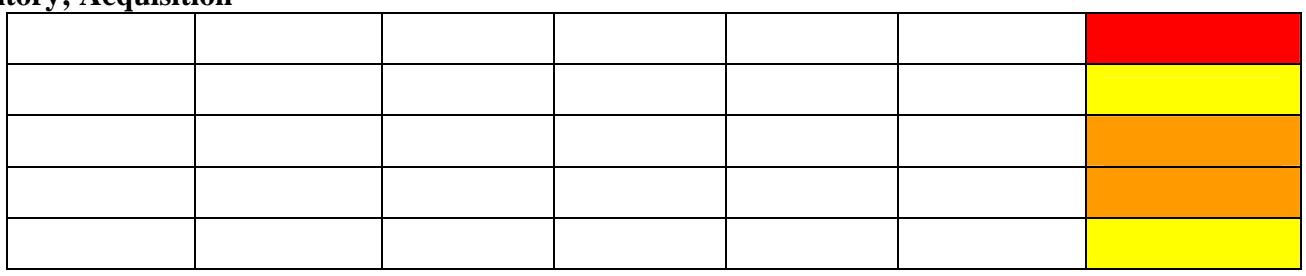

Recovery

IIIB

IIIF

IIIG

IVK

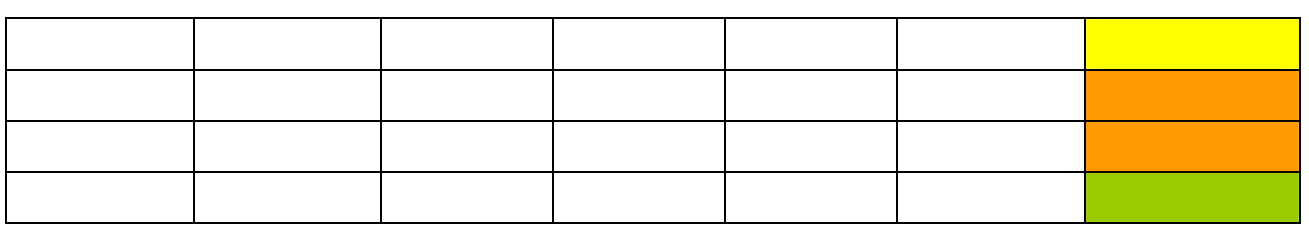

IV. Command and Management

Incident Management Structure

IVF

IVI

IVR

IVS

IVT

IVW

Incident Management Planning

IVC

IVD

IVE

IVG

Establishment of Command

\begin{tabular}{|l|l|l|l|l|l|l|}
\hline $\mathrm{X}$ & $\mathrm{X}$ & & $\mathrm{X}$ & & & \\
\hline & & & & & & \\
\hline & & & & & & \\
\hline & & & & & & \\
\hline & & & & & & \\
\hline \\
\hline
\end{tabular}

C. 3 


\begin{tabular}{|c|c|c|c|c|c|c|c|}
\hline NFPA 1561 & Chapter 4 & Chapter 5 & $\begin{array}{c}\text { Chapter } \\
6 \\
\end{array}$ & $\begin{array}{c}\text { Chapter } \\
7 \\
\end{array}$ & $\begin{array}{c}\text { Chapter } \\
8 \\
\end{array}$ & Chapter 9 & NFPA 1561 \\
\hline \multicolumn{8}{|l|}{ IVB } \\
\hline \multicolumn{8}{|l|}{ IVN } \\
\hline Command Operations & & $\mathrm{X}$ & & $\mathrm{X}$ & & $\mathrm{X}$ & \\
\hline \multicolumn{8}{|l|}{ IVA } \\
\hline \multicolumn{8}{|l|}{ IVH } \\
\hline \multicolumn{8}{|l|}{ IVO } \\
\hline \multicolumn{8}{|l|}{ IVQ } \\
\hline \multicolumn{8}{|l|}{ IVU } \\
\hline IVZ & & & & & & & \\
\hline
\end{tabular}

Resource Mobilization \& Deployment

IIIE

IVK

IVM

IVP

\begin{tabular}{|l|l|l|l|l|l|l|}
\hline & & & & & & \\
\hline & & & & & & \\
\hline & & & $\mathrm{X}$ & $\mathrm{X}$ & & \\
\hline & & & $\mathrm{X}$ & $\mathrm{X}$ & & \\
\hline
\end{tabular}

Incident Management Support

IVJ

IVL

IVX

IVY

V. Supporting

\begin{tabular}{|l|c|c|c|l|l|l|}
\hline & & $\mathrm{X}$ & $\mathrm{X}$ & & \\
\hline & & $\mathrm{X}$ & $\mathrm{X}$ & & & \\
\hline & & & & & & \\
\hline & & & $\mathrm{X}$ & & & \\
\hline
\end{tabular}

Technologies 


\section{Appendix D}

Color-Coding, Applicable Chapters, and Missing Criteria Tables for Medical Response Standards 



\section{Appendix D - Color-}

Coding, Applicable Chapters, and Missing Criteria Tables for Medical Response Standards

\begin{tabular}{|c|c|c|c|c|c|c|c|c|c|c|c|}
\hline NFPA 450 & $\begin{array}{c}\text { Chapter } \\
4\end{array}$ & $\begin{array}{c}\text { Chapter } \\
5\end{array}$ & $\begin{array}{c}\text { Chapter } \\
6\end{array}$ & $\begin{array}{c}\text { Chapter } \\
7\end{array}$ & $\begin{array}{c}\text { Chapter } \\
\mathbf{8} \\
\end{array}$ & $\begin{array}{c}\text { Chapter } \\
\mathbf{9} \\
\end{array}$ & $\begin{array}{c}\text { Chapter } \\
10 \\
\end{array}$ & $\begin{array}{c}\text { Chapter } \\
11 \\
\end{array}$ & $\begin{array}{c}\text { Chapter } \\
12 \\
\end{array}$ & $\begin{array}{c}\text { Chapter } \\
13 \\
\end{array}$ & NFPA 450 \\
\hline \multicolumn{12}{|l|}{ I. Preparedness } \\
\hline IA. Organization & & $X$ & & & $\mathrm{X}$ & & & $X$ & $\mathrm{X}$ & & \\
\hline IB. Cycle & & $\mathrm{X}$ & & & & & & & & $X$ & \\
\hline
\end{tabular}

II. Communications \& Information Management

Operational Communications

IIA

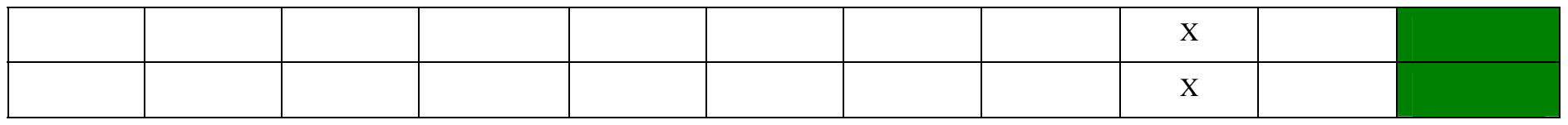

Interoperability

IIC

IID

III. Resource Management

Categorizing; Mgmt; Inventory;

Acquisition

IIIA

IIIB

IIIC

IIID

IVV

Recovery

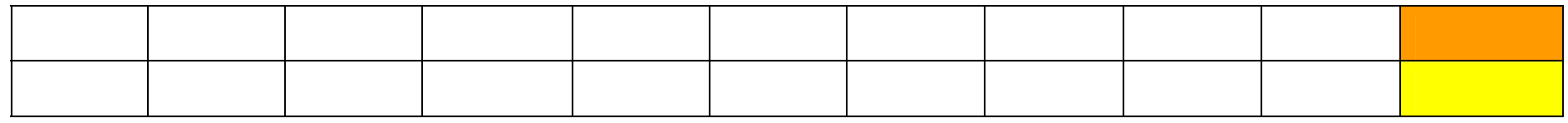

\begin{tabular}{|l|c|c|c|l|l|l|l|l|l|l|}
\hline & $\mathrm{x}$ & $\mathrm{x}$ & & & & & & & & \\
\hline & & & & & & & & & & \\
\hline & & & & & & & & & & \\
\hline & & & & & & & & & & \\
\hline & & & & & & & & & & \\
\hline & $\mathrm{x}$ & $\mathrm{x}$ & & & & & & & & \\
\hline
\end{tabular}




\begin{tabular}{|c|c|c|c|c|c|c|c|c|c|c|c|}
\hline NFPA 450 & $\begin{array}{c}\text { Chapter } \\
4\end{array}$ & $\begin{array}{c}\text { Chapter } \\
5\end{array}$ & $\begin{array}{c}\text { Chapter } \\
6\end{array}$ & $\begin{array}{c}\text { Chapter } \\
7 \\
\end{array}$ & $\begin{array}{c}\text { Chapter } \\
\mathbf{8}\end{array}$ & $\begin{array}{c}\text { Chapter } \\
9\end{array}$ & $\begin{array}{c}\text { Chapter } \\
10\end{array}$ & $\begin{array}{c}\text { Chapter } \\
11\end{array}$ & $\begin{array}{c}\text { Chapter } \\
12 \\
\end{array}$ & $\begin{array}{c}\text { Chapter } \\
13\end{array}$ & NFPA 450 \\
\hline \multicolumn{12}{|l|}{ IIIB } \\
\hline \multicolumn{12}{|l|}{ IIIF } \\
\hline \multicolumn{12}{|l|}{ IIIG } \\
\hline IVK & & & & & & & & & & & \\
\hline
\end{tabular}

IV. Command and Management Incident Management Structure

IVF

IVI

IVR

IVS

$\bullet \quad$ IVT

IVT
IVW

Incident Management Planning

IVC

IVD

IVE

IVG

Establishment of Command

IVB

IVN

Command Operations

IVA

IVH

\begin{tabular}{|l|l|l|l|l|l|l|l|l|l|l|}
\hline & & & & & & & & & & \\
\hline & & & & & & & & & & \\
\hline $\mathrm{x}$ & $\mathrm{x}$ & & & & & & & & & \\
\hline & & & & & & & & & & \\
\hline & & & & & & & & & & \\
\hline & & & & & & & & & & \\
\hline
\end{tabular}
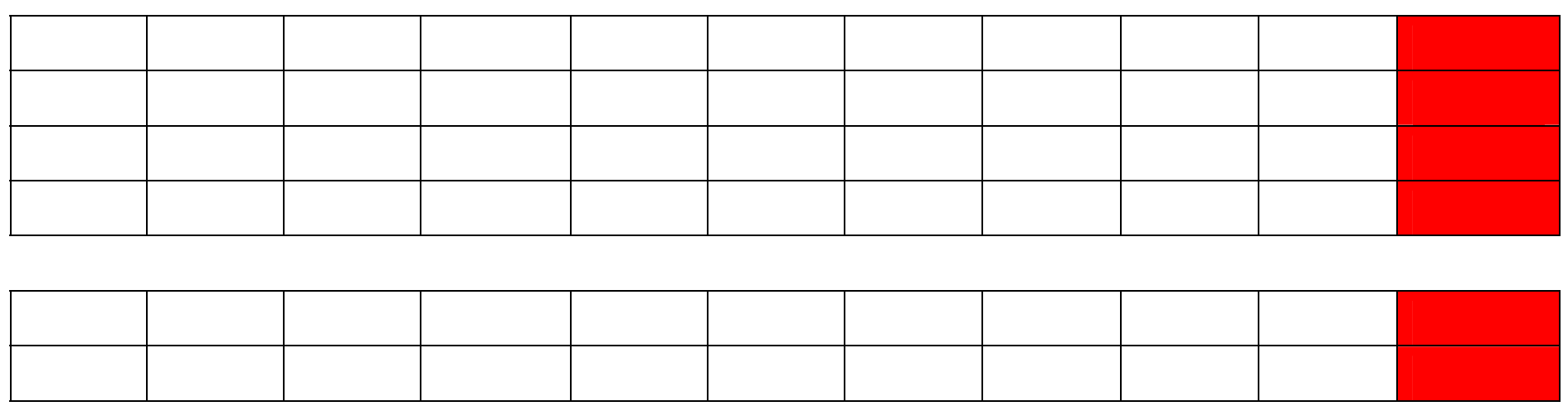

\begin{tabular}{|l|l|l|l|l|l|l|l|l|l|}
\hline & & & & & & & & & $X$ \\
\hline
\end{tabular}




\begin{tabular}{|c|c|c|c|c|c|c|c|c|c|c|c|}
\hline NFPA 450 & $\begin{array}{c}\text { Chapter } \\
4\end{array}$ & $\begin{array}{c}\text { Chapter } \\
5\end{array}$ & $\begin{array}{c}\text { Chapter } \\
6\end{array}$ & $\begin{array}{c}\text { Chapter } \\
7\end{array}$ & $\begin{array}{c}\text { Chapter } \\
8 \\
\end{array}$ & $\begin{array}{c}\text { Chapter } \\
9\end{array}$ & $\begin{array}{c}\text { Chapter } \\
10\end{array}$ & $\begin{array}{c}\text { Chapter } \\
11\end{array}$ & $\begin{array}{c}\text { Chapter } \\
12\end{array}$ & $\begin{array}{c}\text { Chapter } \\
13\end{array}$ & NFPA 450 \\
\hline \multicolumn{12}{|l|}{ IVO } \\
\hline \multicolumn{12}{|l|}{ IVQ } \\
\hline \multicolumn{12}{|l|}{ IVU } \\
\hline IVZ & & $\mathrm{X}$ & & & & & & & & & \\
\hline
\end{tabular}

Resource Mobilization \& Deployment

IIIE

IVK

IVM

IVP

Incident Management Support

\begin{tabular}{|l|l|l|l|l|l|l|l|l|l|l|}
\hline & $\mathrm{X}$ & & & & & & & & $\mathrm{X}$ & \\
\hline & & & & & & & & & & \\
\hline & & & & & & & & & & \\
\hline
\end{tabular}

$\bullet \quad$ IVJ

IVL

IVX

IVY

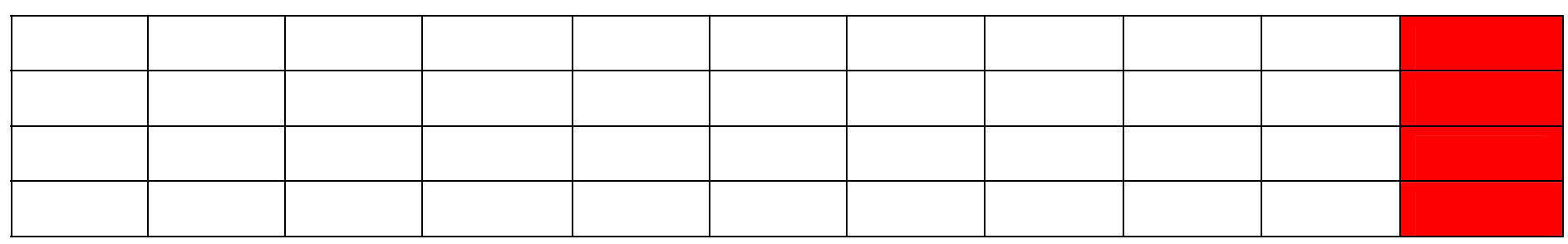

V. Supporting Technologies 


\begin{tabular}{l|c|c|c|c|c|c|c|}
\hline \multicolumn{1}{|c|}{ ASTM F1220 } & Section 6 & Section 7 & Section 8 & Section 9 & Section 10 & Section 11 & ASTM E1220 \\
$\begin{array}{l}\text { I. Preparedness } \\
\text { IA. Organization } \\
\text { IB. Cycle }\end{array}$ & & & & & & & \\
\cline { 2 - 8 }
\end{tabular}

II. Communications \& Information Management

Operational Communications

IIA

IIB

Interoperability

IIC

IID

III. Resource Management

\begin{tabular}{|l|l|l|l|l|l|l|}
\hline & $\mathrm{X}$ & $\mathrm{X}$ & $\mathrm{X}$ & $\mathrm{X}$ & & \\
\hline & $\mathrm{X}$ & $\mathrm{X}$ & $\mathrm{X}$ & $\mathrm{X}$ & $\mathrm{X}$ & \\
\hline
\end{tabular}

Categorizing; Mgmt; Inventory; Acquisition

IIIC

IIID

IVV

\section{Recovery}

IIIB

IIIF

IIIG

IVK

IV. Command and Management

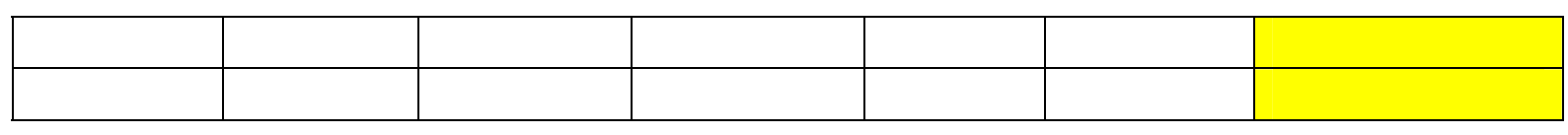

Incident Management Structure IVF

IVI

IVR

IVS

IVT

\begin{tabular}{|l|l|l|l|l|l|l|}
\hline & & & & & & \\
\hline & & & & & & \\
\hline & & & & & & \\
\hline & & & & & & \\
\hline
\end{tabular}

\begin{tabular}{|l|l|l|l|l|l|l|}
\hline & & & & & & \\
\hline & & & & & & \\
\hline & & & & & & \\
\hline & & & & & & \\
\hline
\end{tabular}

\begin{tabular}{|l|l|l|l|l|l|l|}
\hline & & & & & & \\
\hline & & & & & & \\
\hline & & & & & & \\
\hline & & & & & & \\
\hline
\end{tabular}




\begin{tabular}{|c|c|c|c|c|c|c|c|}
\hline ASTM F1220 & Section 6 & Section 7 & Section 8 & Section 9 & Section 10 & Section 11 & ASTM E1220 \\
\hline \multicolumn{8}{|l|}{ IVW } \\
\hline \multicolumn{8}{|c|}{ Incident Management Planning } \\
\hline \multicolumn{8}{|l|}{ IVC } \\
\hline \multicolumn{8}{|l|}{ IVD } \\
\hline \multicolumn{8}{|l|}{ IVE } \\
\hline \multicolumn{8}{|l|}{ IVG } \\
\hline \multicolumn{8}{|l|}{ Establishment of Command } \\
\hline \multicolumn{8}{|l|}{ IVB } \\
\hline IVN & & & & & & & \\
\hline
\end{tabular}

Command Operations

IVA

IVH

IVO

IVQ

IVU

IVZ

Resource Mobilization \& Deployment

IIIE

IVK

IVM

IVP

Incident Management Support

IVJ

IVL

IVX

IVY

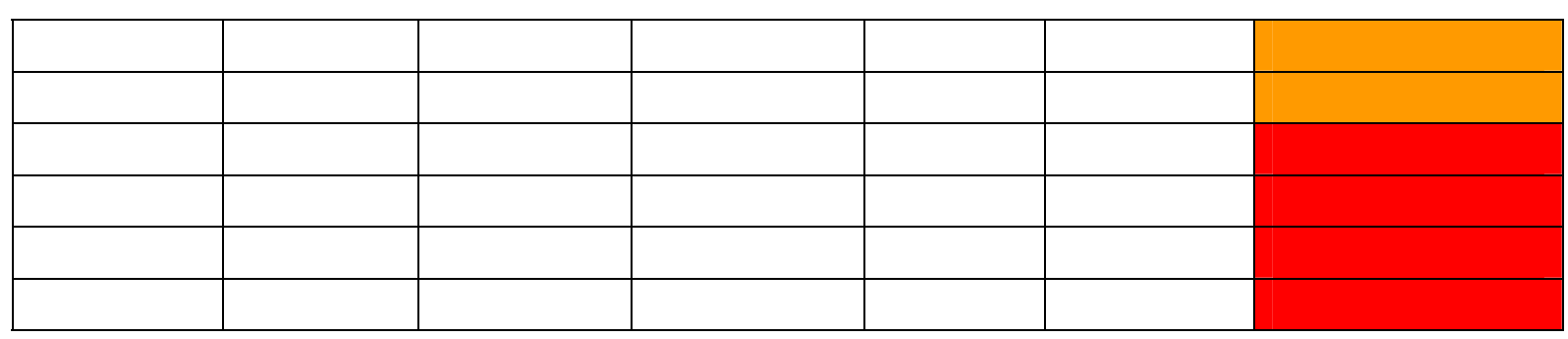

V. Supporting Technologies

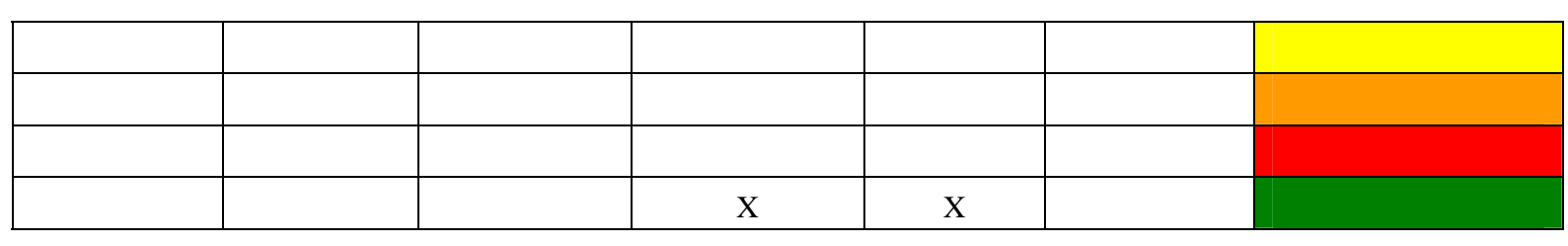

\begin{tabular}{|l|c|c|c|c|c|c|}
\hline & & & & & & \\
\hline & $\mathrm{X}$ & $\mathrm{X}$ & $\mathrm{X}$ & $\mathrm{X}$ & $\mathrm{X}$ & \\
\hline & & & & & & \\
\hline & & & & & & \\
\hline
\end{tabular}




\begin{tabular}{l|c|c|c|c|c|c|c|c|}
\hline \multicolumn{1}{|c|}{ JCAHO } & EC 4.10 & EC 4.20 & HR 1.10 & IC 6.10 & IM 2.30 & LD 3.15 & MS 4.10 & JCAHO-EM \\
$\begin{array}{l}\text { I. Preparedness } \\
\text { A. Organization } \\
\text { IB. Cycle }\end{array}$ & & & & & & & & \\
\hline
\end{tabular}

II. Communications \& Information Management

Operational Communications

IIA

IIB

Interoperability

IIC

IID

\begin{tabular}{|c|l|l|l|l|l|l|l|}
\hline $\mathrm{X}$ & & & & & & & \\
\hline $\mathrm{X}$ & & & & & & & \\
\hline & & & & & & & \\
\hline & & & $\mathrm{X}$ & & & & \\
\hline & & & & & & & \\
\hline
\end{tabular}

III. Resource Management

Categorizing; Mgmt; Inventory; Acquisition

IIIA

IIIB

IIIC

IIID

IVV

\section{Recovery}

IIIB

IIIF

IIIG

IVK

IV. Command and Management Incident Management Structure IVF

IVI

IVR

IVS

IVT

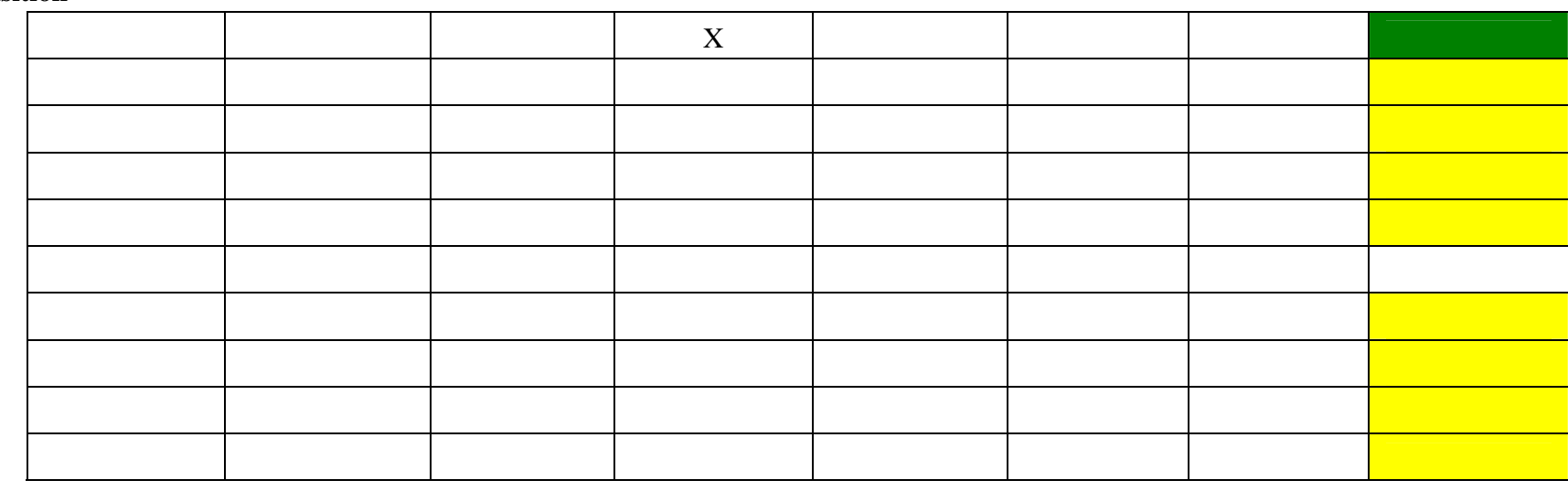

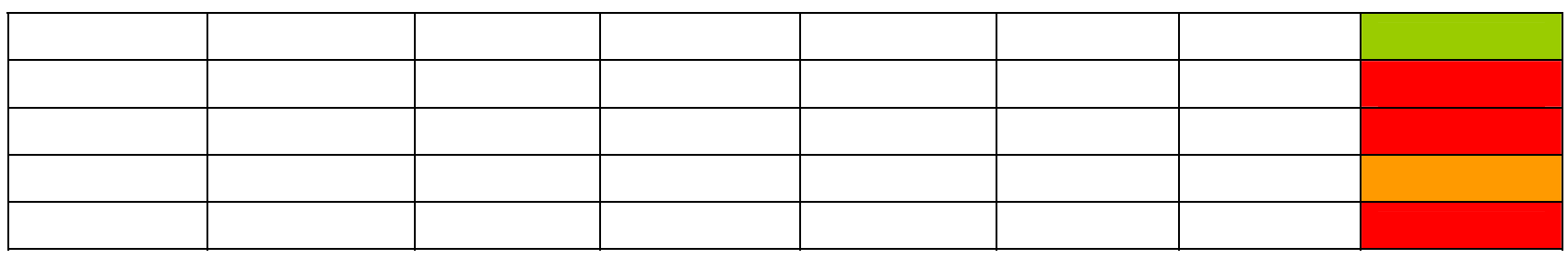




\begin{tabular}{|c|l|l|l|l|l|l|l|l|}
\hline \multirow{2}{*}{ JCAHO } & EC 4.10 & EC 4.20 & HR 1.10 & IC 6.10 & IM 2.30 & LD 3.15 & MS 4.10 & JCAHO-EM \\
\hline \multirow{2}{*}{ IVW } & & & & & & & & \\
\end{tabular}

Incident Management Planning

IVC

IVD

IVE

IVG

Establishment of Command

IVB

IVN

Command Operations

IVA

IVH

IVO

IVQ

IVU

IVZ

Resource Mobilization \& Deployment

IIIE

IVK

IVM

IVP

Incident Management Support

IVJ

IVL

IVX

IVY

V. Supporting Technologies

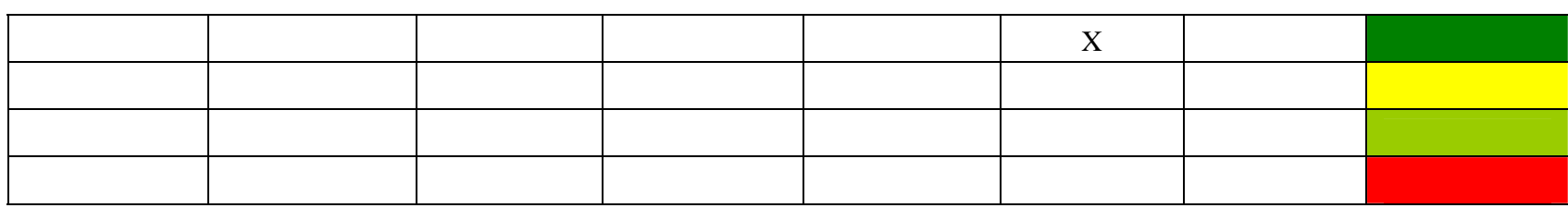

\begin{tabular}{|c|c|c|c|c|c|c|c|}
\hline $\mathrm{X}$ & & $\mathrm{X}$ & & & & $\mathrm{X}$ & \\
\hline & & & & & & & \\
\hline
\end{tabular}

\begin{tabular}{|l|l|l|l|l|l|l|l|}
\hline $\mathrm{X}$ & & & & & & & \\
\hline & & & & & & & \\
\hline $\mathrm{X}$ & $\mathrm{X}$ & & & & & & \\
\hline \\
\hline
\end{tabular}

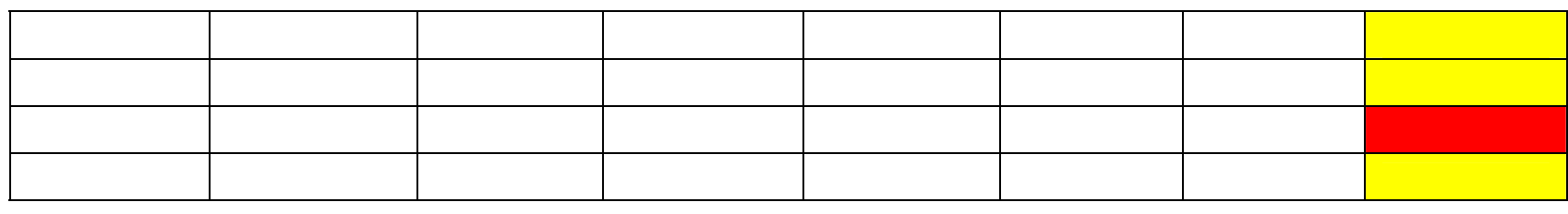

\begin{tabular}{|l|l|l|l|l|l|l|l|}
\hline & & & & & & & \\
\hline & & & & & & & \\
\\
\hline
\end{tabular}




\begin{tabular}{|c|c|c|c|c|c|c|}
\hline ASTM 2413 & Chapter 6 & Chapter 7 & Chapter 8 & Chapter 9 & Chapter 10 & ASTM F2413 \\
\hline \multicolumn{7}{|l|}{ I. Preparedness } \\
\hline IA. Organization & $\mathrm{X}$ & & $\mathrm{X}$ & & & \\
\hline IB. Cycle & $\mathrm{X}$ & $\mathrm{X}$ & & & & \\
\hline
\end{tabular}

II. Communications \& Information Management

Operational Communications

IIA

IIB

Interoperability

IIC

IID

III. Resource Management

Categorizing; Mgmt; Inventory; Acquisition

IIIA

$\underset{\infty}{+\infty}$

IIIB

IIIC

IIID

IVV

\section{Recovery}

IIIB

IIIF

IIIG

IVK

IV. Command and Management Incident Management Structure IVF

IVI

IVR

IVS

IVT
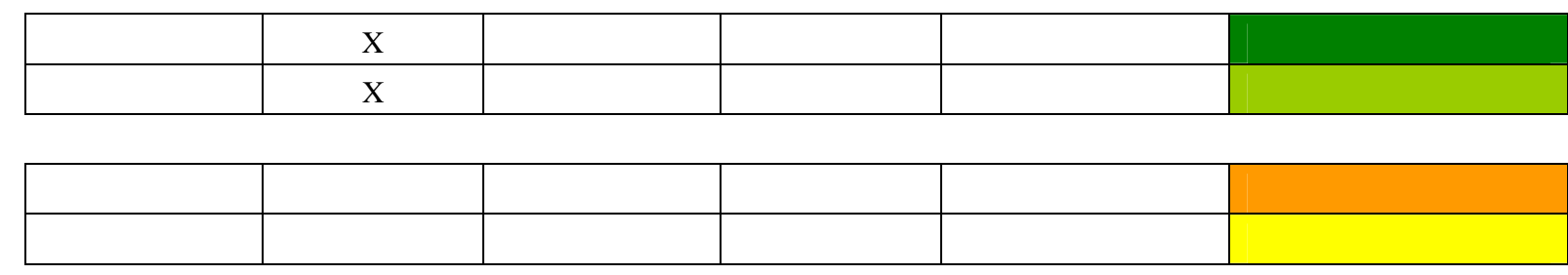

\begin{tabular}{|c|c|c|c|l|l|}
\hline & & & & & \\
\hline $\mathrm{X}$ & $\mathrm{X}$ & & $\mathrm{X}$ & & \\
\hline & & $\mathrm{X}$ & $\mathrm{X}$ & & \\
\hline $\mathrm{X}$ & $\mathrm{X}$ & & & & \\
\hline & & & $\mathrm{X}$ & & \\
\hline
\end{tabular}

\begin{tabular}{|l|l|l|l|l|l|}
\hline & & & & & \\
\hline & & & & $\mathrm{x}$ & \\
\hline & & & & $\mathrm{X}$ & \\
\hline & & & & & \\
\hline
\end{tabular}

\begin{tabular}{|l|l|l|l|l|l|}
\hline & & & $\mathrm{X}$ & & \\
\hline & & & & & \\
\hline & & & $\mathrm{X}$ & & \\
\hline & & & & & \\
\hline & & & & & \\
\hline
\end{tabular}




\begin{tabular}{|c|c|c|c|c|c|c|}
\hline ASTM 2413 & \begin{tabular}{|l|} 
Chapter 6 \\
\end{tabular} & Chapter 7 & Chapter 8 & Chapter 9 & Chapter 10 & ASTM F2413 \\
\hline \multicolumn{7}{|l|}{ IVW } \\
\hline \multicolumn{7}{|l|}{ Incident Management Planning } \\
\hline \multicolumn{7}{|l|}{$\begin{array}{l}\text { IVC } \\
\text { IVD }\end{array}$} \\
\hline \multicolumn{7}{|l|}{ IVD } \\
\hline \multicolumn{7}{|l|}{ IVE } \\
\hline \multicolumn{7}{|l|}{ IVG } \\
\hline \multicolumn{7}{|l|}{ Establishment of Command } \\
\hline \multirow{2}{*}{\multicolumn{7}{|c|}{$\begin{array}{l}\text { IVB } \\
\text { IVN }\end{array}$}} \\
\hline & & & & & & \\
\hline \multicolumn{7}{|l|}{ Command Operations } \\
\hline \multicolumn{7}{|l|}{ IVA } \\
\hline \multicolumn{7}{|l|}{$\mathrm{IVH}$} \\
\hline \multicolumn{7}{|l|}{ IVO } \\
\hline \multicolumn{7}{|l|}{ IVQ } \\
\hline \multicolumn{7}{|l|}{ IVU } \\
\hline \multicolumn{7}{|l|}{ IVZ } \\
\hline \multicolumn{7}{|c|}{ Resource Mobilization \& Deployment } \\
\hline \multicolumn{7}{|l|}{ IIIE } \\
\hline \multicolumn{7}{|l|}{ IVK } \\
\hline \multicolumn{7}{|l|}{ IVM } \\
\hline \multicolumn{7}{|l|}{ IVP } \\
\hline \multicolumn{7}{|l|}{ Incident Management Support } \\
\hline \multicolumn{7}{|l|}{ IVJ } \\
\hline \multicolumn{7}{|l|}{ IVL } \\
\hline \multicolumn{7}{|l|}{ IVX } \\
\hline \multirow{2}{*}{\multicolumn{7}{|c|}{$\begin{array}{l}\text { IVY } \\
\text { V. Supporting Technologies }\end{array}$}} \\
\hline & & & & & & \\
\hline & & & & & & \\
\hline
\end{tabular}




\section{NFPA 1710}

I. Preparedness

IA. Organization

IB. Cycle

II. Communications \& Information Management Operational Communications

IIA

IIB

Interoperability

IIC

IID

III. Resource Management

Categorizing; Mgmt; Inventory; Acquisition

IIIA

IIIB

IIIC

IIID

IVV

\section{Recovery}

IIIB

IIIF

IIIG

IVK

IV. Command and Management Incident Management Structure IVF

IVI

IVR

IVS

IVT \begin{tabular}{|l|l|l|}
\hline Chapter 4 & Chapter 5 & Chapter 6 \\
\hline
\end{tabular}

\begin{tabular}{|l|l|l|l|}
\hline $\mathrm{X}$ & & & \\
\hline $\mathrm{X}$ & $\mathrm{X}$ & & \\
\hline
\end{tabular}
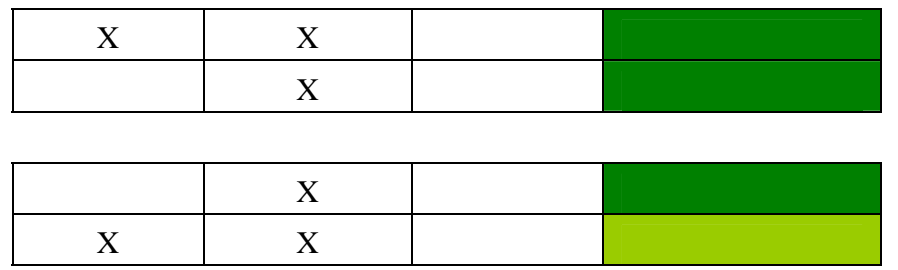

\begin{tabular}{|c|c|c|c|}
\hline $\mathrm{X}$ & & & \\
\hline $\mathrm{X}$ & & & \\
\hline & $\mathrm{X}$ & & \\
\hline & $\mathrm{X}$ & & \\
\hline & & $\mathrm{X}$ & \\
\hline
\end{tabular}

\begin{tabular}{|c|c|l|l|}
\hline $\mathrm{X}$ & & & \\
\hline & $\mathrm{X}$ & & \\
\hline $\mathrm{X}$ & & & \\
\hline & $\mathrm{X}$ & & \\
\hline
\end{tabular}

\begin{tabular}{|l|l|l|l|}
\hline $\mathrm{X}$ & $\mathrm{X}$ & & \\
\hline & $\mathrm{X}$ & $\mathrm{X}$ & \\
\hline & & $\mathrm{X}$ & \\
\hline & & $\mathrm{X}$ & \\
\hline & & $\mathrm{X}$ & \\
\hline
\end{tabular}




\begin{tabular}{l|l|c|c|c|}
\hline \multicolumn{1}{|c|}{ NFPA 1710 } & Chapter 4 & Chapter 5 & Chapter 6 & NFPA 1710 \\
\hline IVW & & & $\mathrm{X}$ & \\
Incident Management Planning & & & \\
IVC & & & $\mathrm{X}$ & \\
IVD & & & $\mathrm{X}$ & \\
IVE & & $\mathrm{X}$ & $\mathrm{X}$ & \\
IVG & & & $\mathrm{X}$ & \\
\cline { 2 - 6 } &
\end{tabular}

Establishment of Command

IVB

IVN

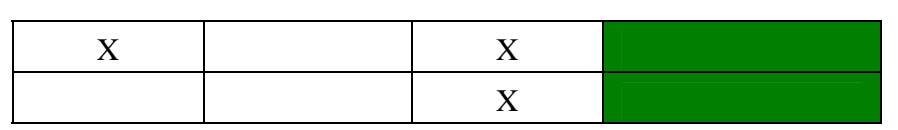

Command Operations

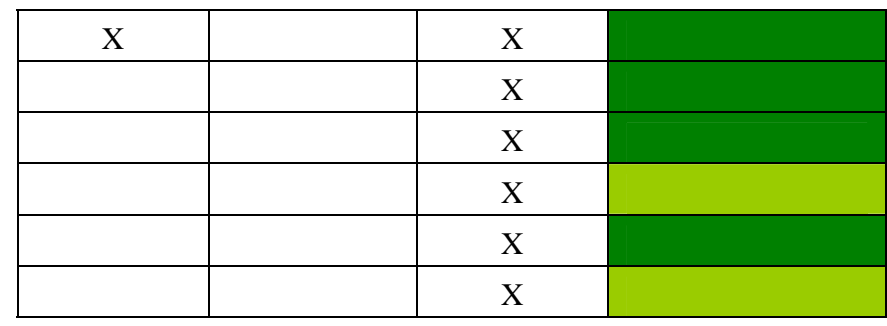

$\stackrel{\bullet}{\bullet}$

IVA

IVH

IVO

IVQ

IVU

IVZ

Resource Mobilization \& Deployment

IIIE

IVK

IVM

IVP

Incident Management Support

IVJ

IVL

IVX

IVY

V. Supporting Technologies

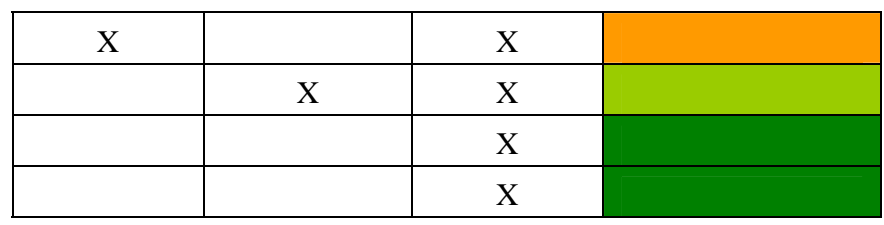

\begin{tabular}{|c|c|c|c|}
\hline & & $X$ & \\
\hline$X$ & & $X$ & \\
\hline & & $X$ & \\
\hline & & $X$ & \\
\hline
\end{tabular}




\begin{tabular}{|c|c|c|c|}
\hline NFPA 1720 & Chapter 4 & Chapter 5 & NFPA 1720 \\
\hline \multicolumn{4}{|l|}{ I. Preparedness } \\
\hline \multicolumn{4}{|l|}{ IA. Organization } \\
\hline IB. Cycle & & $\mathrm{X}$ & \\
\hline \multicolumn{4}{|c|}{ II. Communications \& Information Management } \\
\hline \multicolumn{4}{|l|}{ Operational Communications } \\
\hline IIA & $\mathrm{X}$ & $\mathrm{X}$ & \\
\hline IIB & & $\mathrm{X}$ & \\
\hline \multicolumn{4}{|l|}{ Interoperability } \\
\hline IIC & & $\mathrm{X}$ & \\
\hline IID & & $\mathrm{X}$ & \\
\hline III. Resource Management & & & \\
\hline
\end{tabular}

Categorizing; Mgmt; Inventory; Acquisition

IIIA

IIIB

IIIC

IIID

IVV

Recovery

IIIB

IIIF

IIIG

IVK

IV. Command and Management Incident Management Structure IVF

IVI

IVR

IVS

IVT
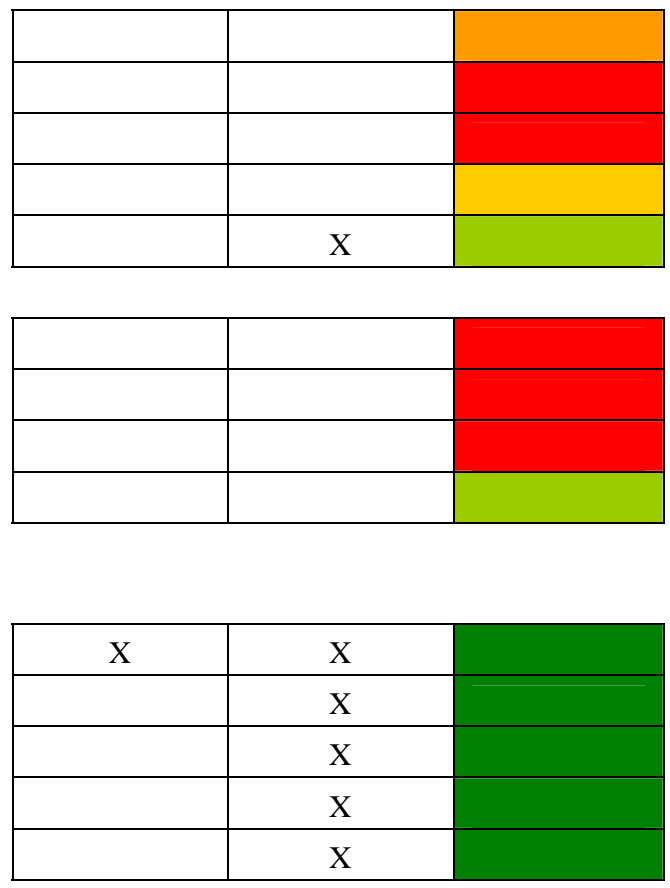


\begin{tabular}{|c|c|c|c|}
\hline NFPA 1720 & Chapter 4 & Chapter 5 & NFPA 1720 \\
\hline IVW & & $\mathrm{X}$ & \\
\hline \multicolumn{4}{|c|}{ Incident Management Planning } \\
\hline IVC & & $\mathrm{X}$ & \\
\hline IVD & & $\mathrm{X}$ & \\
\hline IVE & & $\mathrm{X}$ & \\
\hline IVG & & & \\
\hline \multicolumn{4}{|l|}{ Establishment of Command } \\
\hline IVB & & $\mathrm{X}$ & \\
\hline IVN & & $\mathrm{X}$ & \\
\hline \multicolumn{4}{|l|}{ Command Operations } \\
\hline IVA & & $\mathrm{X}$ & \\
\hline IVH & & $\mathrm{X}$ & \\
\hline IVO & & $\mathrm{X}$ & \\
\hline IVQ & & $\mathrm{X}$ & \\
\hline IVU & & $\mathrm{X}$ & \\
\hline IVZ & $\mathrm{X}$ & $\mathrm{X}$ & \\
\hline \multicolumn{4}{|c|}{ Resource Mobilization \& Deployment } \\
\hline \multicolumn{4}{|l|}{ IIIE } \\
\hline IVK & $\mathrm{X}$ & $\mathrm{X}$ & \\
\hline IVM & & $\mathrm{X}$ & \\
\hline IVP & & $\mathrm{X}$ & \\
\hline \multicolumn{4}{|c|}{ Incident Management Support } \\
\hline IVJ & & $\mathrm{X}$ & \\
\hline IVL & & $\mathrm{X}$ & \\
\hline \multicolumn{4}{|l|}{ IVX } \\
\hline IVY & & $\mathrm{X}$ & \\
\hline
\end{tabular}

V. Supporting Technologies 


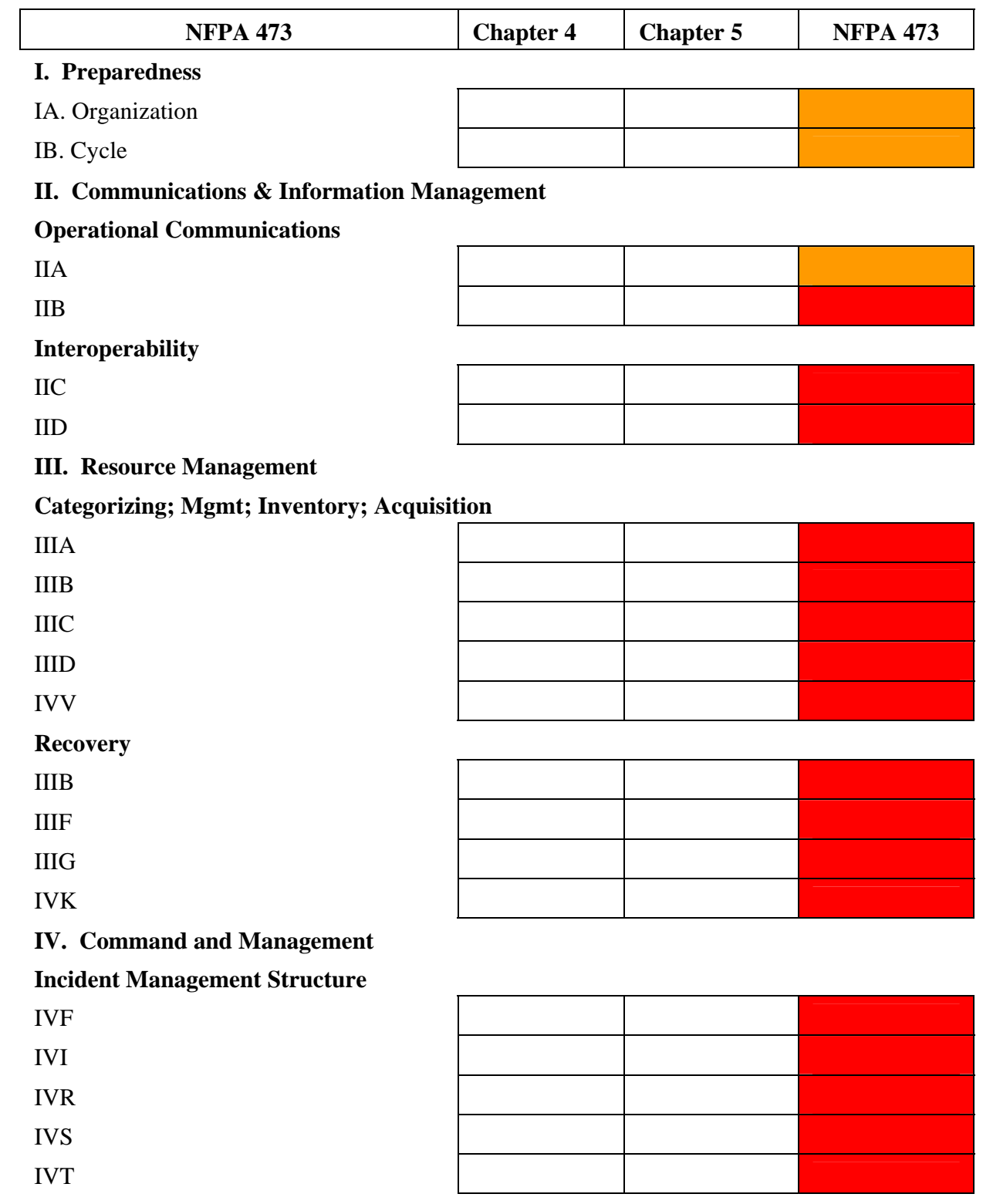




\begin{tabular}{|c|c|c|c|}
\hline NFPA 473 & Chapter 4 & Chapter 5 & NFPA 473 \\
\hline \multicolumn{4}{|l|}{ IVW } \\
\hline \multicolumn{4}{|c|}{ Incident Management Planning } \\
\hline \multicolumn{4}{|l|}{ IVC } \\
\hline \multicolumn{4}{|l|}{ IVD } \\
\hline \multicolumn{4}{|l|}{ IVE } \\
\hline \multicolumn{4}{|l|}{ IVG } \\
\hline \multicolumn{4}{|l|}{ Establishment of Command } \\
\hline \multicolumn{4}{|l|}{ IVB } \\
\hline \multicolumn{4}{|l|}{ IVN } \\
\hline \multicolumn{4}{|l|}{ Command Operations } \\
\hline IVA & $\mathrm{X}$ & $\mathrm{X}$ & \\
\hline \multicolumn{4}{|l|}{ IVH } \\
\hline \multicolumn{4}{|l|}{ IVO } \\
\hline IVQ & $\mathrm{X}$ & $\mathrm{X}$ & \\
\hline \multicolumn{4}{|l|}{ IVU } \\
\hline IVZ & $\mathrm{X}$ & $\mathrm{X}$ & \\
\hline \multicolumn{4}{|c|}{ Resource Mobilization \& Deployment } \\
\hline \multicolumn{4}{|l|}{ IIIE } \\
\hline \multicolumn{4}{|l|}{ IVK } \\
\hline \multicolumn{4}{|l|}{ IVM } \\
\hline \multicolumn{4}{|l|}{ IVP } \\
\hline \multicolumn{4}{|c|}{ Incident Management Support } \\
\hline \multicolumn{4}{|l|}{ IVJ } \\
\hline \multicolumn{4}{|l|}{ IVL } \\
\hline \multicolumn{4}{|l|}{ IVX } \\
\hline IVY & & & \\
\hline
\end{tabular}

V. Supporting Technologies 


\begin{tabular}{l|l|l|l|l|l|l|l|}
\hline \multicolumn{1}{|c|}{ HEICS } & Chapter 4 & Chapter 5 & Chapter 6 & Chapter 7 & Chapter 8 & Chapter 9 & HEICS \\
I. Preparedness \\
\begin{tabular}{|l|l|l|l|l|l|} 
IA. Organization \\
IB. Cycle
\end{tabular} & & & & & & \\
\hline
\end{tabular}

II. Communications \& Information Management

Operational Communications

IIA

IIB

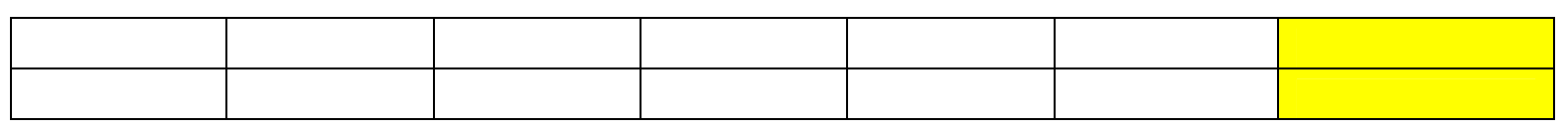

Interoperability

IIC

IID

III. Resource Management

Categorizing; Mgmt; Inventory; Acquisition

$\begin{array}{ll}\bullet & \text { IIIA } \\ \stackrel{\sigma}{ } & \text { IIIB }\end{array}$

IIIC

IIID

IVV

Recovery

IIIB

IIIF

IIIG

IVK

IV. Command and Management

Incident Management Structure

IVF

IVI

IVR

IVS

IVT

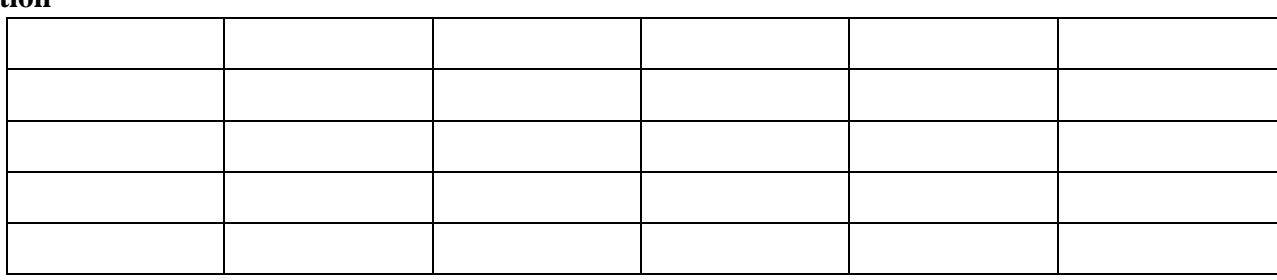
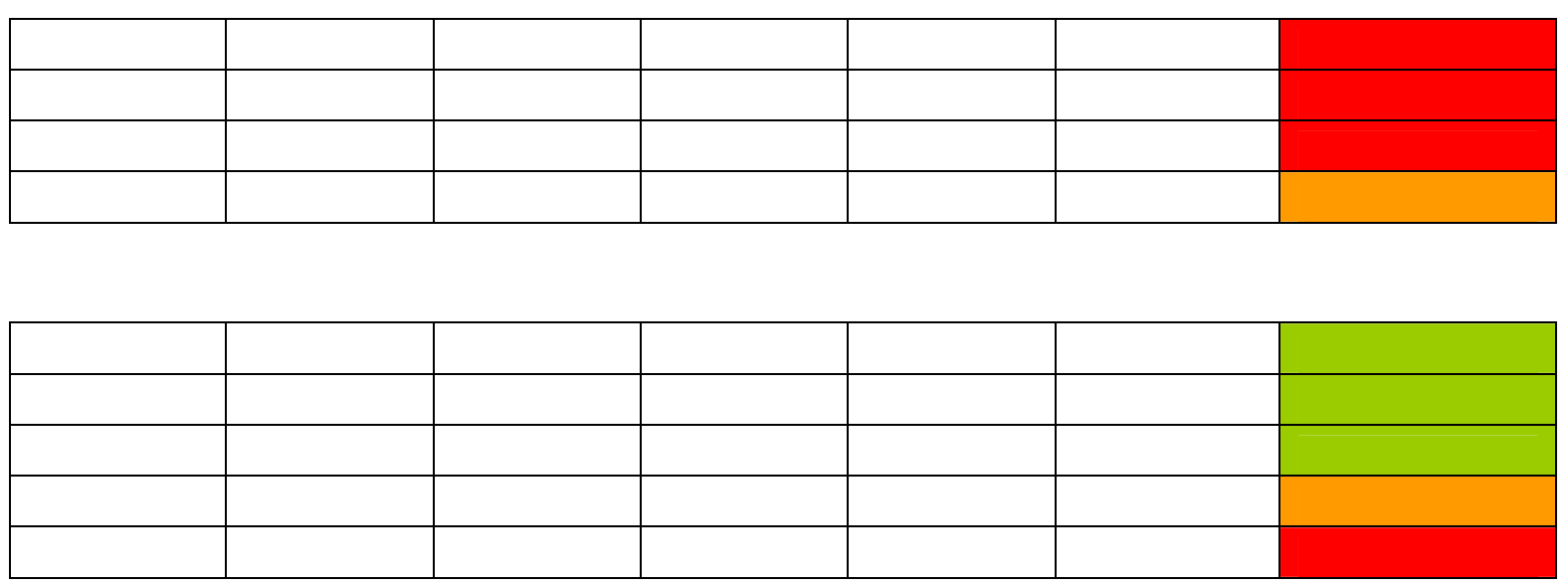


\begin{tabular}{|c|c|c|c|c|c|c|c|}
\hline HEICS & Chapter 4 & Chapter 5 & Chapter 6 & Chapter 7 & Chapter 8 & Chapter 9 & HEICS \\
\hline \multicolumn{8}{|l|}{ IVW } \\
\hline \multicolumn{8}{|c|}{ Incident Management Planning } \\
\hline \multicolumn{8}{|l|}{ IVC } \\
\hline \multicolumn{8}{|l|}{ IVD } \\
\hline \multicolumn{8}{|l|}{ IVE } \\
\hline \multicolumn{8}{|l|}{ IVG } \\
\hline \multicolumn{8}{|c|}{ Establishment of Command } \\
\hline \multicolumn{8}{|l|}{ IVB } \\
\hline \multicolumn{8}{|l|}{ IVN } \\
\hline \multicolumn{8}{|l|}{ Command Operations } \\
\hline \multicolumn{8}{|l|}{ IVA } \\
\hline \multicolumn{8}{|l|}{ IVH } \\
\hline \multicolumn{8}{|l|}{ IVO } \\
\hline \multicolumn{8}{|l|}{ IVQ } \\
\hline \multicolumn{8}{|l|}{ IVU } \\
\hline \multicolumn{8}{|l|}{ IVZ } \\
\hline \multicolumn{8}{|c|}{ Resource Mobilization \& Deployment } \\
\hline \multicolumn{8}{|l|}{ IIIE } \\
\hline \multicolumn{8}{|l|}{ IVK } \\
\hline \multicolumn{8}{|l|}{ IVM } \\
\hline \multicolumn{8}{|l|}{ IVP } \\
\hline \multicolumn{8}{|c|}{ Incident Management Support } \\
\hline \multicolumn{8}{|l|}{ IVJ } \\
\hline \multicolumn{8}{|l|}{ IVL } \\
\hline \multicolumn{8}{|l|}{ IVX } \\
\hline IVY & & & & & & & \\
\hline V. Supporting Technolog & & & & & & & \\
\hline
\end{tabular}





\section{Appendix E}

Color-Coding, Applicable Chapters, and Missing Criteria Tables for Fire/HAZMAT 



\section{Appendix E - Color-Coding, Applicable Chapters, and Missing Criteria Tables for Fire/HAZMAT}

\begin{tabular}{|c|c|c|c|c|c|c|c|}
\hline NFPA 1500 & Chapter 4 & Chapter 5 & Chapter 6 & Chapter 7 & Chapter 8 & Chapter 8 & NFPA 1500 \\
\hline \multicolumn{8}{|l|}{ I. Preparedness } \\
\hline \multicolumn{8}{|l|}{ IA. Organization } \\
\hline \multicolumn{8}{|l|}{ IB. Cycle } \\
\hline \multicolumn{8}{|c|}{ II. Communications \& Information Management } \\
\hline \multicolumn{8}{|c|}{ Operational Communications } \\
\hline IIA & & & & & $\mathrm{x}$ & & \\
\hline \multicolumn{8}{|l|}{ IIB } \\
\hline \multicolumn{8}{|l|}{ Interoperability } \\
\hline IIC & & & & & $\mathrm{X}$ & & \\
\hline IID & & & & & $\mathrm{X}$ & & \\
\hline
\end{tabular}

III. Resource Management

Categorizing; Mgmt; Inventory; Acquisition

IIIA
IIIB
IIIC
IIID
IVV
Recovery
IIIB
IIIF
IIIG
IVK
IV. Command and Management
Incident Management Structure
IVF
IVI

\begin{tabular}{|l|l|l|l|l|l|l|}
\hline & & $x$ & & $x$ & \\
\hline & & & & & \\
\hline & & & & & \\
\hline & & & & & & \\
\hline & & & & & & \\
\hline
\end{tabular}

\begin{tabular}{|c|c|c|c|c|c|c|}
\hline & & & & & & \\
\hline & & & & & & \\
\hline & & & & & & \\
\hline $\mathrm{X}$ & & & & $\mathrm{X}$ & & \\
\hline
\end{tabular}

\begin{tabular}{|l|l|l|l|l|l|l|}
\hline $\mathrm{X}$ & & & & $\mathrm{X}$ & \\
\hline & & & & $\mathrm{X}$ & & \\
\hline
\end{tabular}




\begin{tabular}{l|l|l|l|l|l|c|c|}
\hline \multicolumn{1}{|c|}{ NFPA 1500 } & Chapter 4 & Chapter 5 & Chapter 6 & Chapter 7 & Chapter 8 & Chapter 8 & NFPA 1500 \\
\hline IVR & & & & & X & \\
IVS & & & & & $X$ & \\
IVT & & & & & $X$ & \\
IVW \\
Incident Management Planning
\end{tabular}

IVC

IVD

IVE

IVG

\begin{tabular}{|c|c|c|c|c|c|}
\hline & & & & $\mathrm{X}$ & \\
\hline $\mathrm{X}$ & & & & $\mathrm{X}$ & \\
\hline $\mathrm{X}$ & $\mathrm{X}$ & $\mathrm{X}$ & & $\mathrm{X}$ & \\
\hline $\mathrm{X}$ & & & & $\mathrm{X}$ & \\
\hline
\end{tabular}

Establishment of Command IVB

\section{IVN}

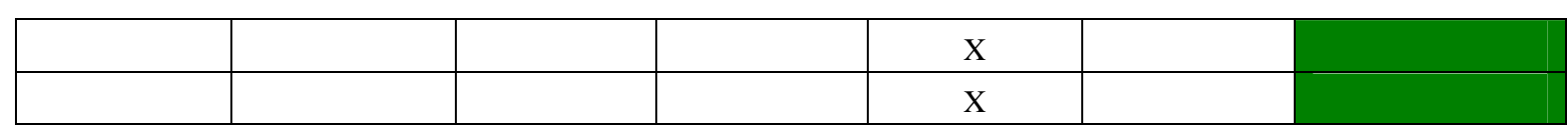

\section{Command Operations}

IVA

IVH

IVO

IVQ

IVU

IVZ

Resource Mobilization \& Deployment

IIIE

IVK

IVM

IVP

\begin{tabular}{|c|c|c|c|c|c|c|}
\hline $\mathrm{X}$ & & & & $\mathrm{X}$ & & \\
\hline & & & & $\mathrm{X}$ & \\
\hline & $\mathrm{X}$ & $\mathrm{X}$ & & $\mathrm{X}$ & & \\
\hline $\mathrm{X}$ & & & & $\mathrm{X}$ & & \\
\hline & & $\mathrm{X}$ & & & & \\
\hline $\mathrm{X}$ & & & & $\mathrm{X}$ & & \\
\hline
\end{tabular}

\begin{tabular}{|c|c|c|c|c|c|c|}
\hline & & & & $\mathrm{X}$ & & \\
\hline $\mathrm{X}$ & & & & $\mathrm{X}$ & & \\
\hline $\mathrm{X}$ & & $\mathrm{X}$ & & $\mathrm{X}$ & & \\
\hline & & & & $\mathrm{X}$ & & \\
\hline
\end{tabular}




\begin{tabular}{|c|c|c|c|c|c|c|c|}
\hline NFPA 1500 & Chapter 4 & Chapter 5 & Chapter 6 & Chapter 7 & Chapter 8 & Chapter 8 & NFPA 1500 \\
\hline \multicolumn{8}{|c|}{ Incident Management Support } \\
\hline IVJ & & & & & $\mathrm{X}$ & & \\
\hline IVL & & & & & $X$ & & \\
\hline IVX & & & & & $\mathrm{X}$ & & \\
\hline IVY & & & & & $X$ & & \\
\hline
\end{tabular}

V. Supporting Technologies 


\begin{tabular}{|c|c|c|c|c|c|c|c|c|c|}
\hline NFPA 1670 & Chapter 4 & Chapter 5 & Chapter 6 & Chapter 7 & Chapter 8 & Chapter 9 & Chapter 10 & Chapter 11 & NFPA 1670 \\
\hline \multicolumn{10}{|l|}{ I. Preparedness } \\
\hline IA. Organization & & & & & & & & & \\
\hline IB. Cycle & & & & & & & & & \\
\hline
\end{tabular}

II. Communications \& Information Management

Operational Communications

IIA

IIB

Interoperability

IIC

IID

III. Resource Management

Categorizing; Mgmt; Inventory; Acquisition

IIIA
+
IIIB
IIIC
IIID
IVV
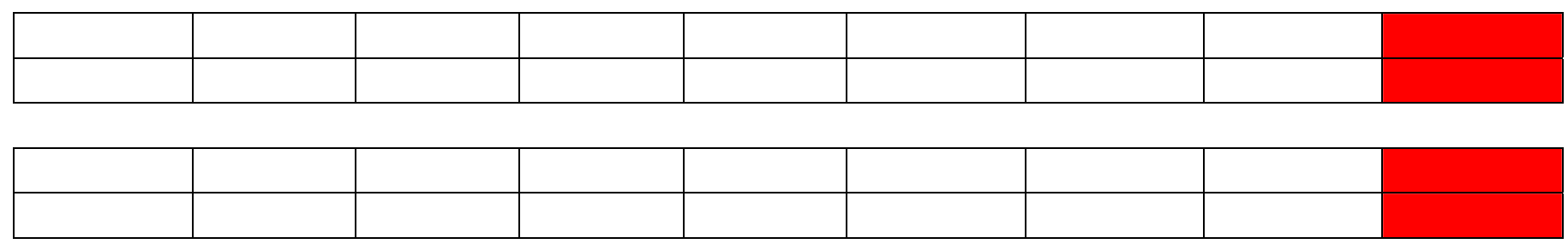

Recovery

IIIB

IIIF

IIIG

IVK

IV. Command and Management Incident Management Structure

IVF

IVI

IVR

IVS

IVT

\begin{tabular}{|l|l|l|l|l|l|l|l|l|}
\hline $\mathrm{X}$ & & & & & & & \\
\hline $\mathrm{X}$ & & & & & & & & \\
\hline $\mathrm{X}$ & & & & & & & & \\
\hline $\mathrm{X}$ & & & & & & & & \\
\hline & & & & & & & & \\
\hline
\end{tabular}

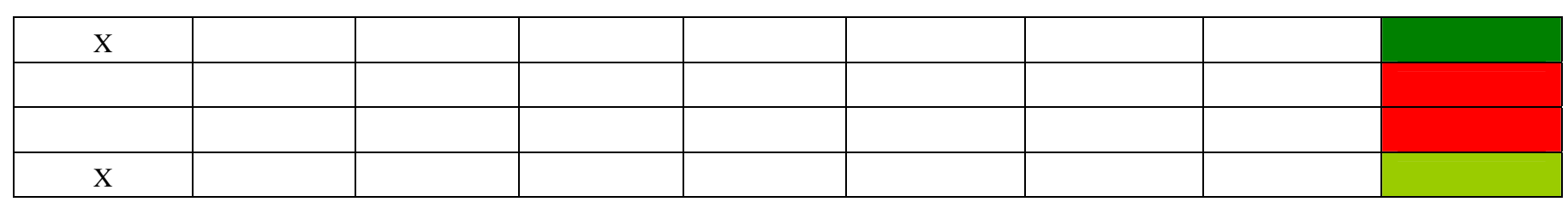

\begin{tabular}{|l|l|l|l|l|l|l|l|l|}
\hline & & & & & & & & \\
\hline $\mathrm{X}$ & & & & & & & & \\
\hline & & & & & & & & \\
\hline \\
\hline
\end{tabular}




\begin{tabular}{|c|c|c|c|c|c|c|c|c|c|}
\hline NFPA 1670 & Chapter 4 & Chapter 5 & Chapter 6 & Chapter 7 & Chapter 8 & Chapter 9 & Chapter 10 & Chapter 11 & NFPA 1670 \\
\hline IVW & & & & & & & & & \\
\hline
\end{tabular}

Incident Management Planning

IVC

IVD

IVE

IVG

Establishment of Command

IVB

IVN

Command Operations

IVA

IVH

IVO

IVQ

in IVU

IVZ

Resource Mobilization \& Deployment

IIIE

IVK

IVM

IVP

Incident Management Support

IVJ

IVL

IVX

IVY

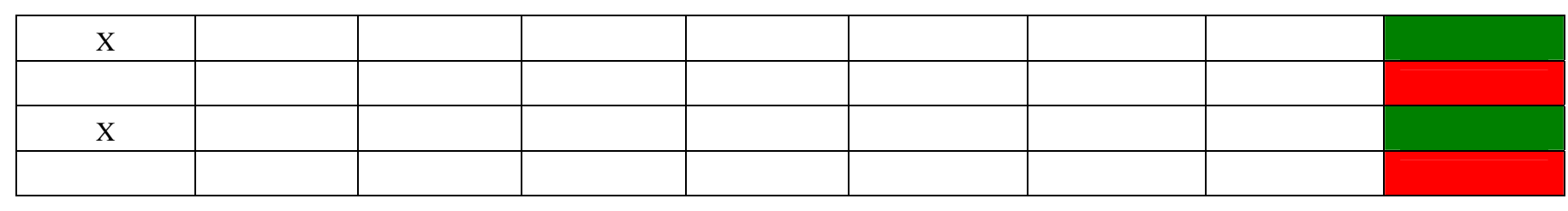

\begin{tabular}{|l|l|l|l|l|l|l|l|l|}
\hline $\mathrm{X}$ & & & & & & & \\
\hline & & & & & & & & \\
\hline
\end{tabular}

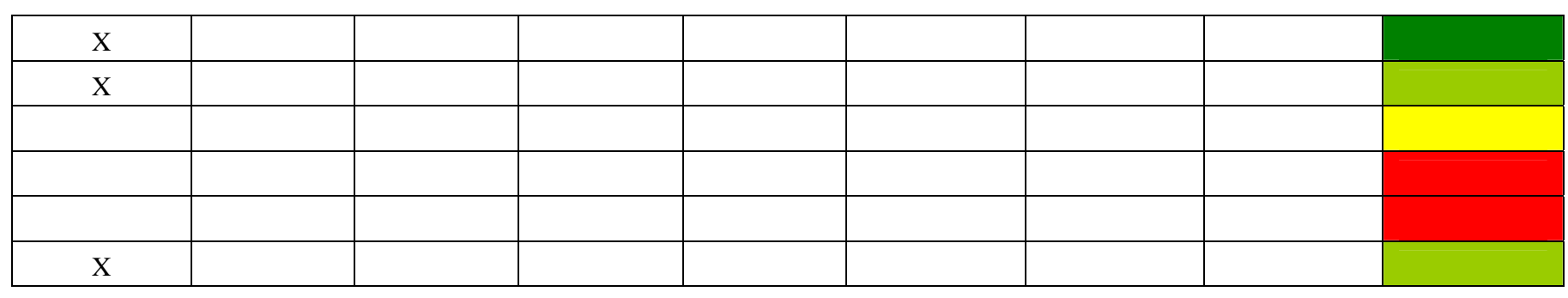

\begin{tabular}{|l|l|l|l|l|l|l|l|}
\hline & & & & & & & \\
\hline $\mathrm{X}$ & & & & & & & \\
\hline
\end{tabular}

\begin{tabular}{|l|l|l|l|l|l|l|l|}
\hline & & & & & & & \\
\hline \\
\hline
\end{tabular}

V. Supporting Technologies 


\begin{tabular}{|c|c|c|c|c|c|c|c|c|c|c|c|c|}
\hline NFPA 1710 & $\begin{array}{c}\text { Chapter } \\
1\end{array}$ & $\begin{array}{c}\text { Chapter } \\
2\end{array}$ & $\begin{array}{c}\text { Chapter } \\
3\end{array}$ & $\begin{array}{c}\text { Chapter } \\
4\end{array}$ & $\begin{array}{c}\text { Chapter } \\
5\end{array}$ & $\begin{array}{c}\text { Chapter } \\
6\end{array}$ & $\begin{array}{c}\text { Chapter } \\
7\end{array}$ & $\begin{array}{c}\text { Chapter } \\
8\end{array}$ & $\begin{array}{c}\text { Chapter } \\
9\end{array}$ & $\begin{array}{c}\text { Chapter } \\
10\end{array}$ & $\begin{array}{c}\text { Chapter } \\
11\end{array}$ & $\begin{array}{c}\text { NFPA } \\
1710\end{array}$ \\
\hline
\end{tabular}

I. Preparedness

IA. Organization

IB. Cycle

\begin{tabular}{|l|l|l|l|l|l|l|l|l|l|l|}
\hline & & & $\mathrm{X}$ & & & & & & & \\
\hline & & & $\mathrm{X}$ & $\mathrm{X}$ & & & & & & \\
\hline
\end{tabular}

II. Communications \& Information Management

Operational Communications

IIA

IIB

\begin{tabular}{|l|l|l|l|l|l|l|l|l|l|l|}
\hline & & & $\mathrm{X}$ & $\mathrm{X}$ & & & & & & \\
\hline & & & & $\mathrm{X}$ & & & & & & \\
\hline
\end{tabular}

Interoperability

IIC

IID

\begin{tabular}{|l|l|l|l|l|l|l|l|l|l|l|}
\hline & & & & $\mathrm{X}$ & & & & & & \\
\hline & & & $\mathrm{X}$ & $\mathrm{X}$ & & & & & & \\
\hline
\end{tabular}

III. Resource Management

Categorizing; Mgmt; Inventory; Acquisition

IIID

IVV

Recovery

IIIB

IIIF

IIIG

IVK

IV. Command and Management

\begin{tabular}{|l|l|l|l|l|l|l|l|l|l|l|}
\hline & & & $\mathrm{X}$ & & & & & & & \\
\hline & & & $\mathrm{X}$ & & & & & & & \\
\hline & & & & $\mathrm{X}$ & & & & & & \\
\hline & & & & $\mathrm{X}$ & & & & & & \\
\hline
\end{tabular}

Incident Management Structure

IVF
IVI
IVR
IVS

\begin{tabular}{|l|l|l|l|l|l|l|l|l|l|l|}
\hline & & & $\mathrm{X}$ & & & & & & & \\
\hline & & & & $\mathrm{X}$ & & & & & & \\
\hline & & & $\mathrm{X}$ & & & & & & & \\
\hline
\end{tabular}

IVI

IVS

\begin{tabular}{|l|l|l|l|l|l|l|l|l|l|l|}
\hline & & & $\mathrm{X}$ & $\mathrm{X}$ & & & & & & \\
\hline & & & & $\mathrm{X}$ & $\mathrm{X}$ & & & & & \\
\hline & & & & & $\mathrm{X}$ & & & & & \\
\hline & & & & & $\mathrm{X}$ & & & & & \\
\hline
\end{tabular}




\begin{tabular}{|c|c|c|c|c|c|c|c|c|c|c|c|c|}
\hline NFPA 1710 & $\begin{array}{c}\text { Chapter } \\
1\end{array}$ & $\begin{array}{c}\text { Chapter } \\
2\end{array}$ & $\begin{array}{c}\text { Chapter } \\
3\end{array}$ & $\begin{array}{c}\text { Chapter } \\
4\end{array}$ & $\begin{array}{c}\text { Chapter } \\
5\end{array}$ & $\begin{array}{c}\text { Chapter } \\
6\end{array}$ & $\begin{array}{c}\text { Chapter } \\
7\end{array}$ & $\begin{array}{c}\text { Chapter } \\
8\end{array}$ & $\begin{array}{c}\text { Chapter } \\
9\end{array}$ & $\begin{array}{c}\text { Chapter } \\
10\end{array}$ & $\begin{array}{c}\text { Chapter } \\
11\end{array}$ & $\begin{array}{c}\text { NFPA } \\
1710\end{array}$ \\
\hline IVW & & & & & & $\mathrm{X}$ & & & & & & \\
\hline
\end{tabular}

\section{Incident Management Planning}

IVC

IVD

IVE

IVG

Establishment of Command

IVB

IVN

\section{Command Operations}

IVA

IVH

[T] IVO

IVQ

IVU

IVZ

\section{Resource Mobilization \& Deployment}

IIIE

IVK

IVM

IVP

Incident Management Support

IVJ

IVL

IVX

IVY

V. Supporting Technologies

\begin{tabular}{|l|l|l|l|l|l|l|l|l|l|l|}
\hline & & & & & $\mathrm{X}$ & & & & & \\
\hline & & & & & $\mathrm{X}$ & & & & & \\
\hline & & & & $\mathrm{X}$ & $\mathrm{X}$ & & & & & \\
\hline & & & $\mathrm{X}$ & & $\mathrm{X}$ & & & & & \\
\hline
\end{tabular}

\begin{tabular}{|l|l|l|l|l|l|l|l|l|l|l|}
\hline & & & $\mathrm{X}$ & & $\mathrm{X}$ & & & & & \\
\hline & & & & & $\mathrm{X}$ & & & & & \\
\hline
\end{tabular}

\begin{tabular}{|l|l|l|l|l|l|l|l|l|l|l|}
\hline & & & $\mathrm{X}$ & & $\mathrm{X}$ & & & & & \\
\hline & & & & & $\mathrm{X}$ & & & & & \\
\hline & & & & & $\mathrm{X}$ & & & & & \\
\hline & & & & & $\mathrm{X}$ & & & & & \\
\hline & & & & & $\mathrm{X}$ & & & & & \\
\hline
\end{tabular}

\begin{tabular}{|l|l|l|l|l|l|l|l|l|l|l|}
\hline & & & $\mathrm{X}$ & & $\mathrm{X}$ & & & & & \\
\hline & & & & $\mathrm{X}$ & $\mathrm{X}$ & & & & & \\
\hline & & & & & $\mathrm{X}$ & & & & & \\
\hline & & & & & $\mathrm{X}$ & & & & & \\
\hline
\end{tabular}

\begin{tabular}{|l|l|l|l|l|l|l|l|l|l|l|}
\hline & & & & & $\mathrm{X}$ & & & & & \\
\hline & & & $\mathrm{X}$ & & $\mathrm{X}$ & & & & & \\
\hline & & & & & $\mathrm{X}$ & & & & & \\
\hline & & & & & $\mathrm{X}$ & & & & & \\
\hline
\end{tabular}




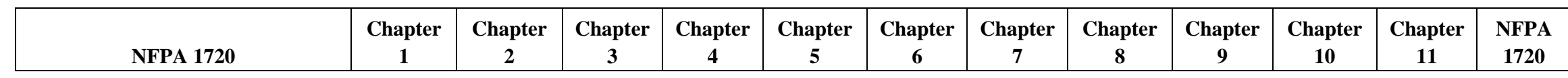

I. Preparedness

IA. Organization

IB. Cycle

\begin{tabular}{|l|l|l|l|l|l|l|l|l|l|l|}
\hline & & & $\mathrm{X}$ & $\mathrm{X}$ & & & & & & \\
\hline & & & & $\mathrm{X}$ & & & & & & \\
\hline
\end{tabular}

II. Communications \& Information Management

Operational Communications

IIA

IIB

\begin{tabular}{|l|l|l|l|l|l|l|l|l|l|l|}
\hline & & & $\mathrm{X}$ & $\mathrm{X}$ & & & & & & \\
\hline & & & & $\mathrm{X}$ & & & & & & \\
\hline
\end{tabular}

Interoperability

IIC

IID
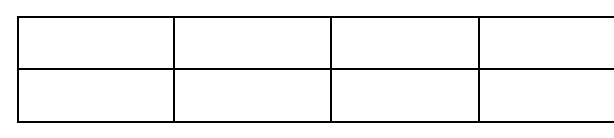

\begin{tabular}{|l|l|l|l|l|l|}
$\mathrm{X}$ & & & & \\
\hline $\mathrm{X}$ & & & & & \\
\hline
\end{tabular}

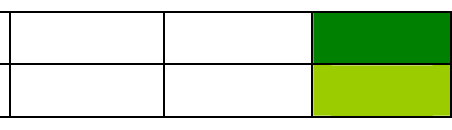

III. Resource Management

Categorizing; Mgmt; Inventory; Acquisition

IIIA

IIIB

IIIC

IIID

IVV

Recovery

IIIB

IIIF

IIIG

IVK

IV. Command and Management

\begin{tabular}{|l|l|l|l|l|l|l|l|l|l|l|}
\hline & & & & & & & & & & \\
\hline \\
\hline
\end{tabular}

Incident Management Structure

IVF

IVI

IVR

IVS

\begin{tabular}{|l|l|l|l|l|l|l|l|l|l|l|}
\hline & & & & & & & & & & \\
\hline \\
\hline
\end{tabular}

\begin{tabular}{|l|l|l|l|l|l|l|l|l|l|l|}
\hline & & & $\mathrm{X}$ & $\mathrm{X}$ & & & & & & \\
\hline & & & & $\mathrm{X}$ & & & & & & \\
\hline & & & & $\mathrm{X}$ & & & & & & \\
\hline
\end{tabular}




\begin{tabular}{|c|c|c|c|c|c|c|c|c|c|c|c|c|}
\hline NFPA 1720 & $\begin{array}{c}\text { Chapter } \\
1 \\
\end{array}$ & $\begin{array}{c}\text { Chapter } \\
2 \\
\end{array}$ & $\begin{array}{c}\text { Chapter } \\
3 \\
\end{array}$ & $\begin{array}{c}\text { Chapter } \\
4 \\
\end{array}$ & $\begin{array}{c}\text { Chapter } \\
5 \\
\end{array}$ & $\begin{array}{c}\text { Chapter } \\
6 \\
\end{array}$ & $\begin{array}{c}\text { Chapter } \\
7 \\
\end{array}$ & $\begin{array}{c}\text { Chapter } \\
8 \\
\end{array}$ & $\begin{array}{c}\text { Chapter } \\
\mathbf{9} \\
\end{array}$ & $\begin{array}{c}\text { Chapter } \\
10\end{array}$ & $\begin{array}{c}\text { Chapter } \\
11\end{array}$ & $\begin{array}{c}\text { NFPA } \\
1720\end{array}$ \\
\hline IVT & & & & & $X$ & & & & & & & \\
\hline IVW & & & & & $\mathrm{X}$ & & & & & & & \\
\hline
\end{tabular}

Incident Management Planning

IVC

IVD

IVE

IVG

Establishment of Command

IVB

IVN

Command Operations

IVA

IVH

(]) IVO

IVQ

IVU

IVZ

Resource Mobilization \&

Deployment

IIIE

IVK

IVM

IVP

Incident Management Support

IVJ

IVL

IVX

IVY

V. Supporting Technologies

\begin{tabular}{|l|l|l|l|l|l|l|l|l|l|l|}
\hline & & & & $\mathrm{X}$ & & & & & & \\
\hline & & & & $\mathrm{X}$ & & & & & & \\
\hline & & & & $\mathrm{X}$ & & & & & & \\
\hline
\end{tabular}

\begin{tabular}{|l|l|l|l|l|l|l|l|l|l|l|}
\hline & & & & $\mathrm{X}$ & & & & & & \\
\hline & & & & $\mathrm{X}$ & & & & & & \\
\hline
\end{tabular}

\begin{tabular}{|l|l|l|l|l|l|l|l|l|l|l|}
\hline & & & & $\mathrm{X}$ & & & & & & \\
\hline & & & & $\mathrm{X}$ & & & & & & \\
\hline & & & & $\mathrm{X}$ & & & & & & \\
\hline & & & & $\mathrm{X}$ & & & & & & \\
\hline & & & & $\mathrm{X}$ & & & & & & \\
\hline & & & $\mathrm{X}$ & $\mathrm{X}$ & & & & & & \\
\hline
\end{tabular}

\begin{tabular}{|l|l|l|l|l|l|l|l|l|l|l|l|}
\hline & & & & & & & & & & & \\
\hline & & & $\mathrm{X}$ & $\mathrm{X}$ & & & & & & \\
\hline & & & & $\mathrm{X}$ & & & & & & \\
\hline & & & & $\mathrm{X}$ & & & & & & \\
\hline
\end{tabular}

\begin{tabular}{|l|l|l|l|l|l|l|l|l|l|l|}
\hline & & & & $\mathrm{X}$ & & & & & & \\
\hline & & & & $\mathrm{X}$ & & & & & & \\
\hline & & & & & & & & & & \\
\hline
\end{tabular}




\begin{tabular}{|c|c|c|c|c|c|c|c|c|c|}
\hline NFPA 472 & Chapter 4 & Chapter 5 & Chapter 6 & Chapter 7 & Chapter 8 & Chapter 9 & Chapter 10 & Chapter 11 & NFPA 472 \\
\hline \multicolumn{10}{|l|}{ I. Preparedness } \\
\hline IA. Organization & $\mathrm{X}$ & $\mathrm{X}$ & $\mathrm{X}$ & $\mathrm{X}$ & & & & & \\
\hline IB. Cycle & $\mathrm{X}$ & $\mathrm{X}$ & $\mathrm{X}$ & $\mathrm{X}$ & & & & & \\
\hline
\end{tabular}

II. Communications \& Information Management

Operational Communications

IIA

IIB

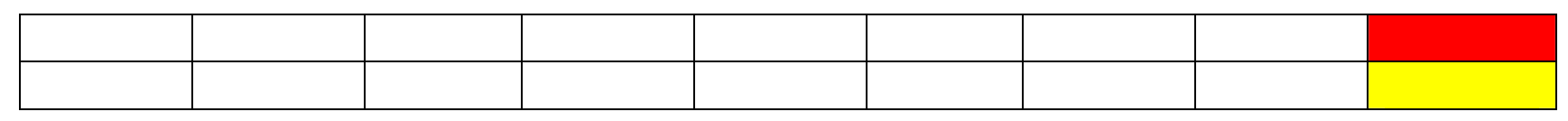

Interoperability

IIC

IID

III. Resource Management

Categorizing; Mgmt; Inventory; Acquisition

$\begin{array}{ll}\text { III } & \text { IIIB } \\ \text { IIIC } \\ \text { IIID } \\ \text { IVV }\end{array}$

\begin{tabular}{|l|l|l|l|l|l|l|l|}
\hline & & & & & & & \\
\hline & & & & & & & \\
\hline
\end{tabular}

IIIA
IIIB
IIIC
IIID
IVV

\section{Recovery}

IIIB

IIIF

IIIG

IVK

IV. Command and Management Incident Management Structure IVF

IVI

IVR

IVS

IVT

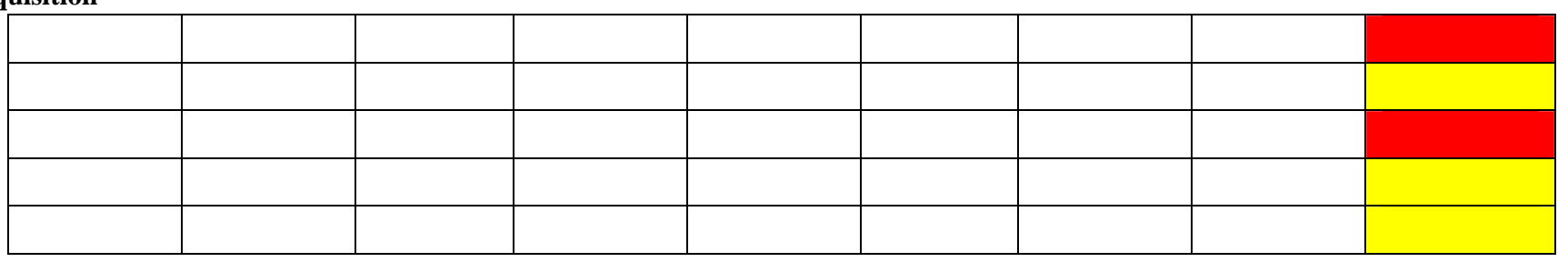

\begin{tabular}{|l|l|l|l|l|l|l|l|l|}
\hline & & & & & & & & \\
\hline & & & & & & & \\
\hline & & & & & & & & \\
\hline & & & & & & & & \\
\hline
\end{tabular}

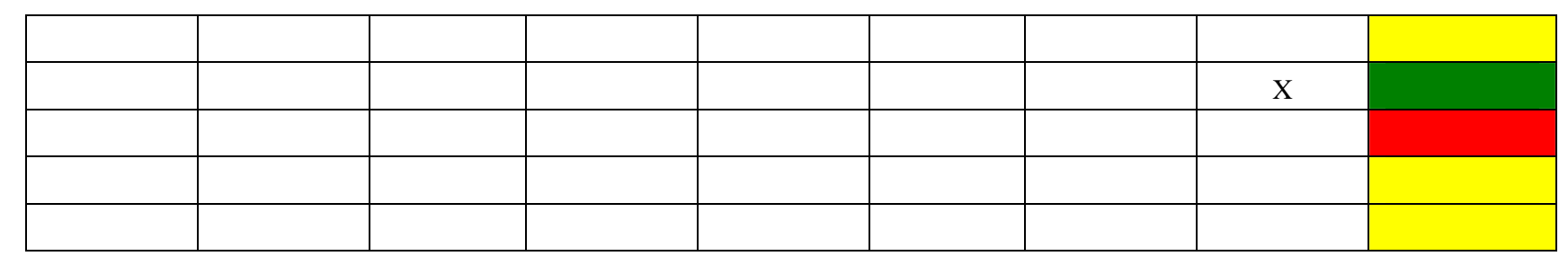




\begin{tabular}{|c|c|c|c|c|c|c|c|c|c|}
\hline NFPA 472 & Chapter 4 & Chapter 5 & Chapter 6 & Chapter 7 & Chapter 8 & Chapter 9 & Chapter 10 & Chapter 11 & NFPA 472 \\
\hline IVW & & & & & & & & & \\
\hline Incident Management P & & & & & & & & & \\
\hline IVC & & & & & & & & & \\
\hline IVD & & & & & & & & & \\
\hline IVE & & & & & & & & & \\
\hline IVG & & & & & & & & & \\
\hline Establishment of Comm & & & & & & & & & \\
\hline IVB & & & & & & $\mathrm{X}$ & & & \\
\hline IVN & & & & & & & & & \\
\hline Command Operations & & & & & & & & & \\
\hline IVA & $\mathrm{X}$ & $\mathrm{X}$ & $\mathrm{X}$ & & & & $\mathrm{X}$ & & \\
\hline $\mathrm{IVH}$ & & $\mathrm{X}$ & & & & & & & \\
\hline IVO & & & & & & & & & \\
\hline IVQ & & & & & & & & & \\
\hline IVU & & & & & & & & & \\
\hline IVZ & & $\mathrm{X}$ & & & & & & & \\
\hline Resource Mobilization & & & & & & & & & \\
\hline IIIE & & & & & & & & & \\
\hline IVK & & & & & & & & & \\
\hline IVM & & & & & & & & & \\
\hline IVP & & & & & & & & & \\
\hline Incident Management S & & & & & & & & & \\
\hline IVJ & & & & & & & & & \\
\hline IVL & & & & & & & & & \\
\hline IVX & & & & & & & & & \\
\hline IVY & & & & & & & & & \\
\hline
\end{tabular}




\begin{tabular}{l|l|l|l|l|l|l|l|l|l|}
\hline \multicolumn{1}{|c|}{ NFPA 1584 } & Chapter 4 & Chapter 5 & Chapter 6 & Chapter 7 & Chapter 8 & Chapter 9 & Chapter 10 & Chapter 11 & NFPA 1584 \\
I. Preparedness \\
\begin{tabular}{|l|l|l|l|l|l|l|} 
IA. Organization \\
IB. Cycle
\end{tabular} & & & & & & & \\
\hline
\end{tabular}

II. Communications \& Information Management

Operational Communications

IIA

IIB

Interoperability

IIC

IID

III. Resource Management
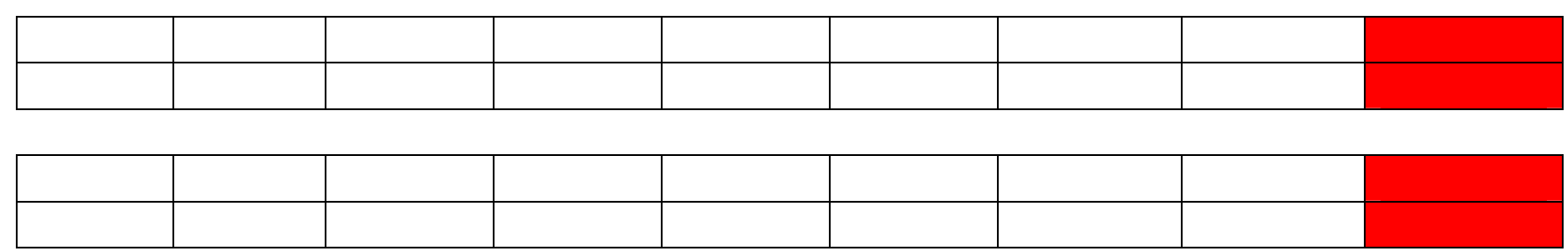

Categorizing; Mgmt; Inventory; Acquisition

(T) IIIA

$\stackrel{\text { TI }}{i}$ IIIB

IIIC

IIID

IVV

Recovery

IIIB

IIIF

IIIG

IVK

IV. Command and Management Incident Management Structure IVF

IVI

IVR

IVS

IVT

\begin{tabular}{|l|l|l|l|l|l|l|l|}
\hline & & & & & & & \\
\hline & & $\mathrm{x}$ & & & & & \\
\hline & & & & & & & \\
\hline & & & & & & & \\
\hline
\end{tabular}

\begin{tabular}{|l|l|l|l|l|l|l|l|l|}
\hline & & $\mathrm{x}$ & & & & & & \\
\hline & & & & & & & \\
\hline & & & & & & & \\
\hline & & & & & & & \\
\hline
\end{tabular}

\begin{tabular}{|c|c|c|c|c|c|c|c|c|}
\hline$x$ & & $x$ & & & & & & \\
\hline & & & & & & & \\
\hline & & & & & & & \\
\hline & & & & & & & \\
\hline
\end{tabular}




\begin{tabular}{|c|c|c|c|c|c|c|c|c|c|}
\hline NFPA 1584 & Chapter 4 & Chapter 5 & Chapter 6 & Chapter 7 & Chapter 8 & Chapter 9 & Chapter 10 & Chapter 11 & NFPA 1584 \\
\hline \multicolumn{10}{|l|}{ IVW } \\
\hline \multicolumn{10}{|c|}{ Incident Management Planning } \\
\hline \multicolumn{10}{|l|}{ IVC } \\
\hline \multicolumn{10}{|l|}{ IVD } \\
\hline \multicolumn{10}{|l|}{ IVE } \\
\hline \multicolumn{10}{|l|}{ IVG } \\
\hline \multicolumn{10}{|c|}{ Establishment of Command } \\
\hline \multicolumn{10}{|l|}{ IVB } \\
\hline \multicolumn{10}{|l|}{ IVN } \\
\hline \multicolumn{10}{|l|}{ Command Operations } \\
\hline \multicolumn{10}{|l|}{ IVA } \\
\hline \multicolumn{10}{|l|}{ IVH } \\
\hline \multicolumn{10}{|l|}{ IVO } \\
\hline \multicolumn{10}{|l|}{ IVQ } \\
\hline \multicolumn{10}{|l|}{ IVU } \\
\hline \multicolumn{10}{|l|}{ IVZ } \\
\hline \multicolumn{10}{|c|}{ Resource Mobilization \& Deployment } \\
\hline \multicolumn{10}{|l|}{ IIIE } \\
\hline \multicolumn{10}{|l|}{ IVK } \\
\hline \multicolumn{10}{|l|}{ IVM } \\
\hline \multicolumn{10}{|l|}{ IVP } \\
\hline \multicolumn{10}{|c|}{ Incident Management Support } \\
\hline \multicolumn{10}{|l|}{ IVJ } \\
\hline \multicolumn{10}{|l|}{ IVL } \\
\hline \multicolumn{10}{|l|}{ IVX } \\
\hline IVY & & & & & & & & & \\
\hline
\end{tabular}

V. Supporting Technologies 



\section{Appendix F}

Complete Technical Analysis Results Tables 



\section{Appendix $F$}

Complete Technical Analysis Results Tables

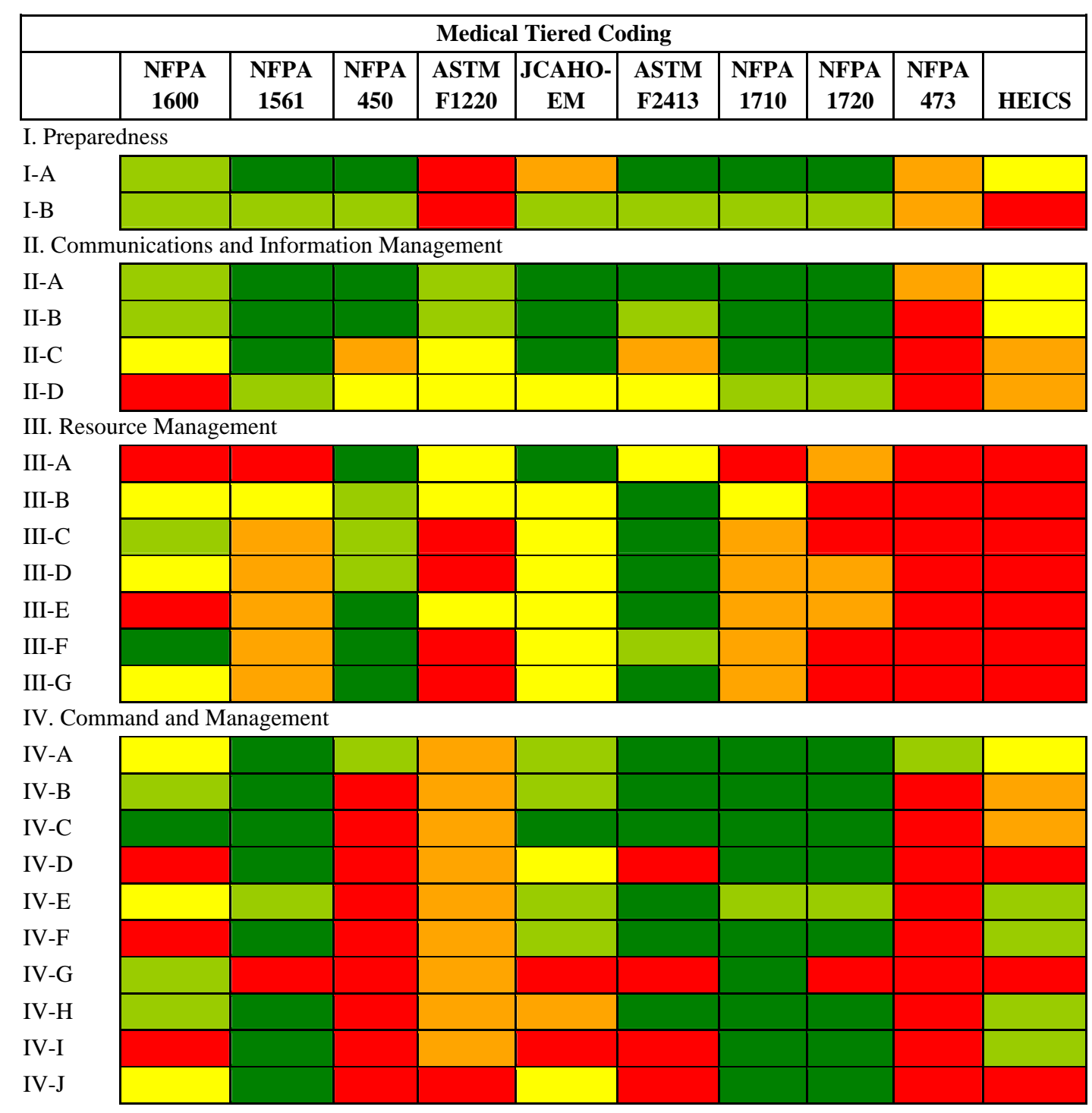




\begin{tabular}{|c|c|c|c|c|c|c|c|c|c|c|}
\hline \multicolumn{11}{|c|}{ Medical Tiered Coding } \\
\hline & $\begin{array}{c}\text { NFPA } \\
1600\end{array}$ & $\begin{array}{c}\text { NFPA } \\
1561\end{array}$ & $\begin{array}{c}\text { NFPA } \\
450\end{array}$ & $\begin{array}{l}\text { ASTM } \\
\text { F1220 }\end{array}$ & \begin{tabular}{|c|} 
JCAHO- \\
EM
\end{tabular} & $\begin{array}{l}\text { ASTM } \\
\text { F2413 }\end{array}$ & $\begin{array}{c}\text { NFPA } \\
1710\end{array}$ & $\begin{array}{c}\text { NFPA } \\
1720\end{array}$ & $\begin{array}{c}\text { NFPA } \\
473\end{array}$ & HEICS \\
\hline \multicolumn{11}{|l|}{ IV-K } \\
\hline \multicolumn{11}{|l|}{ IV-L } \\
\hline \multicolumn{11}{|l|}{ IV-M } \\
\hline \multicolumn{11}{|l|}{ IV-N } \\
\hline \multicolumn{11}{|l|}{ IV-O } \\
\hline \multicolumn{11}{|c|}{ IV-P } \\
\hline \multicolumn{11}{|l|}{ IV-Q } \\
\hline \multicolumn{11}{|l|}{ IV-R } \\
\hline \multicolumn{11}{|l|}{ IV-S } \\
\hline \multicolumn{11}{|l|}{ IV-T } \\
\hline \multicolumn{11}{|c|}{ IV-U } \\
\hline \multicolumn{11}{|l|}{ IV-V } \\
\hline \multicolumn{11}{|c|}{ IV-W } \\
\hline \multicolumn{11}{|c|}{ IV-X } \\
\hline \multicolumn{11}{|c|}{ IV-Y } \\
\hline IV-Z & & & & & & & & & & \\
\hline
\end{tabular}

V. Supporting Technologies 
Fire Tiered Coding

\begin{tabular}{|l|l|l|l|l|l|l|l|} 
NFPA 1500 & NFPA 1561 & NFPA 1584 & NFPA 1600 & NFPA 1670 & NFPA 1710 & NFPA 1720 & NFPA 472 \\
\hline
\end{tabular}

I. Preparedness

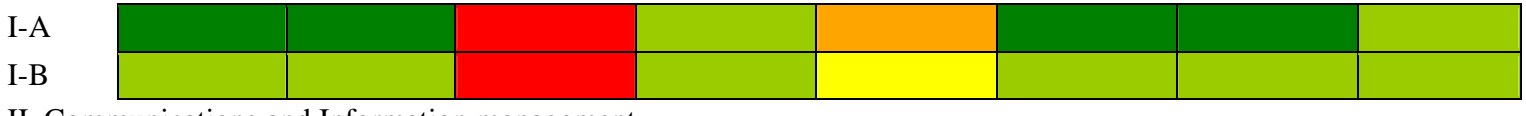

II. Communications and Information management

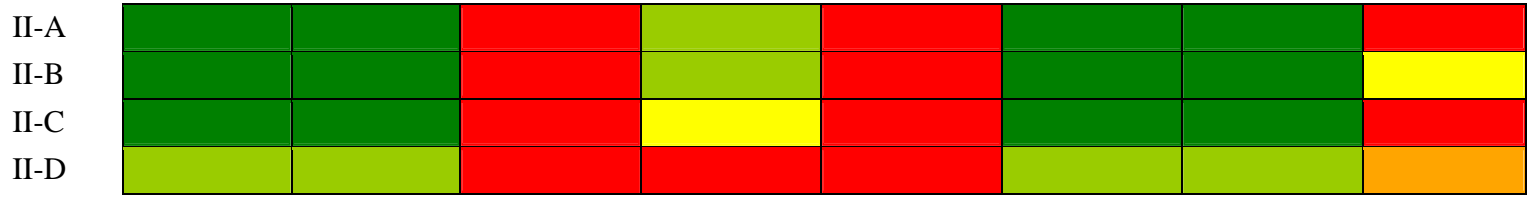

III-D Resource Management

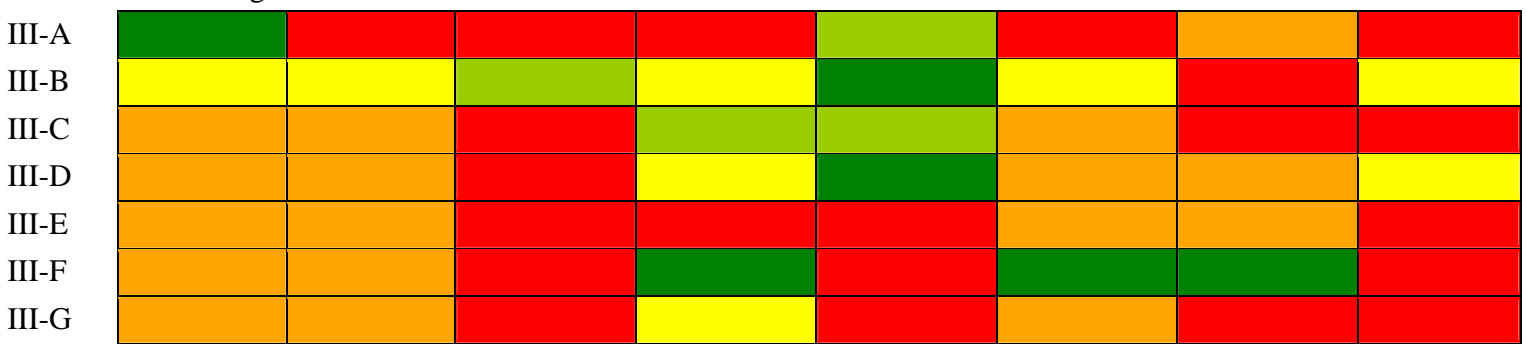

IV. Command and Management

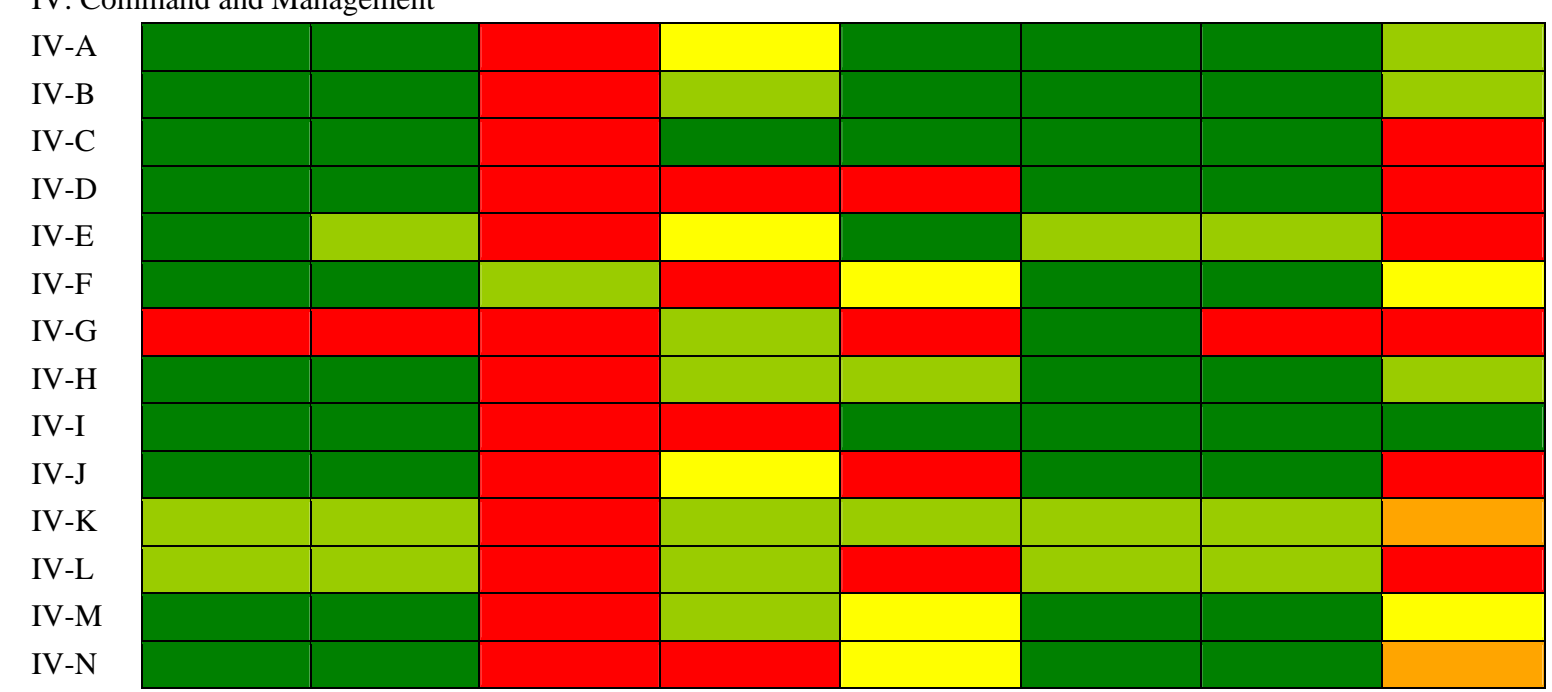


Fire Tiered Coding

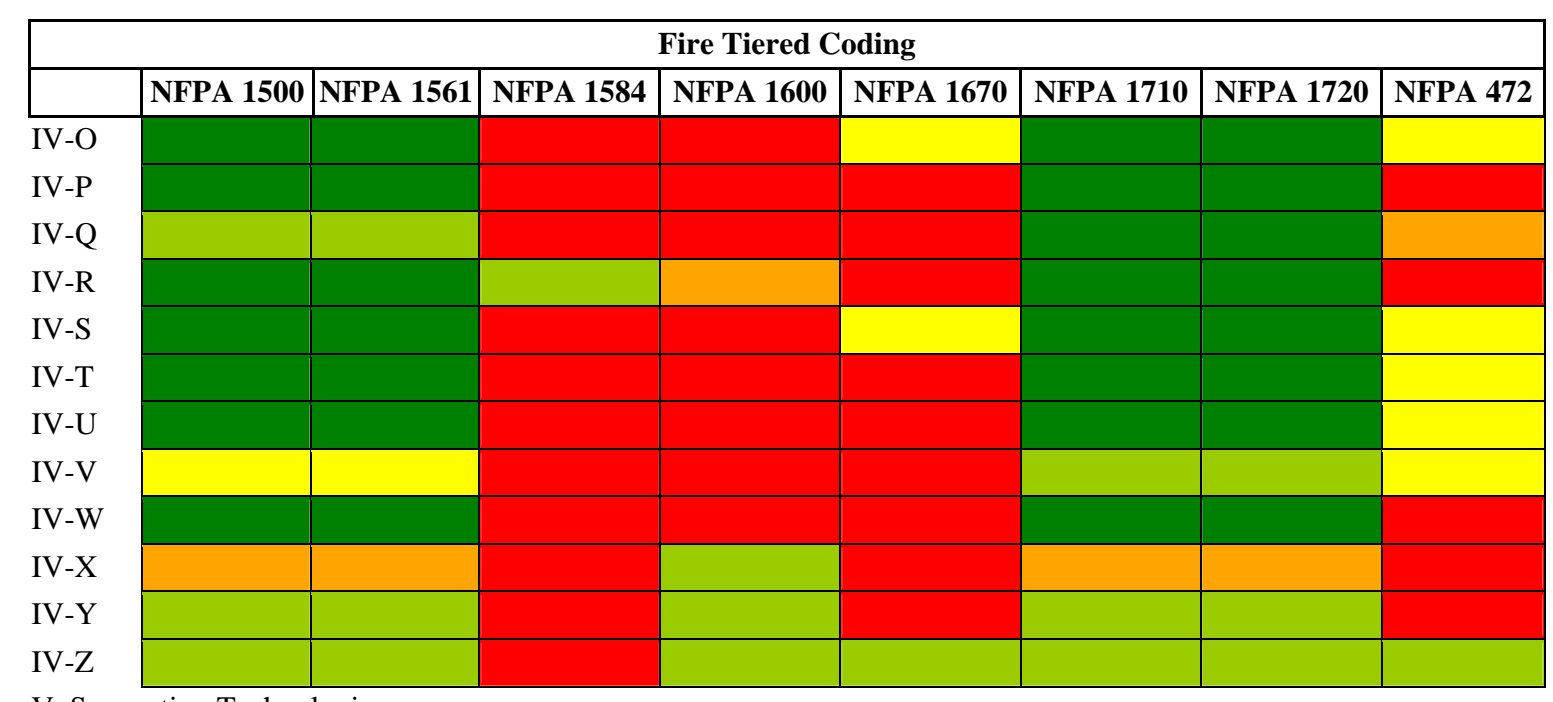

V. Supporting Technologies 


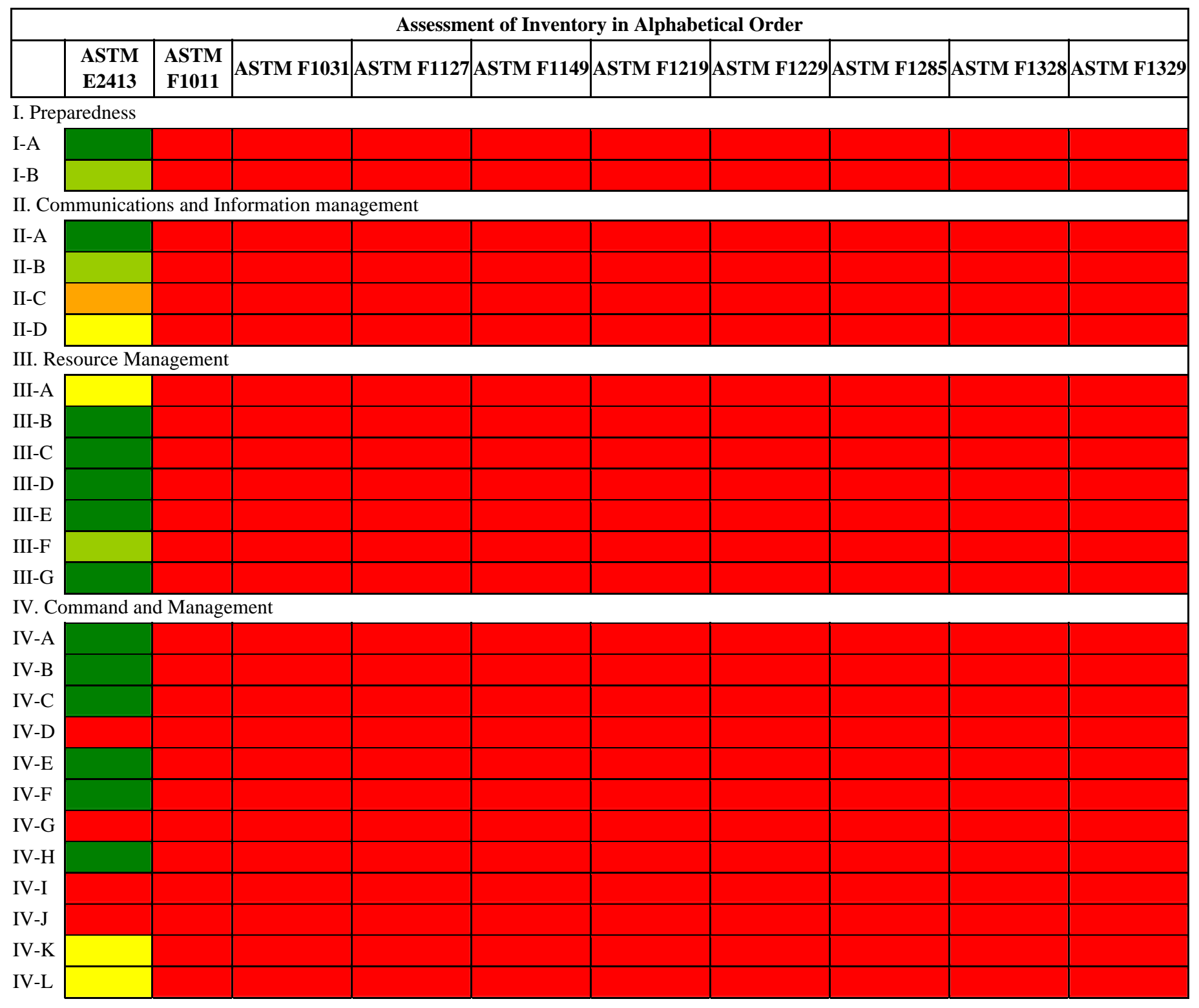




\begin{tabular}{|c|c|c|c|c|c|c|c|c|c|c|}
\hline \multicolumn{11}{|c|}{ Assessment of Inventory in Alphabetical Order } \\
\hline & $\begin{array}{c}\text { ASTM } \\
\text { E2413 }\end{array}$ & $\begin{array}{c}\text { ASTM } \\
\text { F1011 }\end{array}$ & ASTM F1031 & ASTM F1127 & ASTM F1149 & ASTM F1219 & ASTM F1229 & ASTM F1285 & ASTM F1328 & ASTM F1329 \\
\hline IV-M & & & & & & & & & & \\
\hline IV-N & & & & & & & & & & \\
\hline IV-O & & & & & & & & & & \\
\hline IV-P & & & & & & & & & & \\
\hline IV-Q & & & & & & & & & & \\
\hline IV-R & & & & & & & & & & \\
\hline IV-S & & & & & & & & & & \\
\hline IV-T & & & & & & & & & & \\
\hline IV-U & & & & & & & & & & \\
\hline $\mathrm{IV}-\mathrm{V}$ & & & & & & & & & & \\
\hline IV-W & & & & & & & & & & \\
\hline IV-X & & & & & & & & & & \\
\hline IV-Y & & & & & & & & & & \\
\hline IV-Z & & & & & & & & & & \\
\hline
\end{tabular}




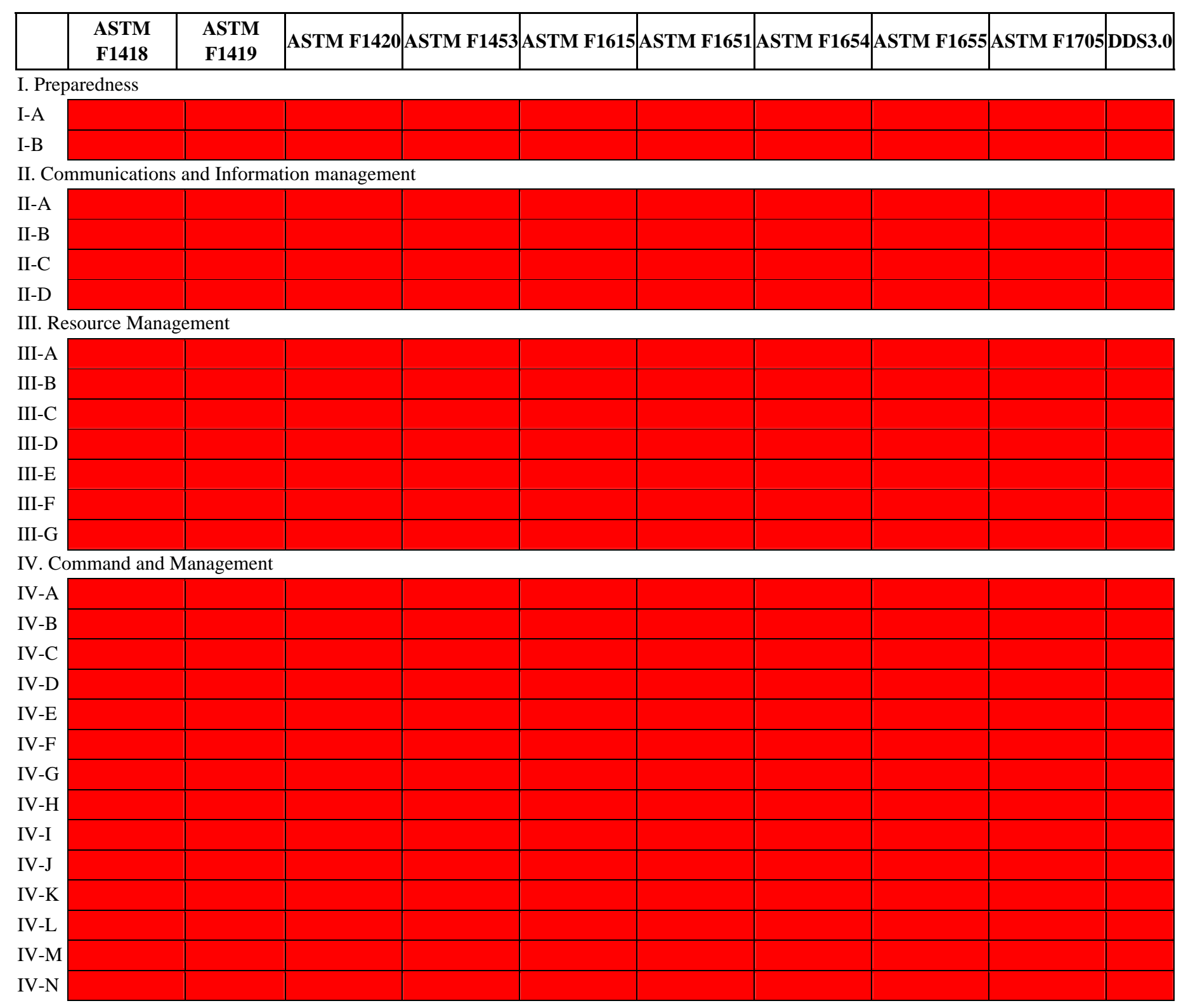




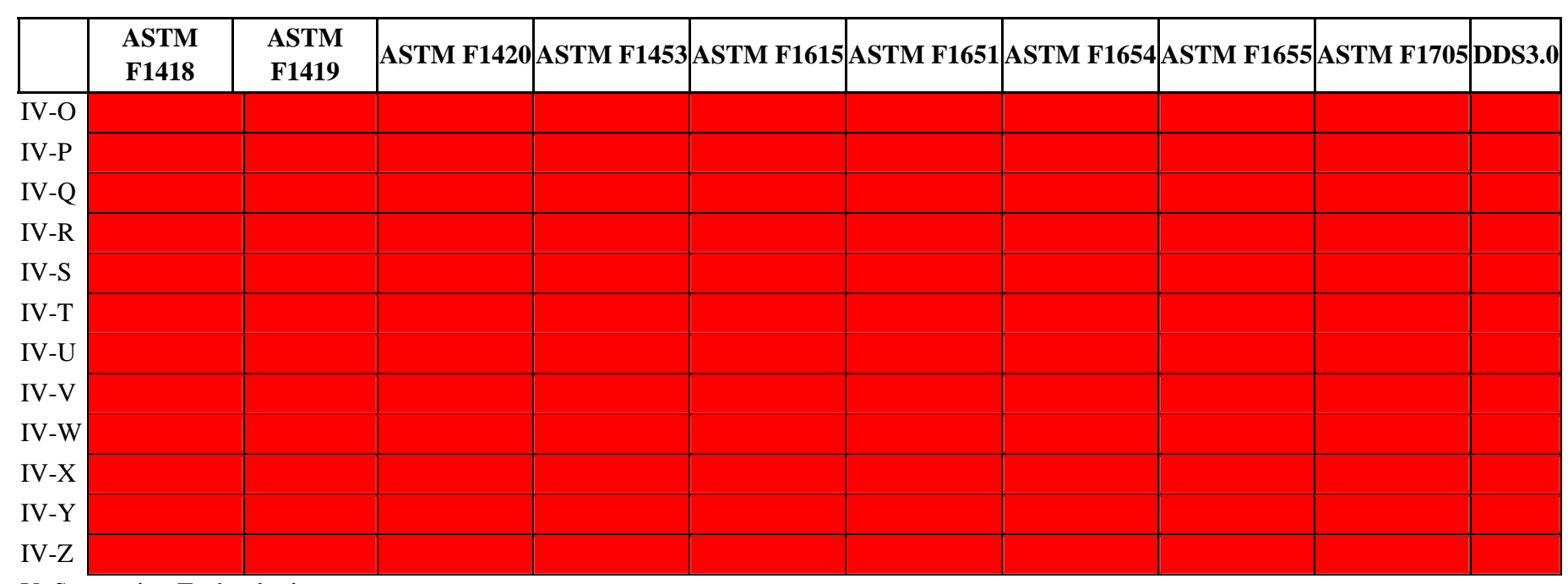

V. Supporting Technologies 


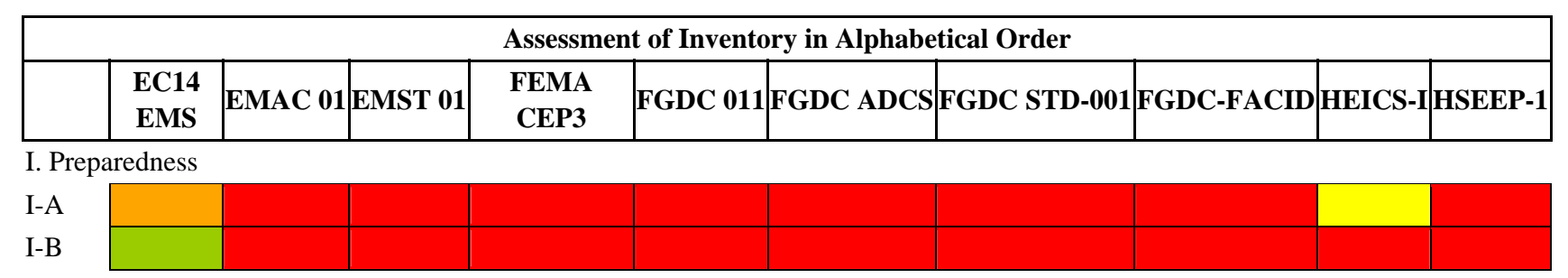

II. Communications and Information management

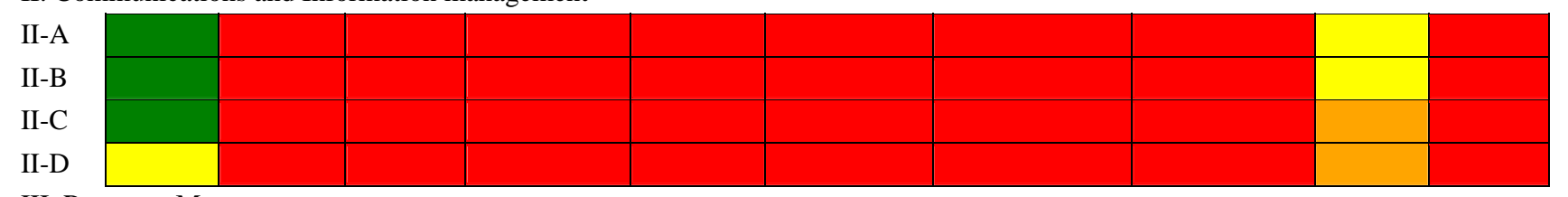

III. Resource Management

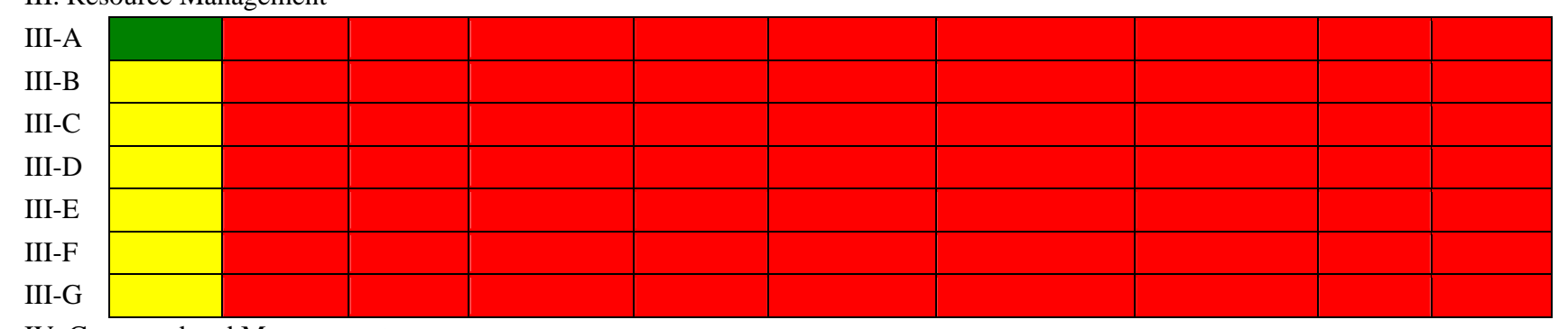

IV. Command and Management

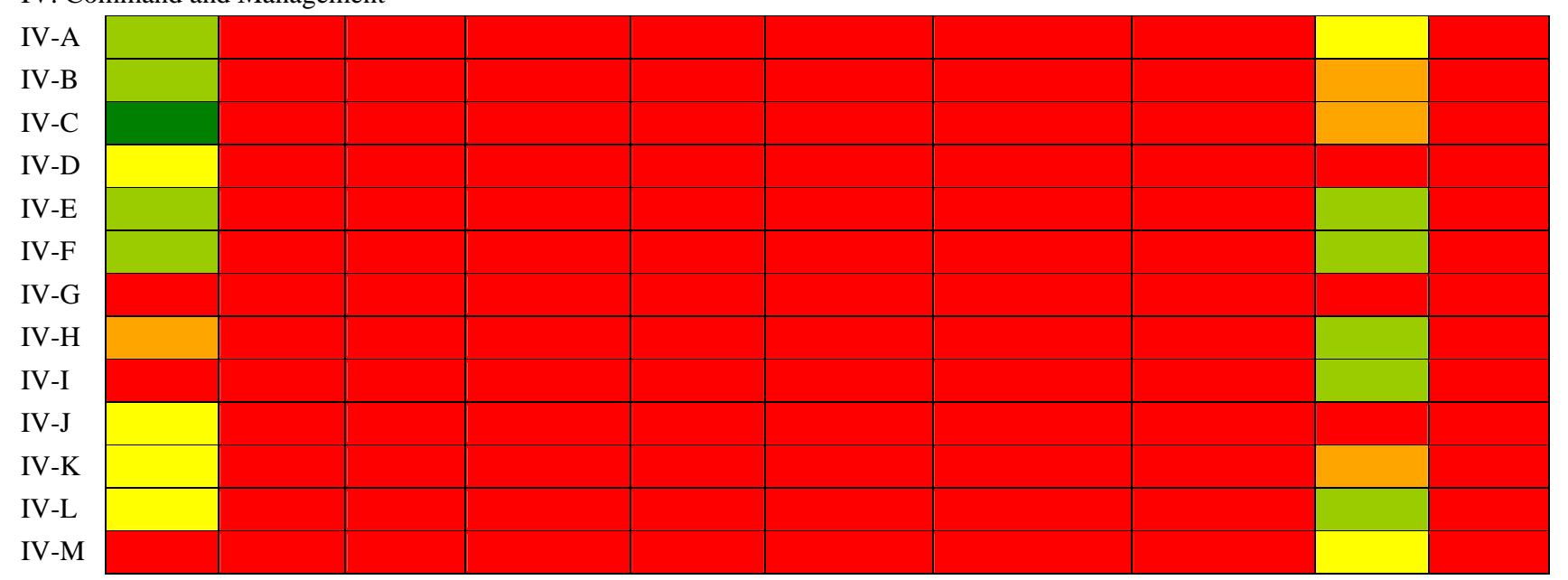




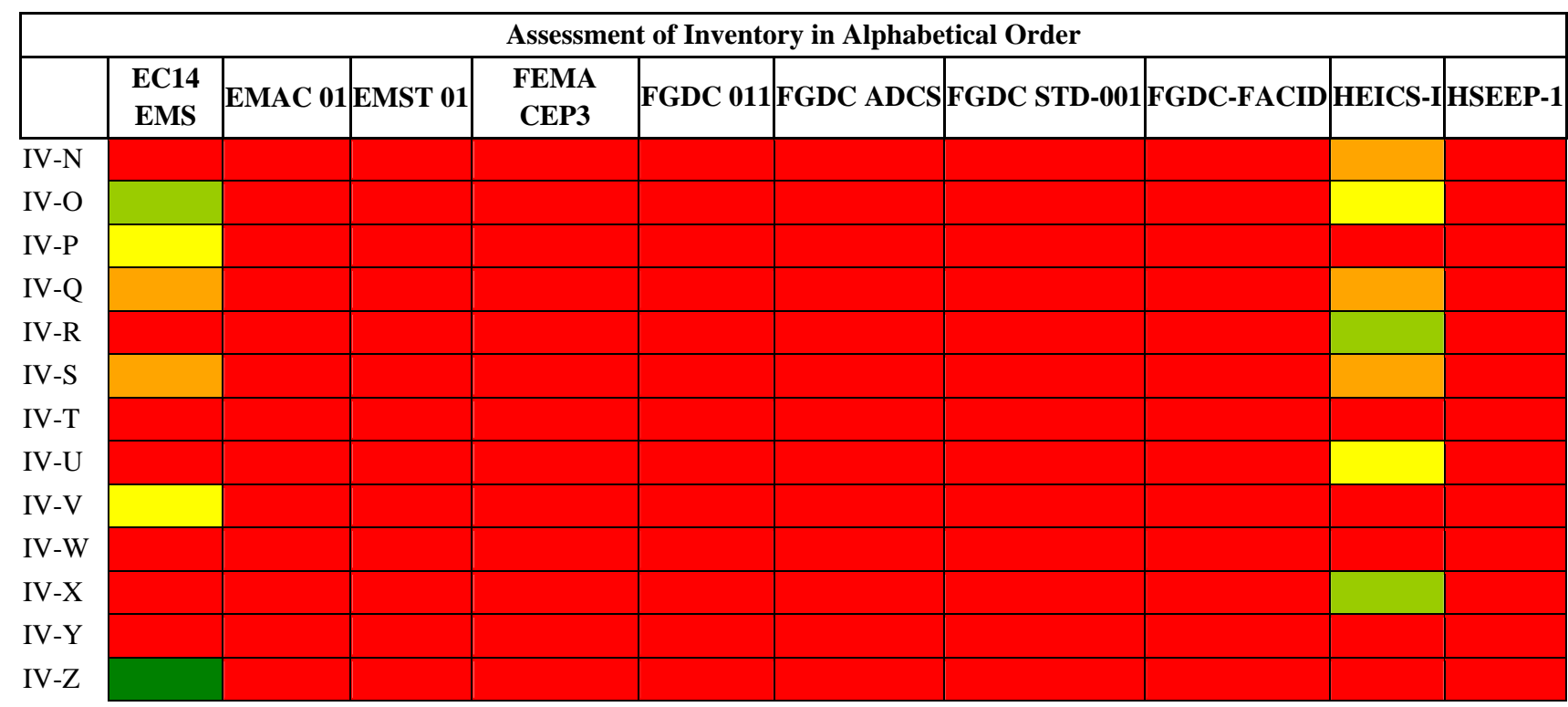

V. Supporting Technologies 


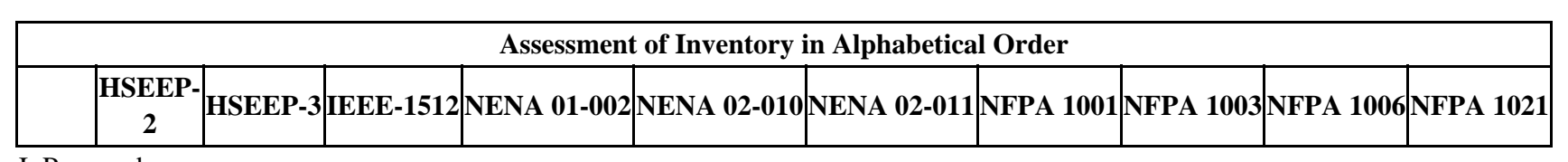

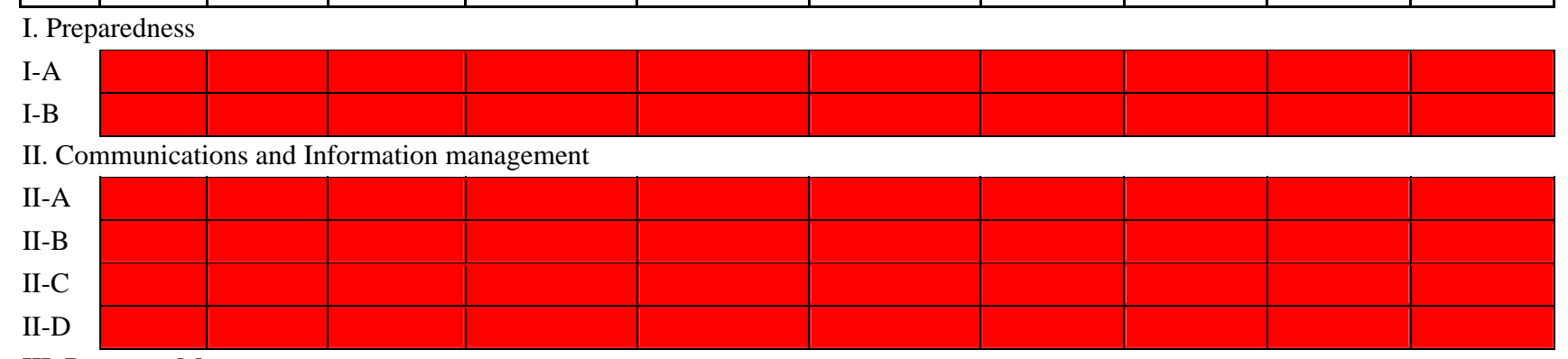

III. Resource Management

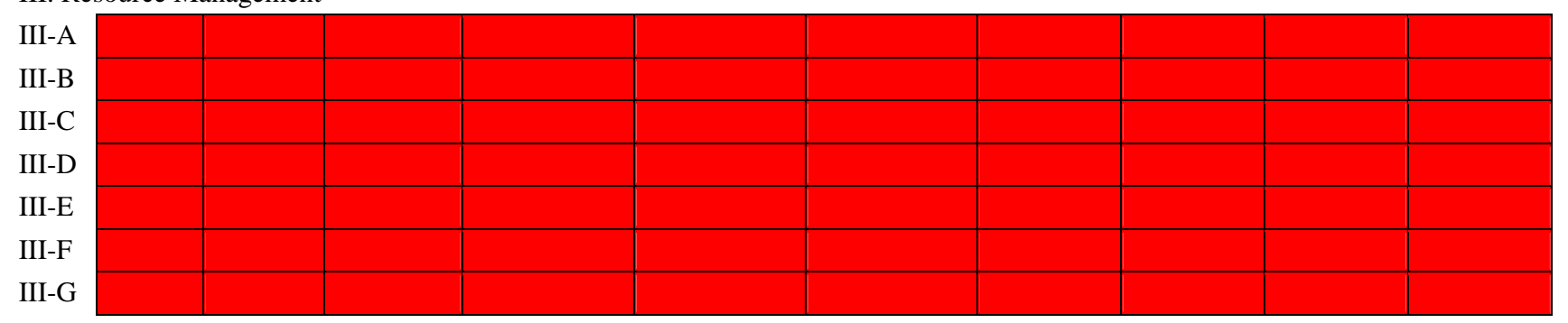

IV. Command and Management

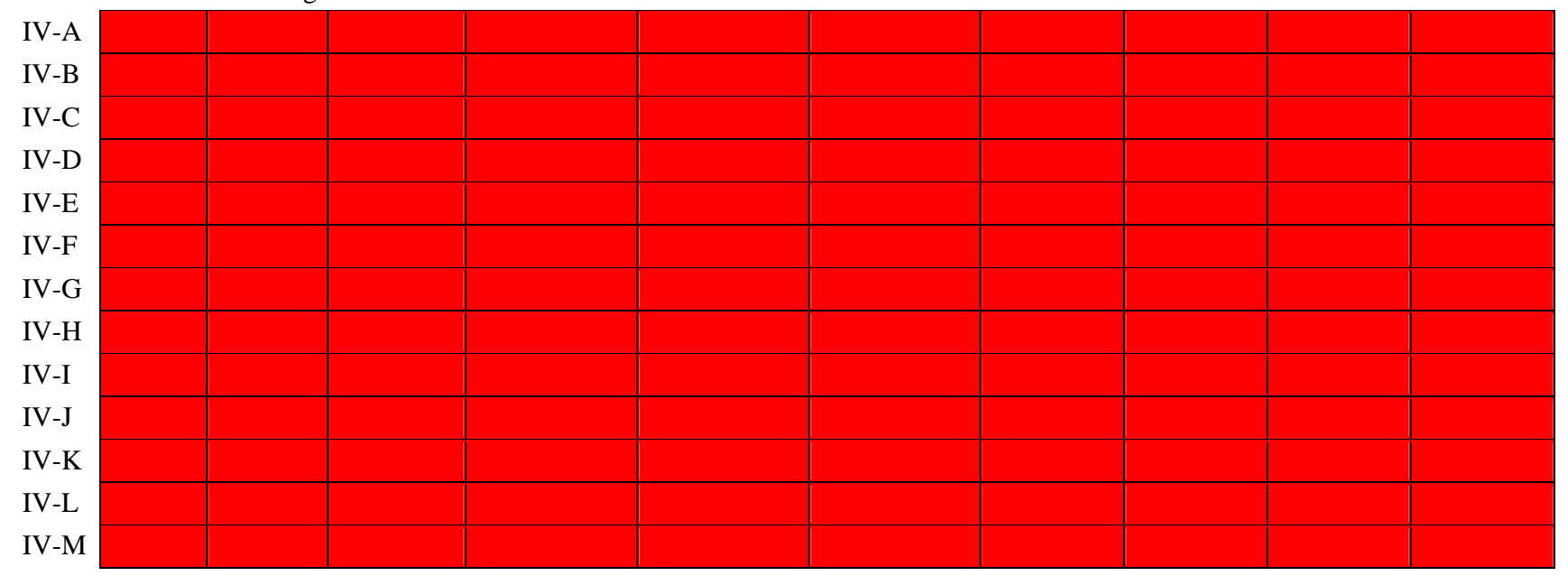




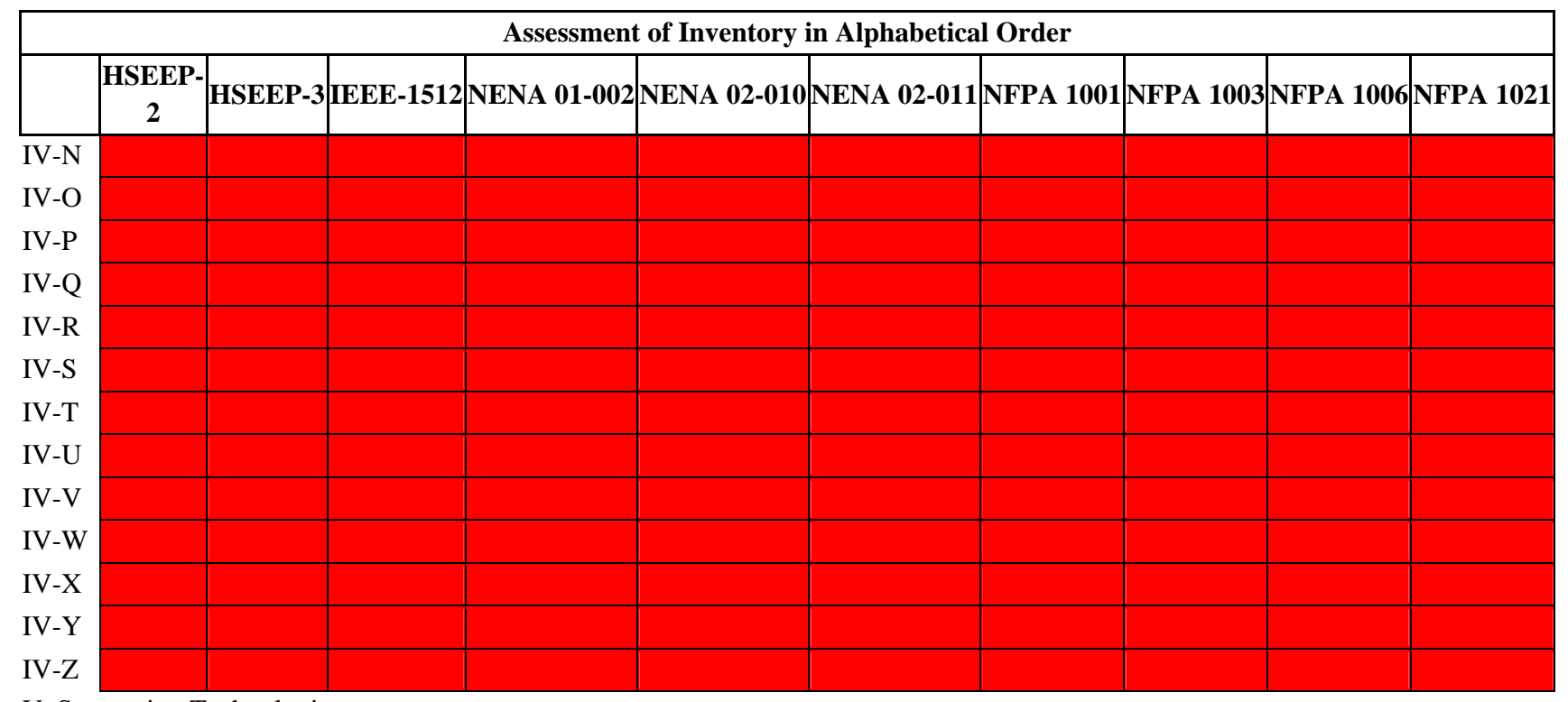

V. Supporting Technologies 


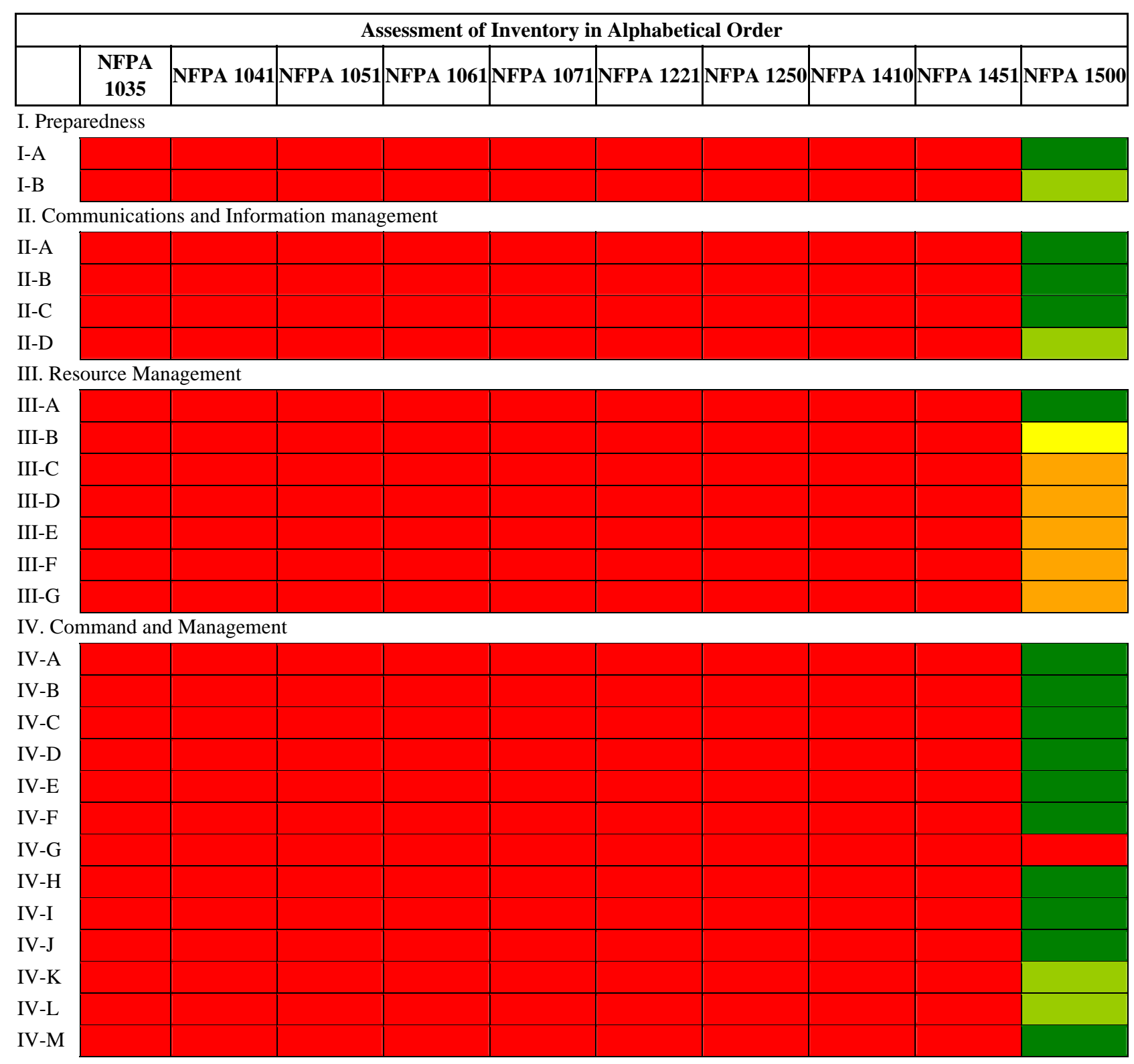




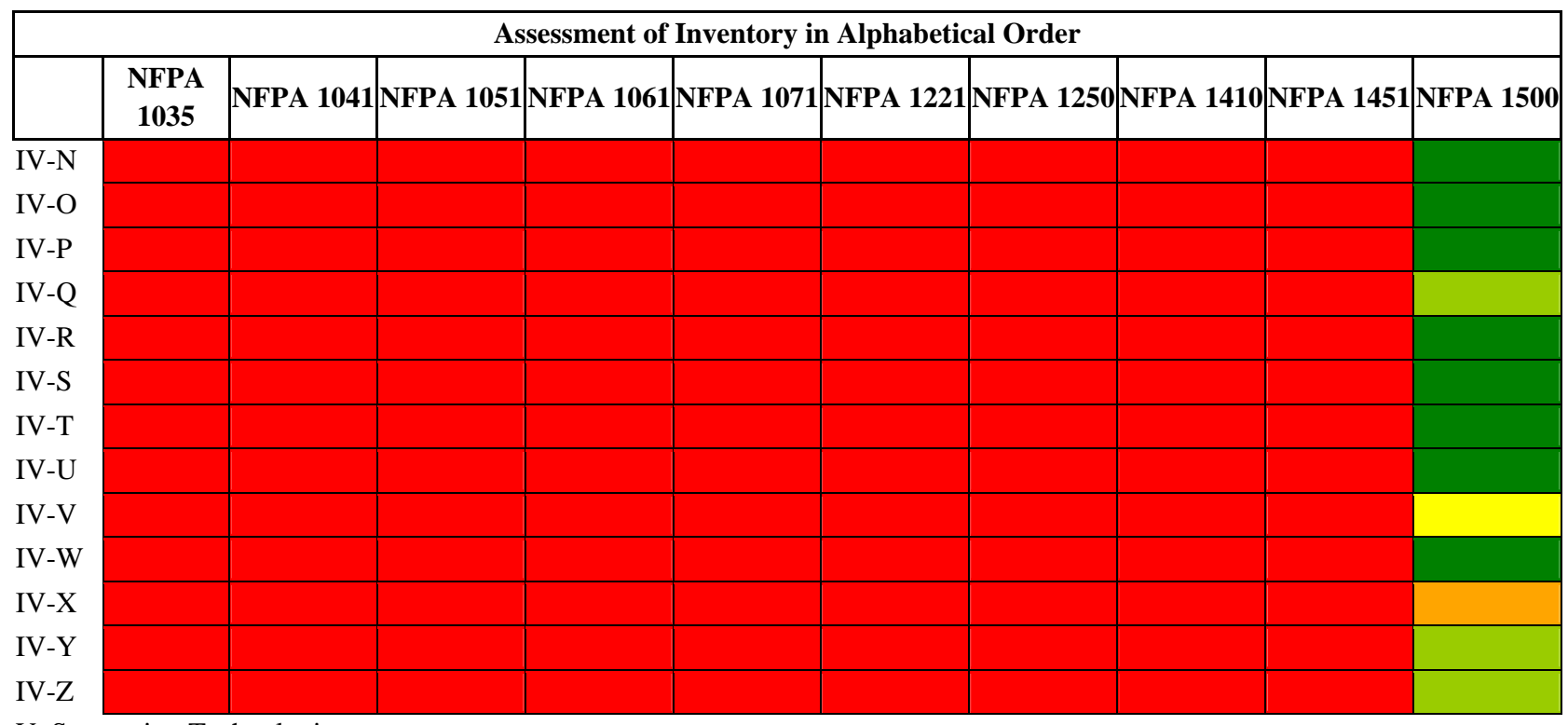

V. Supporting Technologies 


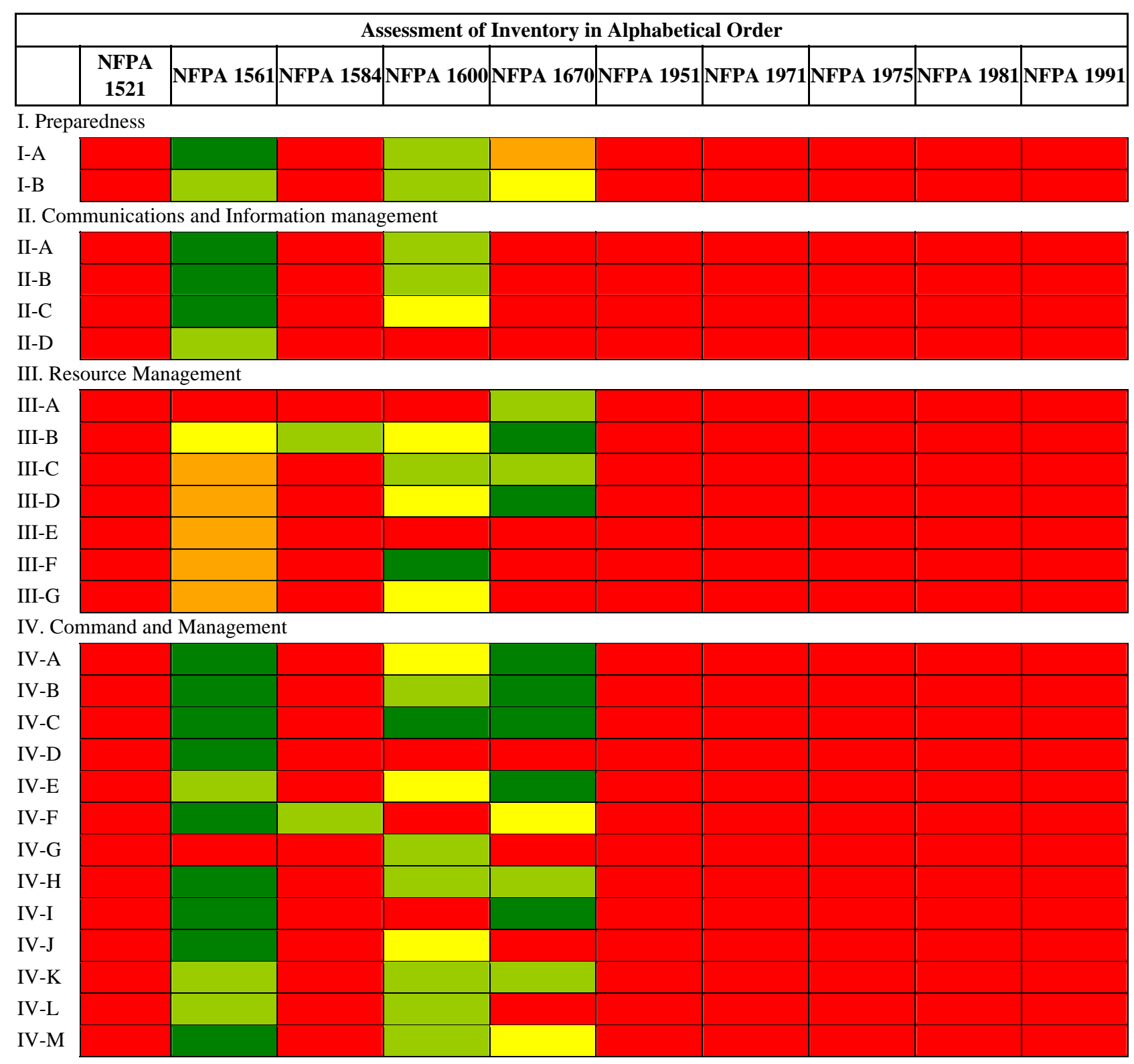




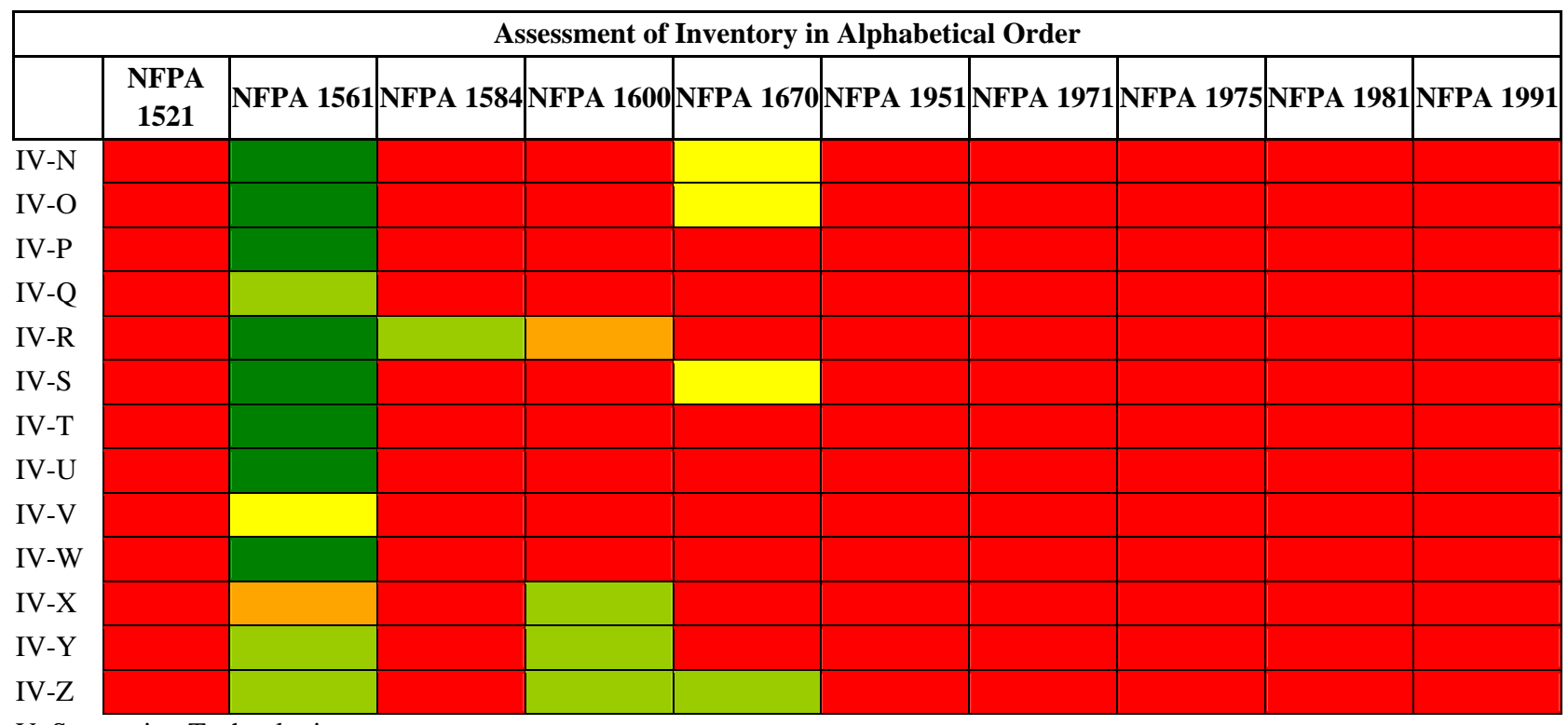

V. Supporting Technologies 
Assessment of Inventory in Alphabetical Order

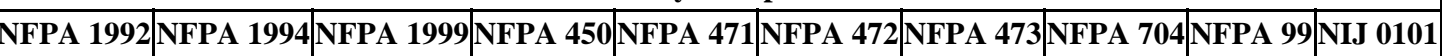
I. Preparedness

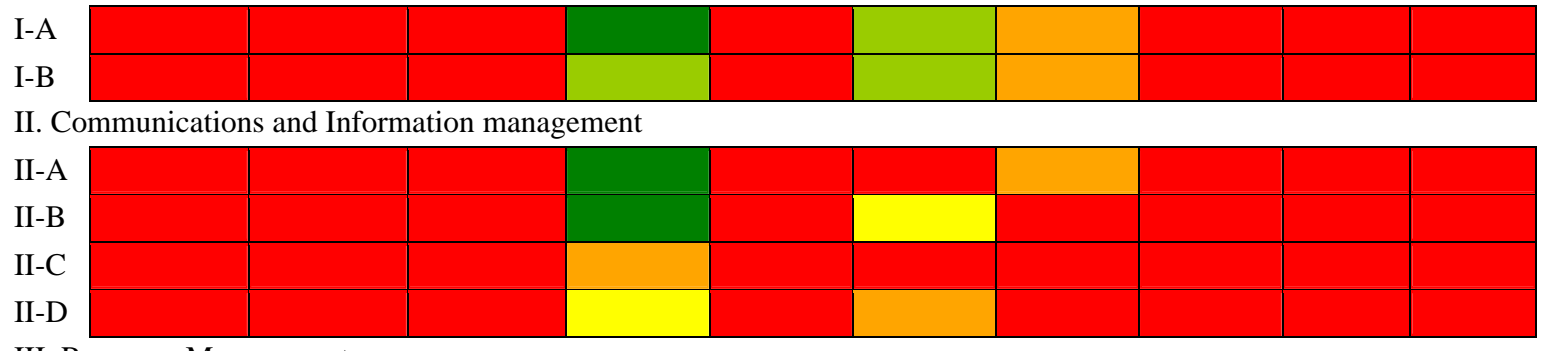

III. Resource Management

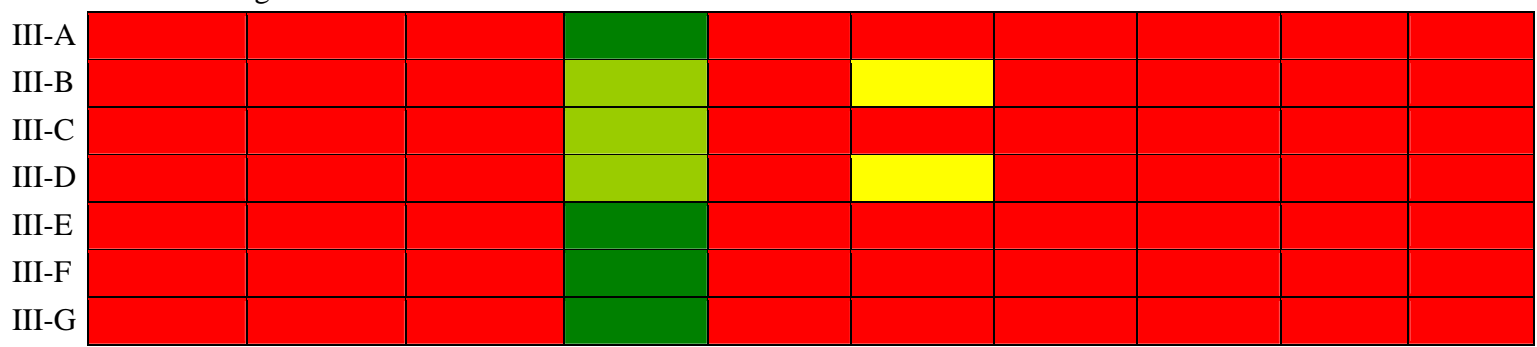

IV. Command and Management

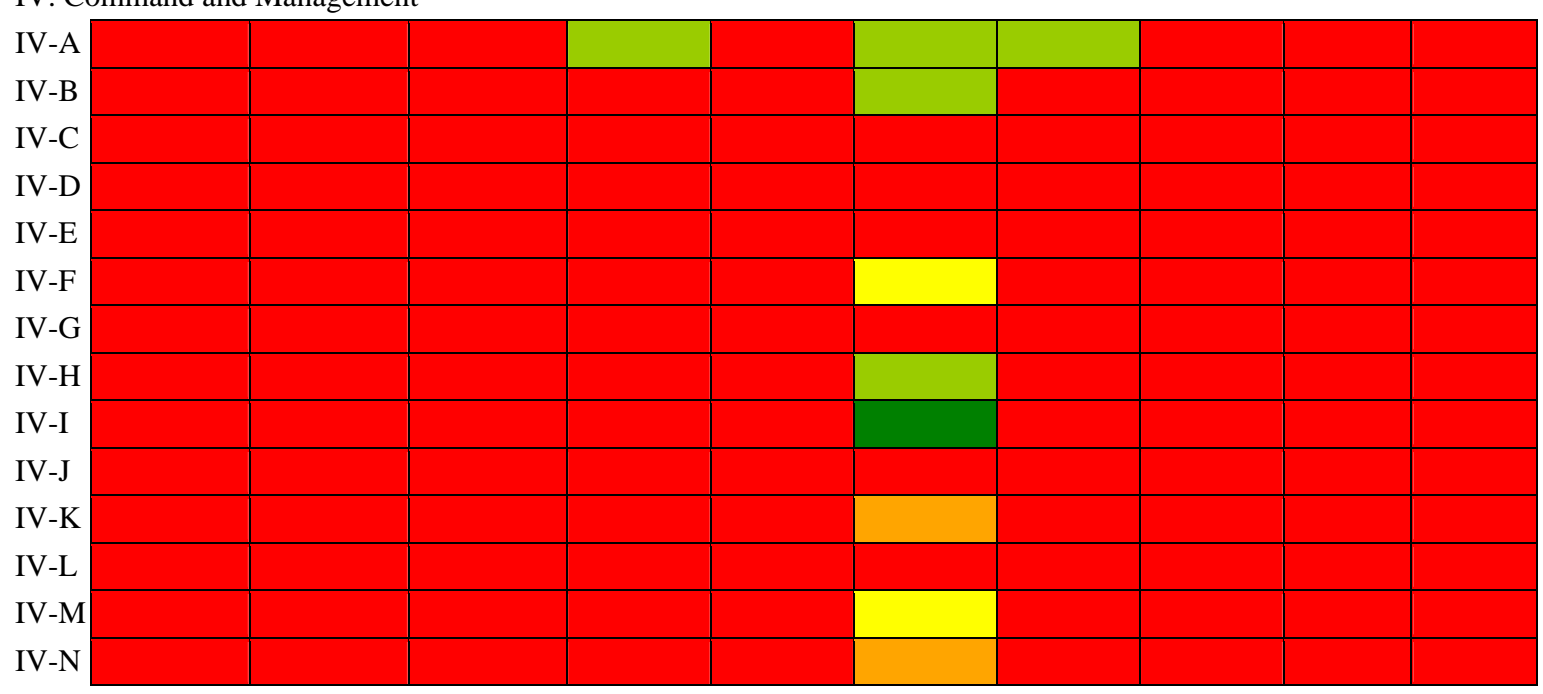


Assessment of Inventory in Alphabetical Order

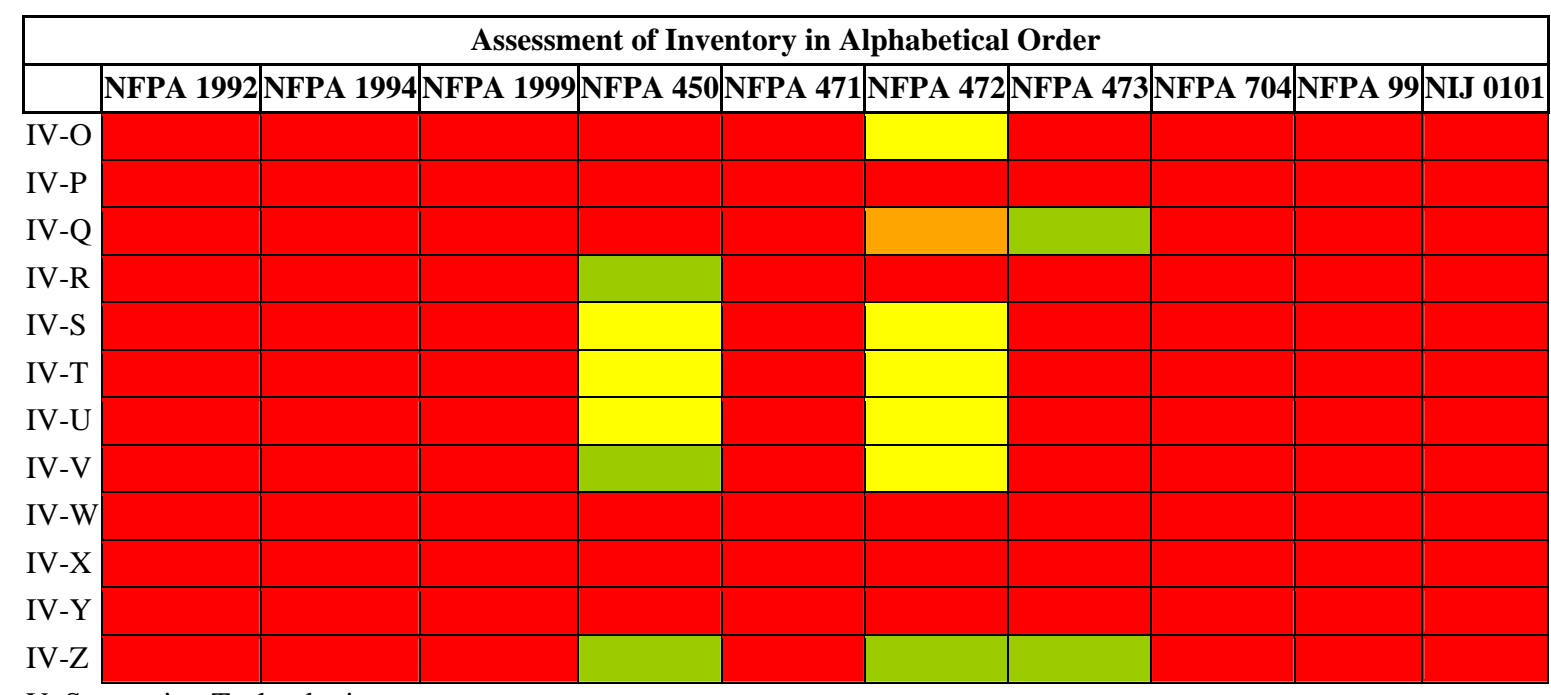

V. Supporting Technologies 
Assessment of Inventory in Alphabetical Order

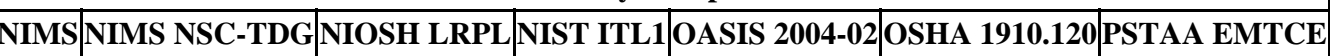
I. Preparedness

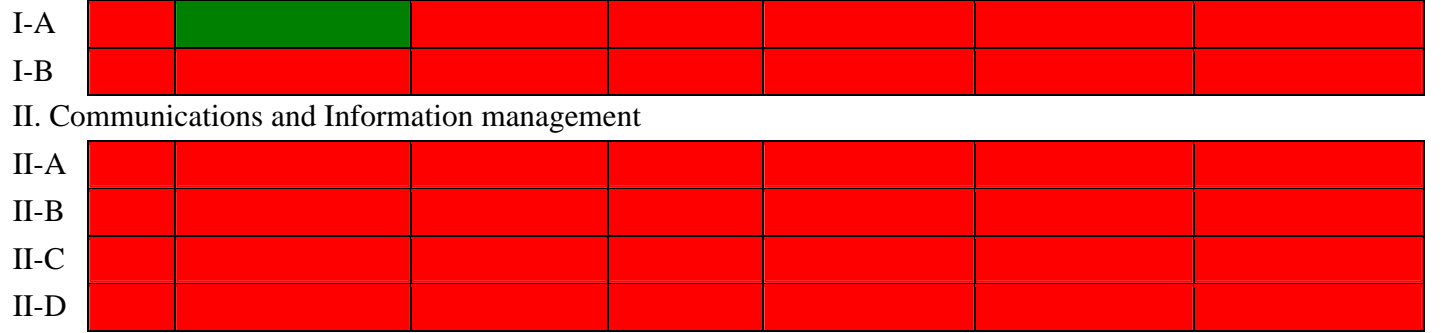

III. Resource Management

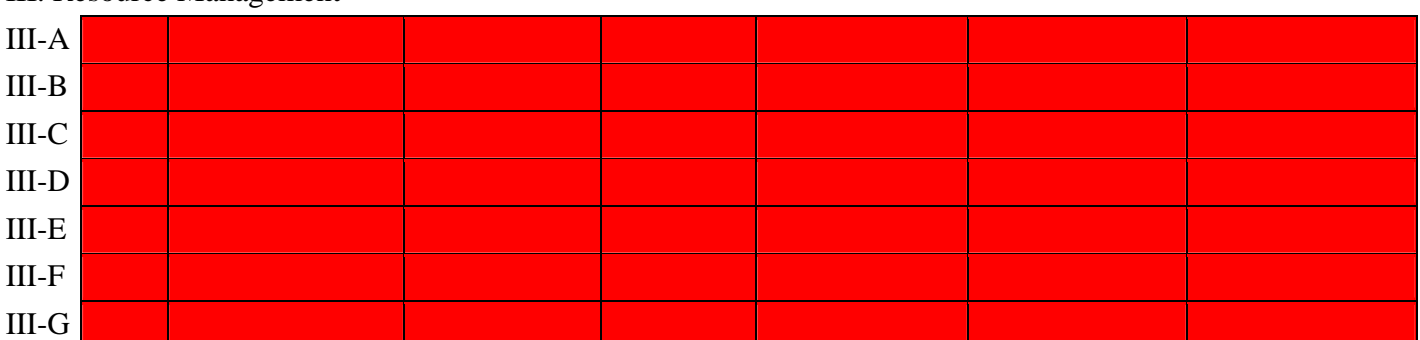

IV. Command and Management

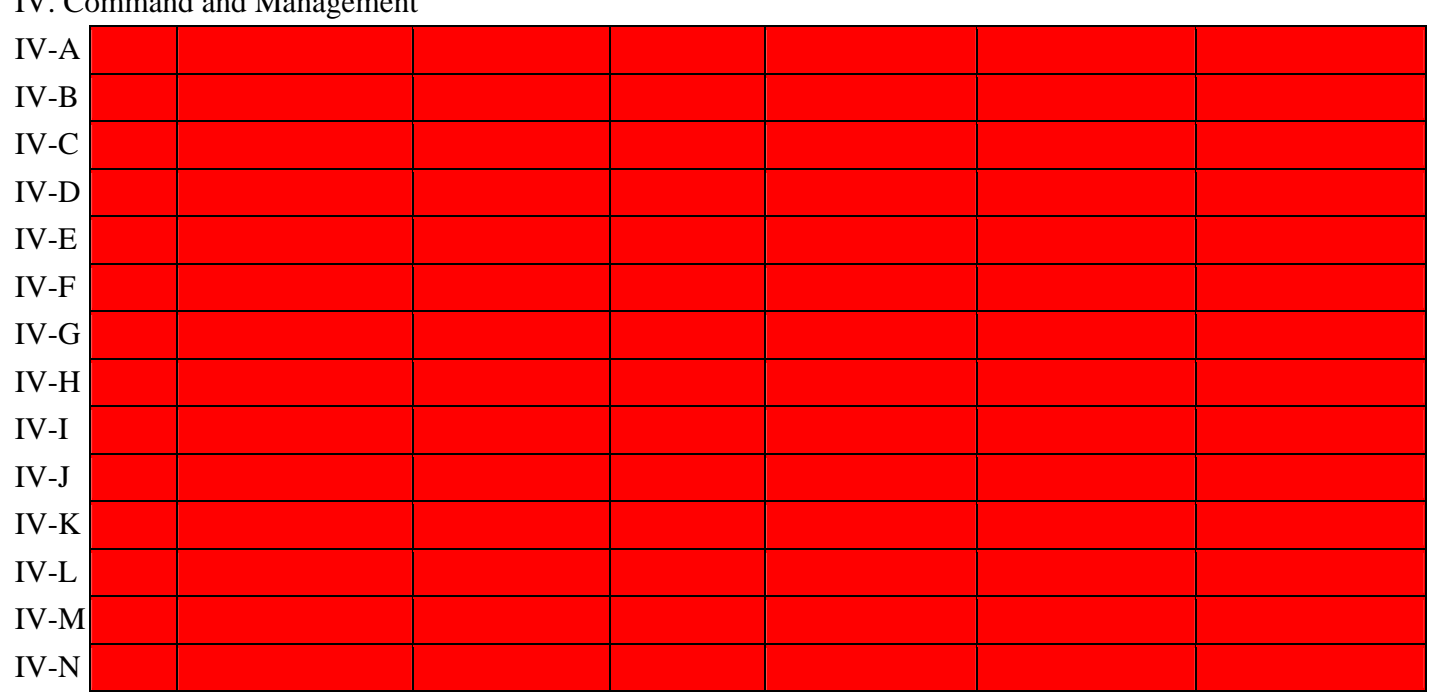


Assessment of Inventory in Alphabetical Order

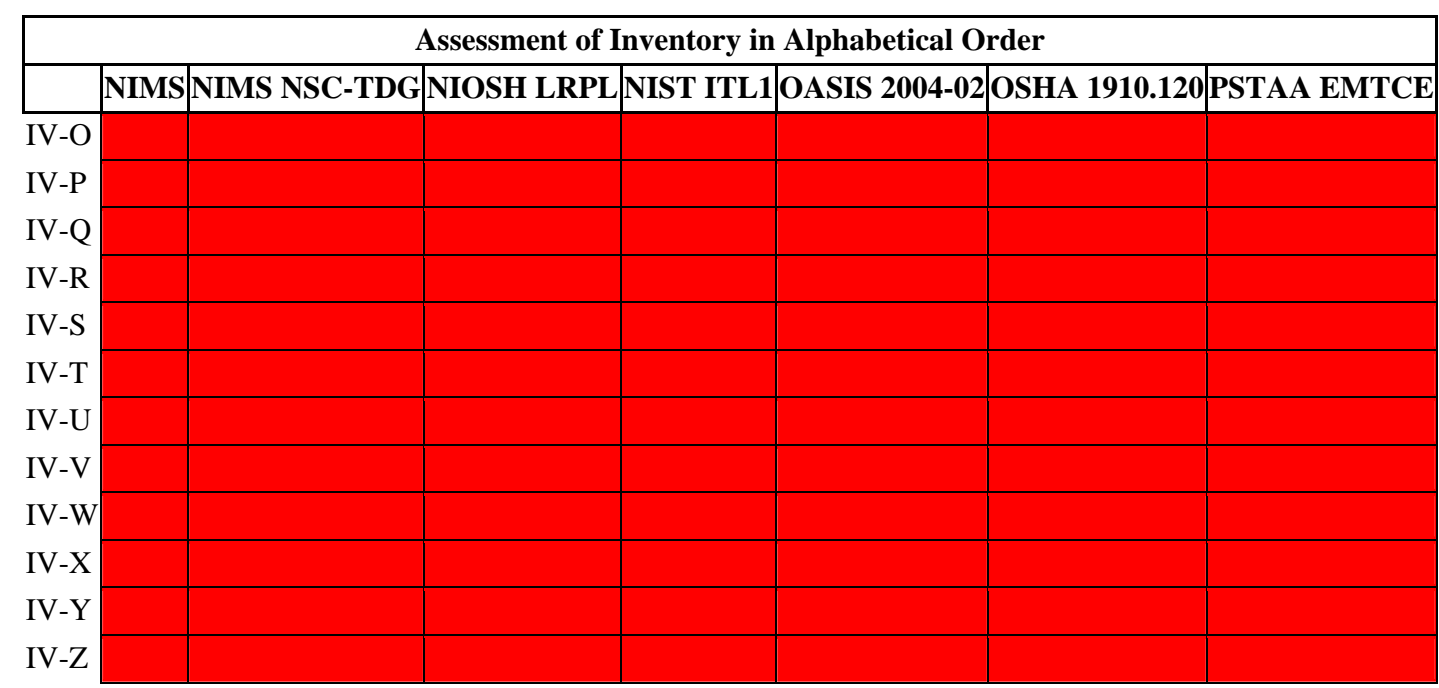

V. Supporting Technologies 


\section{Distribution}

No. of

\section{$\underline{\text { Copies }}$}

\section{Pacific Northwest National Laboratory}

1 P. Cummings K8-30

1 S. Martin K8-21

1 M. Mitchell K8-29

1 S. Shalata K3-53

1 K. Soldat K3-53

60 B. Stenner K3-54

1 K. Thrall P7-59

\section{OFFSITE}

\section{Battelle-Crystal City}

1 V. Lang 1550 Crystal Drive, Suite 601 Arlington, VA 22202-4172

1 R. Dobbs 1550 Crystal Drive, Suite 601 Arlington, VA 22202-4172

\section{Battelle-Seattle Research Center}

1 S. Stein

1100 Dexter Ave N., Suite 400

Seattle, WA 98109

1 A. Lesperance

1100 Dexter Ave N., Suite 400

Seattle, WA 98109

\section{DHS}

1 Kyle Blackman (kyle.blackman@dhs.gov)

1 Roberta Breden (roberta.breden@dhs.gov)

1 Bert Coursey (bert.coursey@dhs.gov)

1 Al Fluman (al.fluman@dhs.gov)

1 Mike Kaminski

(konstanty.kaminski@dhs.gov)

1 David Larimer (david.larimer@dhs.gov)

1 Ashley Moore (ashley.moore@dhs.gov)

1 Laurence Raine (Laurence.raine@DHS.gov)

10 Peter Shebell (peter.shebell@dhs.gov)

1 Jacqueline Snelling

(Jacqueline.Snelling@dhs.gov)

\section{EKU}

1 Stacey Sledge

G\&H International Services, Inc,

1747 Pennsylvania Ave, NW, Suite 800

Washington, D.C. 20006

\section{EPA-EM}

1 Roberta Runge

U.S. EPA, Office of Emergency Management 1200 Pennsylvania Ave. NW

Washington, DC 20460. 
